NIST

PUBLICATIONS

\section{Classified Biblíography}

Insulation Condition Monitoring Methods 1989 - 1995

\section{François D. Martzloff}

U.S. DEPARTMENT OF COMMERCE

Technology Administration

National Institute of Standards

and Technology

Electronics and Electrical Engineering Laboratory Electricity Division

Gaithersburg, MD 20899

QC

100

.456 



\section{Classified Bibliography}

Insulation Condition Monitoring Methods

1989 - 1995

\section{François D. Martzloff}

\author{
U.S. DEPARTMENT OF COMMERCE \\ Technology Administration \\ National Institute of Standards \\ and Technology \\ Electronics and Electrical Engineering Laboratory \\ Electricity Division \\ Gaithersburg, MD 20899
}

November 1995

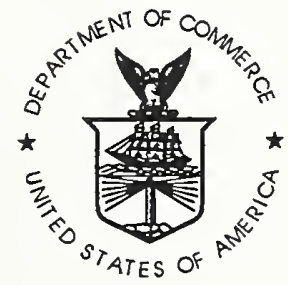

U.S. DEPARTMENT OF COMMERCE Ronald H. Brown, Secretary

TECHNOLOGY ADMINISTRATION Mary L. Good, Under Secretary for Technology

NATIONAL INSTITUTE OF STANDARDS

AND TECHNOLOGY

Arati Prabhakar, Director 



\section{TABLE OF CONTENTS}

1 - GENERAL REVIEWS AND TUTORIALS .................. 1

2 - EXPERIMENTAL PARTIAL DISCHARGE MEASUREMENTS . . . . . . . . . . . 5

3 - PARTIAL DISCHARGE MODELING AND ANALYSIS ........... 13

4 - OTHER TEST METHODS ....................... 17

5 - DIELECTRIC PROPERTIES MEASUREMENTS ... . . . . . . . . . . . 19

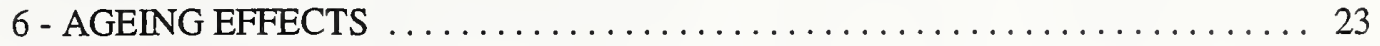

7 - ALPHABETICAL LISTING OF ABSTRACTS . . . . . . . . . . . 27

8 - INDEX OF AUTHORS AND CO-AUTHORS ................. 87 


\section{ACKNOWLEDGMENT}

Entries for this bibliography were collected with contributions by Samara Firebaugh, Arnold Perrey and Richard Van Brunt. The work was undertaken for and supported by the U.S. Nuclear Regulatory Commission. 


\section{FOREWORD}

This Bibliography is a complement to the Annotated Bibliography (NISTIR 4485) that was initially compiled for identifying promising test methods to detect incipient defects due to ageing of cables. That compilation led to the selection of two methods for a demonstration at the National Institute of Standards and Technology (NIST), Partial Discharge Analysis and Time-Domain Spectroscopy. The literature search covers the period 1989-1995, with emphasis on partial discharge measurements, data reduction and simulation, on measurement of dielectric properties, and to some degree, on insulation aging.

The contents are organized in two sections: a listing of authors and titles classified by topic categories, followed by an alphabetical listing of the authors, titles and abstracts. Those papers addressing more than one topic category are cited in all the relevant lists.

The categories selected for topic listings are:

1 - General Reviews and Tutorials

2 - Experimental Partial Discharge Measurements

3 - Partial Discharge Modeling and Analysis

4 - Other Test Methods

5 - Dielectric Properties Measurements

6 - Ageing Effects 


\section{1 - GENERAL REVIEWS AND TUTORIALS}

Aksyonov, Y.P.; Arsentyev, V.M.; Golovkov, M.Y.; Pintal, Y.S.; Antonov, B.D.; Pronin, B.D.; Kozubov, E.D., "Russian Nuclear Stations Approach of Ageing Effects Multiconductor Control Cables Insulation" - Unpublished paper - Copies available at NIST, 1994.

Bartnikas, R.; Novak, J.P., "On the Character of Different Forms of Partial Discharge and Their Related Terminologies," IEEE Transactions on Electrical Insulation, Vol. 28, No. 6, December 1993.

Bernstein, S.; Marks, J., 'Extruded Dielectric Cables: Density Measurements as a Diagnostic Tool," IEEE Electrical Insulation Magazine, Vol. 6, No. 3, May/June 1990.

Bernstein, B.S.; Brancato, E.L., "Aging of Equipment in the Electric Utilities," IEEE Transactions on Electrical Insulation, Vol. 28, No. 5, 1993.

Boggs, S.A., "Partial Discharge - Part II: Detection Sensitivity," IEEE Electrical Insulation Magazine, Vol. 5, No. 5, September/October 1990.

Boggs, S.A., "Partial Discharge III: Cavity-Induced PD in Solid Dielectrics," IEEE Electrical Insulation Magazine, Vol. 6, No. 6, November/December 1990.

Bruning, A.M.; Danikas, M.G., 'Report on Continuing Work on Parallel and Nonparallel Electric Field Chemical Aging of Polymer Cavities," Proceedings of the 4th International Conference on Conduction and Breakdown in Solid Dielectrics, IEEE, 1992.

Bruning, A.M.; Danikas, M.G., "Experiments on Polymer Cavity Currents above and below CIV," Proceedings of IEEE Conference on Electrical Insulation and Dielectric Phenomena October 1992.

Capponi, G.; Schifani, R., "Measurement of Partial Discharge in Solid Dielectrics with a Microprocessor-based System," IEEE Transactions on Electrical Insulation, Vol. 27, No. 1, February 1992.

Chan, J.C.; Duffy, P.; Hiivala, L.J.; Wasik, J., 'Partial Discharge - Part VIII: PD Testing of Solid Dielectric Cable,' IEEE Electrical Insulation Magazine, Vol. 7, No. 5, September/October 1991.

Danikas, M.G., "The Definitions Used for Partial Discharge Phenomena," IEEE Transactions on Electrical Insulation, Vol. 28, No. 6, December 1993.

Dissado, L.A.; Fothergill, J.C., "Electrical Degradation and Breakdown in Polymers," Peter Peregrinus, Stevenage, UK, 1992. 
Dissado, L.A., "Discharges and the Formation of Tree-shaped Breakdown Structures," Proceedings of the International Conference on Partial Discharge, IEE, Michael Faraday House, Stevenage, UK, 1993.

Fantana, N.L.; Bohme, H., "Dynamical Model for Electrical Aging of a Solid Dielectric," European Transactions on Electrical Power Engineering, Vol. 3, No. 6, 1993.

Fruth, B.; Florkowski, M.; Gross, D., "Partial Discharge Signal Generation, Transmission and Acquisition," Proceedings, International Conference on Partial Discharge, 1993.

Fuhr, J.; Fruth, B.; Niemeyer, L.; Konigstein, D.; Hassig, M.; Gutfleisch, F., "Generic Procedure for Classification of Aged Insulating System," Proceedings of the 3rd International Conference on Properties and Applications of Dielectric Materials, IEEE, 1991.

Giddings, J.; Simmons, M.; Hilder, D., "Practical Experience of Partial Discharge Measurement and Location on Power Cables," Proceedings, International Conference on Partial Discharge, 1993.

Gjaerde, A.C., "Multi Factor Ageing of Epoxy Resin," Proceedings, Nordic Insulation Symposium NORD-IS 92, Nygrens Ljuakopla AB, Vasteras, Sweden.

Grünewald, P.; Weidner, J.R., "On-line PD Analysis in Power Plants - A Successful Tool for Early Fault Detection," Proceedings, International Conference on Partial Discharge, 1993.

He, Q.; Kemp, I.J.; MacKinlay, R., "On Data Analysis and Processing of Partial Discharge Pulses Using Software Orientated Techniques," Proceedings, Sixth International Conference on Dielectric Materials, Measurements and Applications, IEE, London, UK, 1992.

Ishida, T.; Mizumo, Y.; Nagao, M.; Kosaki, M., "Computer Aided Partial Discharge Analysis System for Detection of Swarming Pulsive Microdischarges," Proceedings, International Conference on Partial Discharge, 1993.

Kahle, M., "Use of Combined Methods for Location and Identification of PD-sources in Electrical Insulation," Proceedings of the Symposium on Electrical Insulating Materials, Inst. of Electrical Engineers of Japan, Tokyo, 1993.

Kang, D.S.; Lee, W.Y.; Kim, Y.J., "A New Measurement Technique of Partial Discharge Phase Angle Distribution," Proceedings of the 1993 IEEE Conference on Electrical Insulation and Dielectric Phenomena, 1993.

Kärner, H.C., "Solid Dielectrics in HV Systems," Proceedings, Sixth International Symposium on High Voltage Engineering, 1989.

Kemp, I.J., "Developments in Partial Discharge Plant-Monitoring Technology," Proceedings, International Conference on Partial Discharge, 1993. 
Konig, G.; Kopf, U.; Feser, K., "Methods to Improve On-site Partial Discharge Measuring Instruments," Proceedings, Seventh International Symposium on High Voltage Engineering, Dresden Univ. Technol, Dresden, Germany, 1991.

Kreuger, F.H.; Gulski, E.; Krivda, A., "Classification of Partial Discharges," IEEE Transactions on Electrical Insulation, Vol. 28, No. 6, 1993.

Laghari, J.R.; Sarjeant, W.J., "Energy-storage Pulsed-power Capacitor Technology," IEEE Transactions on Power Electronics, Vol. 7, No. 1, January 1992.

Laghari, J.R., "Complex Electrical Thermal and Radiation Aging of Dielectric Films," IEEE Transactions of Electrical Insulation, Vol. 28, No. 5, October 1993.

Lamarre, L.; Morin, R.; Fournier, D., "Partial Discharge Measurements in Underground Distribution Cable Joints," Proceedings of the International Conference on Partial Discharge, IEE, Michael Faraday House, Stevenage, UK, 1993.

Laurent, C.; Mayoux, C., "Partial Discharge - XI. Limitations to PD as a Diagnostic for Deterioration and Remaining Life," IEEE Electrical Insulation Magazine, Vol. 8, No. 2, March-April 1992.

Lefkowitz, S.; Burnay, S., "A New Approach to Managing Cable Ageing (Nuclear Plants)," Nuclear Engineering International, Vol. 39, No. 485, December 1994.l

Leijon, M.; Ming, L.; Bengtsson, T., "PD - Source Identification in Solids," Conference Record of the 1992 IEEE International Symposium on Electrical Insulation.

Lundgaard, L.E., 'Partial Discharge - XIV. Acoustic Partial Discharge Detection - Practical Application," IEEE Electrical Insulation Magazine, Vol. 8, No. 5, September-October 1992.

Mashikian, M.S.; Palmieri, F.; Bansal, R.; Northrop, R.B., 'Location of Partial Discharges in Shielded Cables in the Presence of High Noise," IEEE Transactions on Electrical Insulation, Vol. 27, No. 1, February 1992.

Miri, S.M.; Privette, A., "A Survey of Incipient Fault Detection and Location Techniques for Extruded Shielded Power Cables," Proceedings of 26th Southeastern Symposium on System Theory, IEEE, 1994.

Morshuis, P.H.F., "Partial Discharge Mechanisms in Voids Related to Dielectric Degradation," IEE Proceedings Science, Measurement and Technology, Vol. 142, No. 1, January 1995.

Murata, K.; Yasuda, S., "The Latest Technique of Portable Oil-dissolved Gas Analyzer for Distribution Oil-immersed Transformer," Transactions of the Institute of Electrical Engineers of Japan, Part B, Vol. 112-B, No. 3, March 1992 (In Japanese). 
Naboka, B.G.; Besprozvannykh, A.V.; Gladchenko, V.Y., "Diagnostics of High-Voltage Insulation Using Multichannel Analyzers," Electrical Technology, No. 2, 1991, UK.

Nattrass, D.A., "Partial Discharge Measurement and Interpretation," IEEE Electrical Insulation Magazine, Vol. 4, No. 3, May/June 1988.

Niemeyer, L., "The Physics of Partial Discharges," Proceedings, International Conference on Partial Discharge, 1993.

Osvath, P.; Zahn, H., "Evaluation and Location of Partial Discharge in Plastic-Insulated High Voltage Cables," Proceedings, CABLEWIRE - 91. 3rd International Seminar on Cables, Conductors and Winding Wires, 1991, Indian Electr. Electron. Manuf. Assoc, Bombay, India.

Pfeiffer, W., "Partial-discharge Testing of Components for Low-voltage Equipment," IEEE Transactions on Electrical Insulation, Vol. 26, No. 2, 1991.

Reynolds, P.R., "A Review of the Current Status of Partial Discharge Studies, Proceedings, Sixth International Symposium on High Voltage Engineering, 1989.

Ryder, D.M., "Interpretation of Partial Electrical Discharge Measurements with Insulation Damage and Ageing," Proceedings of the 1993 IEEE Conference on Electrical Insulation and Dielectric Phenomena, 1992.

Satish, L.; Gururaj, B.I., "Use of Markov Models for Partial Discharge Recognition," IEEE Transactions on Electrical Insulation, Vol. 28, No. 2, April 1993.

Steiner, J. P., "Partial Discharge - Part IV: Commercial PD Testing," IEEE Electrical Insulation Magazine, Vol. 7, No. 1, January/February 1991.

Stone, G.C.; Kuffel, J., "Digital Recording Techniques for Electrical Insulation Measurements," IEEE Electrical Insulation Magazine, Vol. 5, No. 3, May/June 1989.

Tanaka, T.; Okamoto, T.; Nakanishi, K.; Miyamoto, T., "Aging and Related Phenomena in Modern Electric Power Systems," IEEE Transactions on Electrical Insulation, Vol. 28, No. 5, 1993.

Van Brunt, R.J., "Stochastic Properties of Partial-discharge Phenomena," IEEE Transactions on Electrical Insulation, Vol. 26, No. 5, October 1991. 


\section{2 - EXPERIMENTAL PARTIAL DISCHARGE MEASUREMENTS}

Aksyonov, Y.P.; Arsentyev, V.M.; Golovkov, M.Y.; Pintal, Y.S.; Pronin, B.D., "In Situ Age Condition Monitoring Methods of Mechanical Damages in Control Cables Insulation" - Unpublished paper - Copies available at NIST, 1994.

Allan, D.; Blundell, M.; Boyd, K.; Hinde, D., "New Techniques for Monitoring the Insulation Quality of In-service HV Apparatus," IEEE Transactions on Electrical Insulation Vol. 27, No. 2, June 1992.

Alsheikhly, A.; Kranz, H.-G., "A New Approach for a Basic Understanding of PD Phenomena," Proceedings, Seventh International Symposium on High Voltage Engineering, Dresden Univ. Technol, Dresden, Germany, 1991.

Alsheilchy, A.; Kranz, H.G., "Determination of the Ratio of the PD Damaging Energy to the Measurable Input Energy for a PD Afflicted Solid Insulation," Proceedings, International Conference on Partial Discharge, 1993.

Aksenov, Y.P.; Arsentiev, V.; Golovkov, M.; Pintal, Y.S.; Bromley, J.C.; Glodjo, A.; McDermid, W., "Measurement \& Location of Dielectric Anomalies in Field Aged XLPE Cables," Conference Record of the 1994 International Symposium on Electrical Insulation.

Banford, H.M.; Given, M.J.; Tedford, D.J., "A Space Simulation Chamber for Space Power Insulation," Conference Record of the 1992 IEEE International Symposium on Electrical Insulation, IEEE, 1992.

Borsi, H., "Digital Location of Partial Discharges in HV Cables," IEEE Transactions on Electrical Insulation, Vol. 27, No. 1, February 1992.

Borsi, H., "Dielectric Behavior of Silicone and Ester Fluids for Use in Distribution Transformers," IEEE Transactions on Electrical Insulation, Vol. 26, No. 4, 1990.

Borsi, H., "New Method for Partial Discharges (PD) Location in High Voltage Cables under Noisy Condition," Proceedings, Seventh International Symposium on High Voltage Engineering, Dresden Univ. Technol., Dresden, Germany, 1991.

Bozzo, R.; Coletti, G.; Hagi, A., "Pre-breakdown Phenomena in XLPE under Highly Divergent Field Conditions," Proceedings of the 4th International Conference on Conduction and Breakdown in Solid Dielectrics, IEEE, 1992.

Bozzo, R.; Guastaaino, F.; Cicciari, M.; Contin, A.; Montanari, G.C., "Stochastic Procedures for the Investigation of Tree Growth in Insulating Material for H.V. Applications," Conference Record of the 1994 IEEE International Symposium on Electrical Insulation. 
Braun, J.M.; Sedding, H.G.; Stein, J., "Electrical Testing of Aged Station Cables," Proceedings of the American Power Conference, Vol. 1, 1993.

Bressani, M.; Contin, A.; Rabach, G.; Razza, F.; Secco, M., "A Test Methodology, Based on Partial Discharge Analysis, for the Evaluation of a Solid Insulation System," Proceedings, Sixth International Symposium on High Voltage Engineering, 1989.

Bruning, A.M.; Danikas, M.G., "Report on Continuing Work on Parallel and Nonparallel Electric Field Chemical Aging of Polymer Cavities," Proceedings of the 4th International Conference on Conduction and Breakdown in Solid Dielectrics, IEEE, 1992.

Capponi, G.; Schifani, R., "Measurement of Partial Discharge in Solid Dielectrics with a Microprocessor-based System," IEEE Transactions on Electrical Insulation, Vol. 27, No. 1, February 1992.

Changchang, W.; Heng, G.; Dehend, Z; Kexiong, T. " "The Study of Current Transducer System for On-line Monitoring Partial Discharge in Electrical Equipment," Proceedings, Sixth International Symposium on High Voltage Engineering, 1989.

Coletti, G.; Guastavino, F., "A Contribution to the Evaluation of Power Generators Insulation Ageing Due to Long Term Service," Energia Elettrica, Vol. 68, No. 1, 1991.

Coletti, G.; Guastavino, F., "An Experimental Testing Procedure to Study the Resistance to Partial Discharges of Thin Polymeric Films," Proceedings, Nordic Insulation Symposium NORD-IS 92, Nygrens Ljuakopla AB, Vasteras, Sweden, 1992.

Contin, A.; Rabach, G., "Identification and Detection of Slot Discharges During Accelerated Ageing Tests," Proceedings of the 1992 IEEE Conference on Electrical Insulation and Dielectric Phenomena, 1992.

Dejean, P.; Foulon, N.; Goldman, M.; Dejean, H., "Chemical Aspects of the Ageing of Solid Insulating Materials Submitted to Partial Discharges," Proceedings of the 4th International Conference on Conduction and Breakdown in Solid Dielectrics, IEEE, New York, NY, USA, 1992.

Domun, M.K.; MacKinley, R.R.; Miller, R., "The Effects of Voltage and Frequency on the Partial Discharge Characteristics of HV Paper Cables," Proceedings, Sixth International Symposium on High Voltage Engineering, 1989.

Du, Z.; Mashikian, M.S., "Self-Learning Digital Filter for the Field Location of Partial Discharge in Cables," Conference Record of the 1994 International Symposium on Electrical Insulation, 1994.

Ebinuma, Y.; Ogishima, M.; Aihara, M.; Haga, K., "Insulation Measurement of 22 Approximately $33 \mathrm{kV}$ XLPE Insulated Cable by Very Low Frequency High Voltage," Showa Electric Wire and Cable Review, Vol. 43, No. 2, 1993 (In Japanese). 
Egiziano, L.; Femia, N.; Garamella, G.; Lupo, G.; Tucci, V., "Characterization of Composite Organic Materials for Field Stress Control of HV Cables Terminations," Proceedings of the 4th International Conference on Conduction and Breakdown in Solid Dielectrics, IEEE, 1992.

Ehara, Y.; Koizumi, N.; Kishida, H.; Ito, T., "Characteristics of Humidity on Partial Discharge Deterioration," Proceedings of the Symposium on Electrical Insulating Materials, 1993, Inst. of Electrical Engineers of Japan, Tokyo, 1993.

Florkowska, B.; Wlodek, R., "Pulse Height Analysis of Partial Discharge in Air," IEEE Transactions on Electrical Insulation, Vol. 28, No. 6, December 1993.

Fruth, B.; Niemeyer, L., "The Importance of Statistical Characteristics of Partial Discharge Data," IEEE Transactions on Electrical Insulation, Vol. 27, No. 1, February 1992.

Fukunaga, K., "A New Partial Discharge Detection Method for Live UHV/EHV Cable Joints," Electrical Engineering in Japan, Vol. 113, No. 4, June 1994.

Fukunaga, K.; Tan, M.; Takehana, H.; Takahashi, T.; Yoshida, S., "New Partial Discharge Detection Method for Live Power Cable Systems," Proceedings of the 3rd International Conference on Properties and Applications of Dielectric Materials, IEEE, 1991.

Gjaerde, A.C.; Sletbak, J., "Influence of Partial Discharges on Void Gas Pressure," Proceedings of the International Conference on Partial Discharge, IEE, Michael Faraday House, Stevenage, UK, 1993.

Gluchowski, S.; Juchniewicz, J., "The Interplay of Treeing Forms and Aging Phenomena," Proceedings of the 3rd International Conference on Properties and Applications of Dielectric Materials, IEEE, 1991.

Gryazin, V.A.; Zavarzina, V.V.; Rozhkov, V.M., "Influence of Pressure on the Breakdown of Small Air Gaps," Elektrotekhnika Vol. 63, No. 11, Translated in Soviet Electrical Engineering Vol. 63, No. $11,1992$.

Guastavino, F.; Guerra, G., "Optimization of Partial Discharge Testing Techniques," Proceedings of the 4th International Conference on Conduction and Breakdown in Solid Dielectrics, IEEE, 1992.

Gulski, E.; Kreuger, F.H., "Diagnostics of Insulating Systems Using Statistical Tools," Conference Record of the 1992 IEEE International Symposium on Electrical Insulation.

Hadid, A.; Laurent, C.; Mammeri, M.; Clavreul, R.; Duchateau, F.; Berdala, J., "An Investigation into Electrical Ageing of Insulating Polymers by Detection of Charge Injection under Alternative Divergent Field," Journal de Physique (Applied Physics, Materials Science, Fluids, Plasma and Instrumentation), Vol. 4, No. 1, January 1994 (In French).

Hantouche, C., "Partial Discharges on Power Capacitors," IEEE Transactions on Electrical Insulation, Vol. 28, No. 6, December 1993. 
Hasegawa, T.; Kimura, K.; Shibuya, Y., "Construction of Expert System Prototype for Degradation Diagnosis and Measurement System Using Personal Computer Application for Degradation Diagnosis of PD Statistical Parameter Using Phase Information," Transactions of the Institute of Electrical Engineers of Japan, Part A, Vol. 113-A, No. 5, 1993 (In Japanese).

Hasegawa, T.; Kimura, K.; Shibuya, Y., "Effect of Applied Voltage Frequency on Swarming Pulsive Microdischarges in Closed Voids," Electrical Engineering in Japan, Vol. 113, No. 3, 1993.

Henriksen, M.; Holboll, J.T.; Rygal, R., "An Improved Method/Setup for Extended Testing after the CIGRE Method II," Conference Record of the 1992 IEEE International Symposium on Electrical Insulation, 1992.

Hikita, M.; Komori, F.; Nishiguchi, N.; Mizutani, T., "Phase-resolved and Time-Sequential Partial Discharge Pulse Measurements in a Metal-Void-Insulator System Using a Personal Computer," Journal of Physics D (Applied Physics) Vol. 27, No. 6, June 1994.

Holboll, J.T.; Henriksen, M., "Partial Discharge Patterns and Surface Deterioration in Voids in Filled and Unfilled Epoxy," Conference Record of the 1992 IEEE International Symposium on Electrical Insulation, 1992.

Hoof, M.; Patsch, R., "Analyzing Partial Discharge Pulse Sequences - A New Approach to Investigate Degradation Phenomena," Conference Record of the 1994 International Symposium on Electrical Insulation.

Ishida, T.; Mizumo, Y.; Nagao, M.; Kosaki, M., "Computer Aided Partial Discharge Analysis System for Detection of Swarming Pulsive Microdischarges," Proceedings, International Conference on Partial Discharge, 1993.

Ivanov, S.I.; Svirachev, D.M.; Pechenyakova, V.P.; Petrov, Ch.V.; Dobreva, E.D., "Surface Modulation of Polyimide in a Gas Discharge: Post-effect," Bulgarian Journal of Physics, Vol. 19, No. 1-2, 1993.

Karapetyan, M.; Khachatryan, A. S.; Bortnik, I. M., "The Short Term and Long Term Electric Strength of Polymeric Composition Materials under DC and AC Stresses," Izvestiya ANSSSR: Energetika Transport, No. 1, January-February 1991 (in Russian)

Katsuta, G.; Toya, A.; Muraoka, K.; Endoh, T.; Sekii, Y.; Ikeda, C., 'Development of a Method of Partial Discharge Detection in Extra-High Voltage Cross-Linked Polyethylene Insulated Cable Lines," IEEE Transactions on Power Delivery, Vol. 7, No. 3, July 1992.

Komori, F.; Nishiguchi, N.; Hikita, M.; Mizutani, T., "Construction of Prototype On-line Expert System for Insulation Degradation Diagnosis of Polymeric Insulation Material Suffering Partial Discharge (PD)," Proceedings of the 4th International Conference on Conduction and Breakdown in Solid Dielectrics, IEEE, 1992. 
Komori, F.; Nishiguchi, N.; Hikita, M.; Mizutani, T., 'Degradation Diagnosis and Estimation of Residual Life of Insulating Material Using Pattern Recognition of Phase Angle Resolved Partial Discharge Pulse Occurrence Distribution," Transactions of the Institute of Electrical Engineers of Japan, Part A, Vol. 113-A, No. 8, 1993.

Komori, F.; Nishiguchi, N.; Hikita, M.; Mizutani, T., 'Detection of Electrical Tree Initiation and Assessment of Shape of the Developing Tree Using Pattern Recognition of Partial Discharge Occurrence Phase Distribution," Proceedings, International Conference on Partial Discharge, 1993.

König, G.; Feser, K., "A New Digital Filter to Reduce Periodical Noise in Partial Discharge Measurements," Proceedings, Sixth International Symposium on High Voltage Engineering, 1989.

Kreuger, F.H.; From, U., "Time Resolved Measurements of Partial Discharges in Gaseous Voids," Proceedings of Nordic Insulation Symposium. NORD-IS 94, June 1994.

Krivda, A.; Gulski, E., "Influence of Aging on Classification of Partial Discharges in Cavities," Japanese Journal of Applied Physics, Part 1 (Regular Papers \& Short Notes) Vol. 33, No. 10, October 1994.

Kurrat, M.; Peier, D., "Wideband Measurement of Partial Discharges for Fundamental Diagnostics," Proceedings, Seventh International Symposium on High Voltage Engineering, Dresden Univ. Technol, Dresden, Germany, 1991.

Laurent, C.; Mayoux, C., "From Initiation to Propagation in Electric Treeing," Proceedings of the IEE International Conference on Partial Discharge, IEE, Michael Faraday House, Stevenage, UK, 1993.

Lemke, E.; Schmiegel, P., "Analysis of Dielectric Properties on the Basis of a Non-conventional Measuring Procedure," Proceedings, 6th International Conference on Dielectric Materials, Measurements and Applications, IEE, London, UK, 1992.

MacKinley, R.R., 'Partial Discharge Measurements at Low Frequencies on High Voltage Cables in Service Within the UK Utilities," Proceedings, Sixth International Symposium on High Voltage Engineering, 1989.

Mammeri, M.; Laurent, C.; Salon, J., "Influence of Space Charge Buildup on the Transition to Electrical Treeing in PE under AC Voltage," IEEE Transactions on Dielectrics and Electrical Insulation, Vol. 2, No. 1, February 1995.

Martzloff, F.D.; Simmon, E.; Steiner, J.P.; Van Brunt, R.J., 'Detection of Incipient Defects in Cables by Partial Discharge Analysis," NISTIR 4487, 1992.

Mashikian, M.S.; Palmieri, F.; Bansal, R.; Northrop, R.B., "Location of Partial Discharges in Shielded Cables in the Presence of High Noise," IEEE Transactions on Electrical Insulation, Vol. 27, No. 1, February 1992. 
Morshuis, P.H.F.; Kreuger, F.H., "The Spatial Distribution and Electrical Parameters of Partial Discharges in Polyethylene Insulation During Ageing," Proceedings of the 4th International Conference on Conduction.

Morshuis, P.H.F., "Time Resolved Discharge Measurements," Proceedings, International Conference on Partial Discharge, 1993.

Nemamcha, M.; Gosse, J.P.; Gosse, B.; Marteau, C., "Monitoring of Partial Discharges in Capacitor Models with Impregnated Polypropylene Films," Proceedings of the 4th International Conference on Conduction and Breakdown in Solid Dielectrics, IEEE, 1992.

Nikolopoulos, P.N.; Agoris, D.P.; Sakkas, G.H., "Comparative Consideration of Aging and Breakdown of Pressboard Dielectric Stressed Either by Impulse or by Alternating Voltages under the Influence of Partial Discharges," Proceedings, Seventh International Symposium on High Voltage Engineering, Dresden Univ. Technol., Dresden, Germany, 1991.

Noriaki, N.; Komori, F.; Hikita, M.; Mizutani, T., 'Detection of Electrical Tree Initiation and Assessment of Shape of the Developing Tree Using Pattern Recognition of Partial Discharge Occurrence Phase Distribution," Transactions of the Institute of Electrical Engineers of Japan, Part A, Vol. 113-A, No. 7, 1993 (In Japanese).

Ohno, H.; Katsuta, G.; Sakaguchi, R.; Ebinuma, Y.; Sasaki, N.; Nagaoka, A., 'Development of Partial Discharge Location Method of Power Cable," Transactions of the Institute of Electrical Engineers of Japan, Part B, Vol. 112-B, No. 8, 1992 (In Japanese). Also, in English, in Electrical Engineering in Japan, Vol. 113, No. 8, December 1993.

Ohno, M.; Yoshida, S.; Takehana, H.; Tan, M.; Fukunaga, K., "Measurement of Partial Discharge on Live Power Cables Using a High Frequency Component Detection Method Partial Discharge Sensor for Live Power Cable Systems," Fujikura Technical Review, No. 21, January 1992.

Phung, B.T.; Blackburn, T.R.; James, R.E., "Use of Artificial Neural Networks in Discriminating Partial Discharge Patterns," Proceedings, Sixth International Conference on Dielectric Materials, Measurements and Applications, IEE, Michael Faraday House, Stevenage, UK, 1992.

Pietsch, R., "Integral and Spectral Investigations of Luminescence Light During Electrical Aging in Polyethylene," Proceedings, Seventh International Symposium on High Voltage Engineering, Dresden Univ. Technol., Dresden, Germany, 1991.

Schnettler, A.; Peier, D., "A New Computer-aided Partial Discharge (PD) Measuring System for Dielectric Diagnosis," Proceedings, Seventh International Symposium on High Voltage Engineering, Dresden Univ. Technol., Dresden, Germany, 1991.

Shalimov, V.V.; Bespalova, E.B.; Zorin, G.A.; Kandibolotskaya, T.B., "Stability of Layered Materials Against Electric Discharges," Zhurnal Tekhnicheskoi Fiziki Vol. 63, No. 9, 1993. Translated in: Technical Physics, Vol. 38, 1993. 
Shihab, S.; Moorty, S.; Cheng, X.; Rao, V., "Partial Discharge Measuring System for On-Line Condition Monitoring of High Voltage Equipment," Proceedings of the 1992 IEEE Conference on Electrical Insulation and Dielectric Phenomena, 1992.

Stone, G.C., "Partial Discharge. VII. Practical Techniques for Measuring PD in Operating Equipment," IEEE Electrical Insulation Magazine, Vol. 7, No. 4, July-August 1991.

Van Brunt, R.J.; Cernyar, E.W., "Influence of Phase-to-Phase Memory Propagation on the Stochastic Behavior of AC-Generated Partial Discharges," Proceedings of the 1993 IEEE Conference on Electrical Insulation and Dielectric Phenomena, 1993.

Van Brunt, R.J.; Cernyar, E.W., "Stochastic Analysis of AC-Generated Partial-discharge Pulses from a Monte-Carlo Simulation," Proceedings of IEEE Conference on Electrical Insulation and Dielectric Phenomena, 1992.

Van Brunt, R.J.; Misakian, M.; Kulkarni, S.V.; Lakdawala, V.K., "Influence of a Dielectric Barrier on the Stochastic Behavior of Trichel-Pulse Corona," IEEE Transactions on Electrical Insulation, Vol. 26, No. 3, June 1991.

Van Brunt, R.J.; Cernyar, E.W.; von Glahn, P.; Las, T., "Variations in the Stochastic Behavior of Partial-discharge Pulses with Point-to-dielectric Gap Spacing," Conference Record of the 1992 IEEE International Symposium on Electrical Insulation, 1992.

Van Brunt, R.J.; Cernyar, E.W., "System for Measuring Conditional Amplitude, Phase, or Time Distributions of Pulsating Phenomena," Journal of Research of the National Institute of Standards and Technology, Vol. 97, No. 6, November/December 1992.

Van Brunt, R.J.; Stricklett, K.L.; Steiner, J.P.; Kulkarni, S.V., 'Recent Advances in Partial Discharge Measurement Capabilities at NIST," IEEE Transactions on Electrical Insulation, Vol. 27, No. 1, February 1992.

Van Brunt, R.J.; von Glahn, P.; Las, T., "Nonstationary Behavior of Partial Discharge During Discharge Induced Ageing of Dielectrics," IEE Proceedings Science, Measurement and Technology, Vol. 142, No. 1, 1995.

Vettese, G.; Libotte, M.; Pompili, M.; Mazzetti, C., "Ultrahigh Frequency Study of PD Pulses," Conference Record of the 1994 International Symposium on Electrical Insulation, 1994.

von Glahn, P.; Van Brunt, R.J., "Performance Evaluation of a New Digital Partial Discharge Recording and Analysis System," Conference Record of the 1994 International Symposium on Electrical Insulation, 1994.

Wichman, A.; Grünewald, P., Weidner, J., "On-Line Monitoring for Incipient Fault Detection in HV Equipment," Proceedings, Sixth International Symposium on High Voltage Engineering, 1989.

Yamashita, H., "Partial Discharge Measurements in Dielectric Liquids under Impulse Voltage," IEEE Transactions on Electrical Insulation, Vol. 28, No. 6, 1993. 
NISTIR 5760

$-12-$ 


\section{3 - PARTIAL DISCHARGE MODELING AND ANALYSIS}

Agoris, D.P.; Hatziargyriou, N.D., 'Two-void Model for Simulation of Partial Discharges in Solid Dielectrics," Modelling, Simulation \& Control A, Vol. 42, No. 2, France, 1992.

Alsheilchy, A.; Kranz, H.G., "Determination of the Ratio of the PD Damaging Energy to the Measurable Input Energy for a PD Afflicted Solid Insulation," Proceedings, International Conference on Partial Discharge, 1993.

Alsheikhly, A.; Guzman, H.; Kranz, H.-G., "A New Diagnostic Tool Through Computer Simulation Calculation Using Expanded Partial Discharge Equivalent Circuit," Proceedings of the 4th International Conference on Conduction and Breakdown in Solid Dielectrics, IEEE, 1992.

Alsheikhly, A.; Kranz, H.-G., "A New Approach for a Basic Understanding of PD Phenomena," Proceedings, Seventh International Symposium on High Voltage Engineering, Dresden Univ. Technol, Dresden, Germany, 1991.

Borsi, H., "New Method for Partial Discharges (PD) Location in High Voltage Cables under Noisy Condition," Proceedings, Seventh International Symposium on High Voltage Engineering, Dresden Univ. Technol., Dresden, Germany, 1991.

Bozzo, R.; Coletti, G.; Hagi, A., 'Pre-breakdown Phenomena in XLPE under Highly Divergent Field Conditions," Proceedings of the 4th International Conference on Conduction and Breakdown in Solid Dielectrics, IEEE, 1992.

Cacciari, M.; Contin, A.; Rabach, G.; Montanari, G.C., "Diagnosis of Practical Insulation Systems by Partial Discharge Measurements in the Presence of Multi-discharge Phenomena," Proceedings of the 1993 IEEE Conference on Electrical Insulation and Dielectric Phenomena, 1993.

Changchang, W.; Heng, G.; Dehend, Z.; Kexiong, T., "The Study of Current Transducer System for On-line Monitoring Partial Discharge in Electrical Equipment," Proceedings, Sixth International Symposium on High Voltage Engineering, 1989.

Florkowska, B.; Wlodek, R., "Pulse Height Analysis of Partial Discharge in Air," IEEE Transactions on Electrical Insulation, Vol. 28, No. 6, December 1993.

Gluchowski, S.; Juchniewicz, J., "The Interplay of Treeing Forms and Aging Phenomena," Proceedings of the 3rd International Conference on Properties and Applications of Dielectric Materials, IEEE, 1991.

Gryazin, V.A.; Zavarzina, V.V.; Rozhkov, V.M., "Influence of Pressure on the Breakdown of Small Air Gaps," Elektrotekhnika Vol. 63, No. 11, Translated in Soviet Electrical Engineering Vol. 63, No. 11, 1992. 
Gulski, E.; Kreuger, F.H., 'Diagnostics of Insulating Systems Using Statistical Tools," Conference Record of the 1992 IEEE International Symposium on Electrical Insulation.

Hadid, A.; Laurent, C.; Mammeri, M.; Clavreul, R.; Duchateau, F.; Berdala, J., "An Investigation into Electrical Ageing of Insulating Polymers by Detection of Charge Injection under Alternative Divergent Field," Journal de Physique (Applied Physics, Materials Science, Fluids, Plasma and Instrumentation), Vol. 4, No. 1, January 1994 (In French).

Hantouche, C., "Partial Discharges on Power Capacitors," IEEE Transactions on Electrical Insulation, Vol. 28, No. 6, December 1993.

Hasegawa, T.; Kimura, K.; Shibuya, Y., "Construction of Expert System Prototype for Degradation Diagnosis and Measurement System Using Personal Computer Application for Degradation Diagnosis of PD Statistical Parameter Using Phase Information," Transactions of the Institute of Electrical Engineers of Japan, Part A, Vol. 113-A, No. 5, 1993 (In Japanese).

Hoof, M.; Patsch, R., "Analyzing Partial Discharge Pulse Sequences - A New Approach to Investigate Degradation Phenomena," Conference Record of the 1994 International Symposium on Electrical Insulation.

Hoof, M.; Patsch, R., "Pulse-sequence Analysis: A New Method for Investigating the Physics of PD- Induced Ageing," IEE Proceedings Science, Measurement and Technology, Vol. 142, No. 1, January 1995.

Hoof, M.; Patsch, R., "Pulse-sequence Analysis: A New Method for Investigating the Physics of PD- Induced Ageing," IEE Proceedings Science, Measurement and Technology, Vol. 142, No. 1, January 1995.

Jianaing, L.; Jinping, Y., "Intelligent Partial Discharge Measurement Device," Conference Record of the 1994 International Symposium on Electrical Insulation, 1994.

Kang, D.S.; Lee, W.Y.; Kim, Y.J., "A New Measurement Technique of Partial Discharge Phase Angle Distribution," Proceedings of the 1993 IEEE Conference on Electrical Insulation and Dielectric Phenomena, 1993.

Karady, G.G.; Oliva, J.R.; Domitz, S.; Meketa, R., "Advanced Digital Instrumentation for Partial-Discharge Measurement," Electric Power Systems Research, Vol. 25, No. 3, December 1992.

Komori, F.; Nishiguchi, N.; Hikita, M.; Mizutani, T., "Construction of Prototype On-line Expert System for Insulation Degradation Diagnosis of Polymeric Insulation Material Suffering Partial Discharge (PD)," Proceedings of the 4th International Conference on Conduction and Breakdown in Solid Dielectrics, IEEE, 1992.

Komori, F.; Nishiguchi, N.; Hikita, M.; Mizutani, T., "Degradation Diagnosis and Estimation of Residual Life of Insulating Material Using Pattern Recognition of Phase Angle Resolved Partial Discharge Pulse Occurrence Distribution," Transactions of the Institute of Electrical Engineers of Japan, Part A, Vol. 113-A, No. 8, 1993. 
König, G.; Feser, K., "A New Digital Filter to Reduce Periodical Noise in Partial Discharge Measurements," Proceedings, Sixth International Symposium on High Voltage Engineering, 1989.

Konig, G.; Kopf, U.; Feser, K., "Methods to Improve On-site Partial Discharge Measuring Instruments," Proceedings, Seventh International Symposium on High Voltage Engineering, Dresden Univ. Technol, Dresden, Germany, 1991.

Krivda, A.; Gulski, E., "Influence of Aging on Classification of Partial Discharges in Cavities," Japanese Journal of Applied Physics, Part 1 (Regular Papers \& Short Notes) Vol. 33, No. 10, October 1994.

MacKinley, R.R., "Partial Discharge Measurements at Low Frequencies on High Voltage Cables in Service Within the UK Utilities," Proceedings, Sixth International Symposium on High Voltage Engineering, 1989.

Martzloff, F.D.; Simmon, E.; Steiner, J.P.; Van Brunt, R.J., 'Detection of Incipient Defects in Cables by Partial Discharge Analysis," NISTIR 4487, 1992.

Mazroua, Amira A.; Salama, M.M.A.; Bartnikas, R., "PD Pattern Recognition with Neural Networks Using the Multilayer Perceptron Technique," IEEE Transactions on Electrical Insulation, Vol. 28, No. 6, December 1993.

Mazroua, A.A.; Bartnikas, R.; Salama, M.M.A., "Neural Network System Using the Multi-Layer Perceptron Technique for the Recognition of PD Pulse Shapes Due to Cavities and Electrical Trees," IEEE Transactions on Power Delivery, Vol. 10, No. 1, January 1995.

Niemeyer, L., "The Physics of Partial Discharges," Proceedings, International Conference on Partial Discharge, 1993.

Noriaki, N.; Komori, F.; Hikita, M.; Mizutani, T., 'Detection of Electrical Tree Initiation and Assessment of Shape of the Developing Tree Using Pattern Recognition of Partial Discharge Occurrence Phase Distribution," Transactions of the Institute of Electrical Engineers of Japan, Part A, Vol. 113-A, No. 7, 1993 (In Japanese).

Okamoto, T.; Tanaka, T., "Partial Discharge Pattern Recognition for Three Kinds of Model Electrodes with a Neural Network," Proceedings, International Conference on Partial Discharge, 1993.

Phung, B.T.; Blackburn, T.R.; James, R.E., "Use of Artificial Neural Networks in Discriminating Partial Discharge Patterns," Proceedings, Sixth International Conference on Dielectric Materials, Measurements and Applications, IEE, Michael Faraday House, Stevenage, UK, 1992.

Schichler, U.; Borsi, H.; Gockenbach, E., "Problems and New solutions for Partial Discharge Measurement on High Voltage Cables under Noisy Conditions," Conference Record of the 1994 International Symposium on Electrical Insulation. 
Schnettler, A.; Peier, D., "A New Computer-aided Partial Discharge (PD) Measuring System for Dielectric Diagnosis," Proceedings, Seventh International Symposium on High Voltage Engineering, Dresden Univ. Technol., Dresden, Germany, 1991.

Sigmond, R.S., "Fast Image Converter and Slow Computer Simulation Studies of Partial Discharge Models," Proceedings, International Conference on Partial Discharge, 1993.

Su, Q., "An Adaptive Filtering Method for Noise Suppression in Partial Discharge Measurements," Proceedings of the 1993 IEEE Conference on Electrical Insulation and Dielectric Phenomena, 1993.

Tanaka, T., "Partial discharge pulse distribution pattern," IEE Proceedings Science, Measurement and Technology, Vol. 142, No. 1, January 1995.

Tsutsumi, Y.; Yonekura, T.; Kikuchi, T., "Cluster Pulse Criteria for Recognition of Partial Discharge," Electrical Engineering in Japan, Vol. 113, No. 7, December 1993.

Van Brunt, R.J.; Cernyar, E.W., "Influence of Phase-to-Phase Memory Propagation on the Stochastic Behavior of AC-Generated Partial Discharges," Proceedings of the 1993 IEEE Conference on Electrical Insulation and Dielectric Phenomena, 1993.

Van Brunt, R.J.; von Glahn, P., "Nonstationary Behavior of Partial Discharge During Insulation Aging," Proceedings of the International Conference on Partial Discharge, IEE, Michael Faraday House, Stevenage, UK, 1993.

Van Brunt, R.J.; Cernyar, E.W., "Stochastic Analysis of AC-Generated Partial-discharge Pulses from a Monte-Carlo Simulation," Proceedings of IEEE Conference on Electrical Insulation and Dielectric Phenomena, 1992.

Van Brunt, R.J.; Cernyar, E.W.; von Glahn, P.; Las, T., "Variations in the Stochastic Behavior of Partial-discharge Pulses with Point-to-dielectric Gap Spacing," Conference Record of the 1992 IEEE International Symposium on Electrical Insulation, 1992.

Van Brunt, R.J.; von Glahn, P.; Las, T., "Partial Discharge-induced Aging of Cast Epoxies and Related Nonstationary Behavior of the Discharge Statistics," Proceedings of the 1993 IEEE Conference on Electrical Insulation and Dielectric Phenomena, 1993.

Van Brunt, R.J.; von Glahn, P.; Las, T., "Nonstationary Behavior of Partial Discharge During Discharge Induced Ageing of Dielectrics," IEE Proceedings Science, Measurement and Technology, Vol. 142, No. 1, 1995.

von Glahn, P.; Van Brunt, R.J., "Performance Evaluation of a New Digital Partial Discharge Recording and Analysis System," Conference Record of the 1994 International Symposium on Electrical Insulation, 1994. 


\section{4 - OTHER TEST METHODS}

Nakanishi, Y.; Nakatani, Y.; lizumi, M.; Kasuya, M., "Partial Discharge Detection by AE Sensors for Prefabricated Joints for XLPE Cables," Electrical Engineering in Japan Vol. 113, No. 8, December 1993.

Oda, T.; Wang, S.-N.; Maruyama, Y.; Ichiyanagi, N.; Tanaka, H., "Thermally Stimulated Discharge Current Observation of Cross-linked Polyethylene," Proceedings of the 3rd International Conference on Properties and Applications of Dielectric Materials, Vol. 1, IEEE, 1991.

Pietsch, R., "Integral and Spectral Investigations of Luminescence Light During Electrical Aging in Polyethylene," Proceedings, Seventh International Symposium on High Voltage Engineering, Dresden Univ. Technol., Dresden, Germany, 1991.

Ramsey, N.W., "The Influence of Manufacture on Post-irradiation Thermally Stimulated Conductivity in Polyethylene, Proceedings of IEEE Conference on Electrical Insulation and Dielectric Phenomena, 1992.

Robinson, G., "Low-frequency Loss Spectra and Ageing in Paper-Insulated Cables," Proceedings, Third International Conference on Power Cables and Accessories, IEE, London, UK, 1993.

Steiner, J.P.; Ward, B.H., "Partial Discharge Measurements and Pulsed Resonant Wave Excitation," Conference Record of the 1992 IEEE International Symposium on Electrical Insulation, 1992.

Tanaka, H.; Ichiyanagi, N.; Iwata, Z., "A Study on Breakdown Phenomena in XLPE Power Cable," Proceedings of the 1992 IEEE Conference on Electrical Insulation and Dielectric Phenomena, 1992.

Van Brunt, R.J.; Stricklett, K.L.; Steiner, J.P.; Kulkarni, S.V., "Recent Advances in Partial Discharge Measurement Capabilities at NIST," IEEE Transactions on Electrical Insulation, Vol. 27, No. 1, February 1992.

van Roggen, A.; Zhou, H., Data Analysis in Dielectric Time-Domain Spectroscopy," Proceedings of the 1992 IEEE Conference on Electrical Insulation and Dielectric Phenomena, 1992.

Xiansheng, W; Demin, T., "Verification of the Trap Model of Electric Breakdown in Polymer by Photo Ageing," Proceedings of the Symposium on Electrical Insulating Materials, Inst. of Electrical Engineers of Japan, Tokyo, 1993.

Yamashita, H., "Partial Discharge Measurements in Dielectric Liquids under Impulse Voltage," IEEE Transactions on Electrical Insulation, Vol. 28, No. 6, 1993. 


\section{5 - DIELECTRIC PROPERTIES MEASUREMENTS}

Ali, A.S.; Andreev, A.M.; Zhuravleva, N.M.; Sazhin, B.I., "Effect of Dissolved $\mathrm{SF}_{6}$ on Performance of Paper-oil Cable Insulation," Elektrotekhnika, Vol. 62, No. 3, 1991. Translated in: Soviet Electrical Engineering, Vol. 62, No. 3, 1991.

Allan, D.; Blundell, M.; Boyd, K.; Hinde, D., "New Techniques for Monitoring the Insulation Quality of In-service HV Apparatus," IEEE Transactions on Electrical Insulation Vol. 27, No. 2, June 1992.

Arakelyan, V.G.; Daryan, L.A.; Lokhanin, A.K., "Chromatographic Technique for Diagnostics of HV Pulse Capacitors in Their Manufacture," Elektrichestvo No. 1, January 1992 (in Russian).

Austin, M.E.; Hill, D.J.T.; O'Donnell, J.H.; Pomery, P.J., "Photodegradation of Polyolefins," Proceedings of the 3rd International Conference on Properties and Applications of Dielectric Materials, IEEE, 1992.

Banford, H.M.; Given, M.J.; Tedford, D.J., "A Space Simulation Chamber for Space Power Insulation," Conference Record of the 1992 IEEE International Symposium on Electrical Insulation, IEEE, 1992.

Banford, H.M.; Given, M.J.; Tedford, D.J., "Effect of Antioxidant Concentration and Radiation Dose on Oxidation Induction Time," Record of the 1992 IEEE International Symposium on Electrical Insulation, 1992.

Borsi, H., "Dielectric Behavior of Silicone and Ester Fluids for Use in Distribution Transformers," IEEE Transactions on Electrical Insulation, Vol. 26, No. 4, 1990.

Braun, J.M.; Sedding, H.G.; Stein, J., "Electrical Testing of Aged Station Cables," Proceedings of the American Power Conference, Vol. 1, 1993.

Bruning, A.M.; Campbell, F.J., "Aging in Wire Insulation under Multifactor Stress," IEEE Transactions on Electrical Insulation, Vol. 28, No. 5, October 1993.

Burnay, S.G.; Hitchon, J.W., "Time-Temperature Superposition in Accelerated Radiation Aging of Elastomers," Transactions of the American Nuclear Society, Vol. 46, 1984.

Burnay, S.G.; Hitchon, J.W., "Prediction of Service Lifetimes of Elastomeric Seals During Radiation Ageing," Journal of Nuclear Materials, Vol. 131, No. 2-3, April 1985.

Burnay, S.G., "The Assessment of Service Lifetimes of Elastomeric Seals in a Nuclear Environment," Proceedings, International Conference on Operability of Nuclear Systems in Normal and Adverse Environments. OPERA 89, Paris, 1989. 
Coletti, G.; Guastavino, F., "A Contribution to the Evaluation of Power Generators Insulation Ageing Due to Long Term Service," Energia Elettrica, Vol. 68, No. 1, 1991.

Dejean, H.; Dejean, P.P.F.; Foulon-Belkacemi, N.; Goldman, M.; Goldman, A., "New Electrical Method of Identification of Polymer Ageing Kinetics," Proceedings of the International Conference on Partial Discharge, IEE, Michael Faraday House, Stevenage, UK, 1993.

Dejean, P.; Foulon, N.; Goldman, M.; Dejean, H., "Chemical Aspects of the Ageing of Solid Insulating Materials Submitted to Partial Discharges," Proceedings of the 4th International Conference on Conduction and Breakdown in Solid Dielectrics, IEEE, 1992.

Ebinuma, Y.; Ogishima, M.; Aihara, M.; Haga, K., "Insulation Measurement of 22 Approximately $33 \mathrm{kV}$ XLPE Insulated Cable by Very Low Frequency High Voltage," Showa Electric Wire and Cable Review, Vol. 43, No. 2, 1993 (In Japanese).

Egiziano, L.; Femia, N.; Garamella, G.; Lupo, G.; Tucci, V., "Characterization of Composite Organic Materials for Field Stress Control of HV Cables Terminations," Proceedings of the 4th International Conference on Conduction and Breakdown in Solid Dielectrics, IEEE, 1992.

Gubanski, S.M.; Montanari, G.C.; Motori, A., "TSDC Investigations of the Thermally and Electro-Thermally Aged Cable Models," Conference Record of the 1994 International Symposium on Electrical Insulation.

Hanson, B.A.; Reynolds, A.B., "Effect of Aging on Breakdown Voltage of Artificially Damaged Cable," Proceedings of the 1993 IEEE Conference on Electrical Insulation and Dielectric Phenomena, 1993.

Homma, H; Takahashi, T.; Taniguchi, T.; Izumi, K., "Evaluation of Surface Degradation of Polymer Insulating Materials Related to Leakage Current," Proceedings of the 21st Electrical Electronics Insulation Conference and Electrical Manufacturing and Coil Winding 1993, IEEE, 1993.

Kako, Y.; Watanabe, S.; Higashimura, Y.; Matsunobu, K., "Internal Partial Discharge Resistance of Sulfur Cured Rubber," Transactions of the Institute of Electrical Engineers of Japan, Part A, Vol. 113-A, No. 10, 1993 (In Japanese).

Kako, Y.; Watanabe, S.; Higashimura, Y.; Matsunobu, K., "Improvement of Partial Discharge (PD) Resistance of Epoxy Resin by Using Sulfur Containing Additives," Transactions of the Institute of Electrical Engineers of Japan, Part A, Vol. 113-A, No. 10, 1993. (In Japanese)

Komatsubara, M.; Ishii, M., "Evaluation Methods on Polymer Materials for Surface of Outdoor Insulators, Electrical Engineering in Japan, Vol. 112, No. 5, 1992. 
Lasky, J.S.; La Bozetta, R., "EPR Power Cables Rated $105^{\circ} \mathrm{C} / 140^{\circ} \mathrm{C}$," Proceedings, 1993 Rural Electric Power Conference, IEEE, 1993.

Lemke, E.; Schmiegel, P., "Analysis of Dielectric Properties on the Basis of a Non-conventional Measuring Procedure," Proceedings, 6th International Conference on Dielectric Materials, Measurements and Applications, IEE, London, UK, 1992.

Mason, L.R.; Doyle, T.E.; Reynolds, A.B., "Effect of Antioxidant Concentration and Radiation Dose on Oxidation Induction Time," Proceedings of the 1992 IEEE International Symposium on Electrical Insulation, 1992.

Mason, L.R.; Doyle, T.E.; Reynolds, A.B., "Oxidation Induction Time Correlations with Radiation Dose and Antioxidant Concentration in EPR and XLPE Polymers," Journal of Applied Polymer Science, Vol. 50 No. 9, December 5, 1993.

Miyairi, K., "Electrical Conduction and Breakdown in Heat-resistive Polyparabanic Acid (PPA) Films," Proceedings of the 4th International Conference on Conduction and Breakdown in Solid Dielectrics, IEEE, 1992.

Mopsik, F.I., "The Use of Time-Domain Dielectric Spectroscopy to Evaluate the Lifetime of Nuclear Power Station Cables,' NISTIR 4486, 1992.

Motori, A.; Montanari, G.C.; Gubanski, S., "Effect of Temperature and Time on the Dissipation Factor of Power Cable Junctions," Proceedings of the 1993 IEEE Conference on Electrical Insulation and Dielectric Phenomena, IEEE, 1993.

Motori, A.; Montanari, G.C.; Gubanski, S., "Investigation of Relaxation Processes in Thermally-aged XLPE Cable Models," Proceedings of the 1993 IEEE Conference on Electrical Insulation and Dielectric Phenomena, IEEE, 1993.

Motori, A.; Sandrolini, F.; Montanari, G.C.; Loggini, M., "Electrical Properties for Detection of Thermal Aging in XLPE Cable Models," Proceedings of the 3rd International Conference on Properties and Applications of Dielectric Materials, IEEE, 1991.

Nemamcha, M.; Gosse, J.P.; Gosse, B.; Marteau, C., "Monitoring of Partial Discharges in Capacitor Models with Impregnated Polypropylene Films," Proceedings of the 4th International Conference on Conduction and Breakdown in Solid Dielectrics, IEEE, 1992.

Nemeth, E., "Measuring the Voltage Response, a Diagnostic Test Method of Insulating," Proceedings, Seventh International Symposium on High Voltage Engineering, Dresden Univ. Technol., Dresden, Germany, 1991.

Qi, Z.N.; Wan, Z.H.; Chen, Y.P., "A Comparative DSC Method for Physical Aging Measurement of Polymers," Polymer Testing, Vol. 12, No. 2, UK, 1993. 
Robinson, G., "Low-frequency Loss Spectra and Ageing in Paper-Insulated Cables," Proceedings, Third International Conference on Power Cables and Accessories, IEE, London, UK, 1993.

Shawn Addington, J.; Ellis, E.; Elshabini-Riad, A.; Su, W.; Riad, S.M., "Environmental and Lifetime Testing of Low-loss Dielectric Materials at Low Frequencies," Proceedings of the 1992 International Symposium on Microelectronics (SPIE Vol. 1847), Int. Soc. Hybrid Microelectron, Reston, VA, 1992.

Sigmond, R.S.; Sigmond, T.; Goldman, A.; Goldman, M., "On the Role of Water in the Aging of Polymers in Air-insulated Electrical Systems," IEEE Transactions on Electrical Insulation, Vol. 26, No. 4, 1990.

Sigmond, R.S.; Sigmond, T.; Goldman, A.; Goldman, M., "On the Role of Water in the Aging of Polymers in Air-insulated Electrical Systems," IEEE Transactions on Electrical Insulation, Vol. 26, No. 4, 1990.

Strobel; J.M.; Lyons, C.S., "Aging of Corona-treated Polypropylene Film," Proceedings, 49th Annual Technical Conference - ANTEC '91 In Search of Excellence Annual Technical Conference, Soc. of Plastics Engineers, Brookfield, CT, 1991.

Suh, K.S.; Cooke, C.M., "Electrical Damage of Metallized Film Capacitors," Transactions of the Korean Institute of Electrical Engineers, Vol. 40, No. 6, 1991.

Unsworth, J.; Li, Y.; Gao, B., "Dynamic Mechanical Thermal Analysis and Dielectric Studies of Physical Ageing in an Epoxy Composite," Materials Forum, Vol. 16, No. 2, 1992.

van Roggen, A.; Zhou, H., Data Analysis in Dielectric Time-Domain Spectroscopy," Proceedings of the 1992 IEEE Conference on Electrical Insulation and Dielectric Phenomena, 1992. 


\section{6 - AGEING EFFECTS}

Banford, H.M.; Given, M.J.; Tedford, D.J., "A Space Simulation Chamber for Space Power Insulation," Conference Record of the 1992 IEEE International Symposium on Electrical Insulation, IEEE, 1992.

Banford, H.M.; Given, M.J.; Tedford, D.J., 'Effect of Antioxidant Concentration and Radiation Dose on Oxidation Induction Time," Record of the 1992 IEEE International Symposium on Electrical Insulation, 1992.

Barsch, R.; Hofmann, J.; Schmuck, F., "Accelerated Ageing Tests and Diagnostic Methods of Housing Materials for Composite Insulators," Proceedings, Seventh International Symposium on High Voltage Engineering, Dresden Univ. Technol., Dresden, Germany, 1991.

Braun, J.M.; Sedding, H.G.; Stein, J., 'Electrical Testing of Aged Station Cables," Proceedings of the American Power Conference, Vol. 1, 1993.

Bruning, A.M.; Campbell, F.J., "Aging in Wire Insulation under Multifactor Stress," IEEE Transactions on Electrical Insulation, Vol. 28, No. 5, October 1993.

Burnay, S.G.; Hitchon, J.W., "Time-Temperature Superposition in Accelerated Radiation Aging of Elastomers," Transactions of the American Nuclear Society, Vol. 46, 1984.

Burnay, S.G.; Hitchon, J.W., "Prediction of Service Lifetimes of Elastomeric Seals During Radiation Ageing," Journal of Nuclear Materials, Vol. 131, No. 2-3, April 1985.

Burnay, S.G., "The Assessment of Service Lifetimes of Elastomeric Seals in a Nuclear Environment," Proceedings, International Conference on Operability of Nuclear Systems in Normal and Adverse Environments. OPERA 89, Paris, 1989.

Burnay, S.G., "The Assessment of Service Lifetimes of Elastomeric Seals in a Nuclear Environment," Proceedings, International Conference on Operability of Nuclear Systems in Normal and Adverse Environments. OPERA 89, Paris, 1989.

Coletti, G.; Guastavino, F., "A Contribution to the Evaluation of Power Generators Insulation Ageing Due to Long Term Service," Energia Elettrica, Vol. 68, No. 1, 1991.

Coletti, G.; Guastavino, F., "An Experimental Testing Procedure to Study the Resistance to Partial Discharges of Thin Polymeric Films," Proceedings, Nordic Insulation Symposium NORD-IS 92, Nygrens Ljuakopla AB, Vasteras, Sweden, 1992.

Dejean, H.; Dejean, P.P.F.; Foulon-Belkacemi, N.; Goldman, M.; Goldman, A., “ New Electrical Method of Identification of Polymer Ageing Kinetics," Proceedings of the International Conference on Partial Discharge, IEE, Michael Faraday House, Stevenage, UK, 1993. 
Dejean, P.; Foulon, N.; Goldman, M.; Dejean, H., "Chemical Aspects of the Ageing of Solid Insulating Materials Submitted to Partial Discharges," Proceedings of the 4th International Conference on Conduction and Breakdown in Solid Dielectrics, IEEE, New York, NY, USA, 1992.

Domun, M.K.; MacKinley, R.R.; Miller, R., "The Effects of Voltage and Frequency on the Partial Discharge Characteristics of HV Paper Cables," Proceedings, Sixth International Symposium on High Voltage Engineering, 1989.

Egiziano, L.; Femia, N.; Garamella, G.; Lupo, G.; Tucci, V., "Characterization of Composite Organic Materials for Field Stress Control of HV Cables Terminations," Proceedings of the 4th International Conference on Conduction and Breakdown in Solid Dielectrics, IEEE, 1992.

Gjaerde, A.C., "Multi Factor Ageing of Epoxy Resin," Proceedings, Nordic Insulation Symposium NORD-IS 92, Nygrens Ljuakopla AB, Vasteras, Sweden.

Hanson, B.A.; Reynolds, A.B., "Effect of Aging on Breakdown Voltage of Artificially Damaged Cable," Proceedings of the 1993 IEEE Conference on Electrical Insulation and Dielectric Phenomena, 1993.

Hantouche, C., "Partial Discharges on Power Capacitors," IEEE Transactions on Electrical Insulation, Vol. 28, No. 6, December 1993.

Hikita, M.; Komori, F.; Nishiguchi, N.; Mizutani, T., "Phase-resolved and Time-Sequential Partial Discharge Pulse Measurements in a Metal-Void-Insulator System Using a Personal Computer," Journal of Physics D (Applied Physics) Vol. 27, No. 6, June 1994.

Holboll, J.T.; Henriksen, M., 'Partial Discharge Patterns and Surface Deterioration in Voids in Filled and Unfilled Epoxy," Conference Record of the 1992 IEEE International Symposium on Electrical Insulation, 1992.

Homma, H; Takahashi, T.; Taniguchi, T.; Izumi, K., "Evaluation of Surface Degradation of Polymer Insulating Materials Related to Leakage Current," Proceedings of the 21st Electrical Electronics Insulation Conference and Electrical Manufacturing and Coil Winding 1993, IEEE, 1993.

Kako, Y.; Watanabe, S.; Higashimura, Y.; Matsunobu, K., 'Internal Partial Discharge Resistance of Sulfur Cured Rubber," Transactions of the Institute of Electrical Engineers of Japan, Part A, Vol. 113-A, No. 10, 1993 (In Japanese).

Kako, Y.; Watanabe, S.; Higashimura, Y.; Matsunobu, K., "Improvement of Partial Discharge (PD) Resistance of Epoxy Resin by Using Sulfur Containing Additives," Transactions of the Institute of Electrical Engineers of Japan, Part A, Vol. 113-A, No. 10, 1993. (In Japanese)

Karady, G.G.; Oliva, J.R.; Domitz, S.; Meketa, R., "Advanced Digital Instrumentation for Partial-Discharge Measurement," Electric Power Systems Research, Vol. 25, No. 3, December 1992. 
Karapetyan, M.; Khachatryan, A. S.; Bortnik, I.M., "The Short Term and Long Term Electric Strength of Polymeric Composition Materials under DC and AC Stresses," Izvestiya ANSSSR: Energetika Transport, No. 1, January-February 1991 (in Russian)

Komatsubara, M.; Ishii, M., "Evaluation Methods on Polymer Materials for Surface of Outdoor Insulators, Electrical Engineering in Japan, Vol. 112, No. 5, 1992.

Kong, A.; Lawson, J.; Bristol, R.; Landinger, C., "Evaluation of Field Aged HMWPE Insulated Distribution Cables," Proceedings of the 1991 IEEE Power Engineering Society Transmission and Distribution Conference, 1991.

Lasky, J.S.; La Bozetta, R., "EPR Power Cables Rated $105^{\circ} \mathrm{C} / 140^{\circ} \mathrm{C}$," Proceedings, 1993 Rural Electric Power Conference, IEEE, 1993.

Mason, L.R.; Doyle, T.E.; Reynolds, A.B., "Effect of Antioxidant Concentration and Radiation Dose on Oxidation Induction Time," Proceedings of the 1992 IEEE International Symposium on Electrical Insulation, 1992.

Mason, L.R.; Doyle, T.E.; Reynolds, A.B., "Oxidation Induction Time Correlations with Radiation Dose and Antioxidant Concentration in EPR and XLPE Polymers," Journal of Applied Polymer Science, Vol. 50 No. 9, December 5, 1993.

Mazzanti, G.; Montanari, G.C.; Simoni, L., "Multistress Endurance Characterization of EPR Cable Models," Conference Record of the 1994 International Symposium on Electrical Insulation.

Miyairi, K., "Electrical Conduction and Breakdown in Heat-resistive Polyparabanic Acid (PPA) Films," Proceedings of the 4th International Conference on Conduction and Breakdown in Solid Dielectrics, IEEE, 1992.

Mopsik, F.I., "The Use of Time-Domain Dielectric Spectroscopy to Evaluate the Lifetime of Nuclear Power Station Cables," NISTIR 4486, 1992.

Motori, A.; Montanari, G.C.; Gubanski, S., "Effect of Temperature and Time on the Dissipation Factor of Power Cable Junctions," Proceedings of the 1993 IEEE Conference on Electrical Insulation and Dielectric Phenomena, IEEE, 1993.

Motori, A.; Montanari, G.C.; Gubanski, S., "Investigation of Relaxation Processes in Thermally-aged XLPE Cable Models," Proceedings of the 1993 IEEE Conference on Electrical Insulation and Dielectric Phenomena, IEEE, 1993.

Motori, A.; Sandrolini, F.; Montanari, G.C.; Loggini, M., "Electrical Properties for Detection of Thermal Aging in XLPE Cable Models," Proceedings of the 3rd International Conference on Properties and Applications of Dielectric Materials, IEEE, 1991. 
Nensi, T.; Davies, A.E.; Vaughan, A.S.; Swingler, S.G., "Electrical Ageing of Low-Density Polyethylene Cable Insulation," Proceedings of the 1992 IEEE Conference on Electrical Insulation and Dielectric Phenomena, 1992.

Shalimov, V.V.; Bespalova, E.B.; Zorin, G.A.; Kandibolotskaya, T.B., "Stability of Layered Materials Against Electric Discharges," Zhurnal Tekhnicheskoi Fiziki Vol. 63, No. 9, 1993. Translated in: Technical Physics, Vol. 38, 1993.

Shawn Addington, J.; Ellis, E.; Elshabini-Riad, A.; Su, W.; Riad, S.M., "Environmental and Lifetime Testing of Low-loss Dielectric Materials at Low Frequencies," Proceedings of the 1992 International Symposium on Microelectronics (SPIE Vol. 1847), Int. Soc. Hybrid Microelectron, Reston, VA, 1992.

Sigmond, R.S.; Sigmond, T.; Goldman, A.; Goldman, M., "On the Role of Water in the Aging of Polymers in Air-insulated Electrical Systems," IEEE Transactions on Electrical Insulation, Vol. 26, No. 4, 1990.

Sigmond, R.S.; Sigmond, T.; Goldman, A.; Goldman, M., "On the Role of Water in the Aging of Polymers in Air-insulated Electrical Systems," IEEE Transactions on Electrical Insulation, Vol. 26, No. 4, 1990.

Strobel; J.M.; Lyons, C.S., "Aging of Corona-treated Polypropylene Film," Proceedings, 49th Annual Technical Conference - ANTEC '91 In Search of Excellence Annual Technical Conference, Soc. of Plastics Engineers, Brookfield, CT, 1991.

Suh, K.S.; Cooke, C.M., "Electrical Damage of Metallized Film Capacitors," Transactions of the Korean Institute of Electrical Engineers, Vol. 40, No. 6, 1991.

Tanaka, T.; Okamoto, T.; Nakanishi, K.; Miyamoto, T., "Aging and Related Phenomena in Modern Electric Power Systems," IEEE Transactions on Electrical Insulation, Vol. 28, No. 5, 1993.

Unsworth, J.; Li, Y.; Gao, B., "Dynamic Mechanical Thermal Analysis and Dielectric Studies of Physical Ageing in an Epoxy Composite," Materials Forum, Vol. 16, No. 2, 1992.

Xiansheng, W; Demin, T., "Verification of the Trap Model of Electric Breakdown in Polymer by Photo Ageing," Proceedings of the Symposium on Electrical Insulating Materials, Inst. of Electrical Engineers of Japan, Tokyo, 1993. 


\section{7 - ALPHABETICAL LISTING OF ABSTRACTS}

[1]

Agoris, D.P.; Hatziargyriou, N.D., "Two-void Model for Simulation of Partial Discharges in Solid Dielectrics," Modelling, Simulation \& Control A, Vol. 42, No. 2, France, 1992.

Treatment: Theoretical (T)

Abstract: A model circuit is introduced for the computer simulation of partial discharges in voids of solid dielectrics, by using the Electromagnetic Transient Program (EMTP). The model is based on the principles of the lumped capacitance equivalent circuit for one gas filled cavity embedded in solid dielectric, extended and modified properly for two neighboring cavities. By this model, further to partial discharge simulation which is successful for stressing voltages of the dielectric even equal or slightly higher than the partial discharge inception voltage, modeling of interaction between discharges in voids is obtained as well. (12 Refs)

$* * * * * * * * * * * * * * * * * * * * * * * * * * * * * * * * * * * * * * * * * * * * * * * * * * * * * * * * * * * * * * * * * * * * * * * * * * * * * * * * * * * * * * * * * * * * * * * * * * * * * * * * * * * * * * * * * * * * *$

[2]

Aksyonov, Y.P.; Arsentyev, V.M.; Golovkov, M.Y.; Pintal, Y.S.; Antonov, B.D.; Pronin, B.D.; Kozubov, E.D., "Russian Nuclear Stations Approach of Ageing Effects Multiconductor Control Cables Insulation" Unpublished paper - Copies available at NIST, 1994.

Treatment: General Review

Abstract: None

Reviewer's comments: The authors make the case of the problems associated with life extension and propose classification of control cables according to type of installation, potential failure modes, and ageing stressors. They suggest a joint USA-Russia research program for cable condition monitoring.

Proposed techniques for assessment include insulation resistance, V-I and leakage characteristics, time-domain reflectometry, "AC tests with ionization collision measurement" (partial discharge ?), and location of defect in a cable -- all made possible with instruments developed by DLACS, a Russian-origin corporation in the U.S.A. (1 Ref)

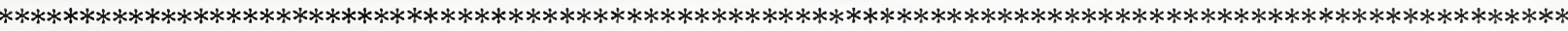

[3]

Aksyonov, Y.P.; Arsentyev, V.M.; Golovkov, M.Y.; Pintal, Y.S.; Pronin, B.D., "In Situ Age condition Monitoring Methods of Mechanical Damages in Control Cables Insulation" - Unpublished paper - Copies available at NIST, 1994.

Treatment: Experimental (X)

Abstract: None

Reviewer's comments: While the title starts with the words "In Situ" the experimental procedure which is described includes AC hipot tests first to detect "ionization collision" (corona inception ?) level, then on to breakdown voltage. These tests are applied to "samples taken according to a certain rule at a nuclear power station." Thus, it seems that the procedure is (1) destructive, (2) applied to samples removed from the installation - not an "in-situ" test. The authors go on to list the corona inception voltages for cables subjected to increasing duration of exposure to 5 times an undefined hipot voltage (possibly a standard value specified by the cable manufacturer?) This reviewer speculates that the foregoing procedure is only intended as a preliminary step to demonstrate that exposure to 5 times the (rated but undefined) hipot test value is harmless in terms of ultimate breakdown. This would then justify the method described later in the paper, where partial discharges detection methods under pulse conditions are applied to a cable left in place, but with both ends disconnected. In this manner, the authors would have overcome industry's reluctance to apply overvoltages for defect detection. 
[4]

Ali, A.S.; Andreev, A.M.; Zhuravleva, N.M.; Sazhin, B.I., "Effect of Dissolved SF 6 on Performance of Paper-oil Cable Insulation," Elektrotekhnika, Vol. 62, No. 3, 1991. Translated in: Soviet Electrical Engineering, Vol. 62, No. 3, 1991.

Treatment: Experimental (X)

Abstract: The effect of $\mathrm{SF}_{6}$ on the performance of paper-oil cable insulation during thermal and integrated aging (under conditions of exposure to temperature and an electric field) of model insulation compositions is investigated. The change in dielectric loss of the cable oil (degassed and saturated with $\mathrm{SF}_{6}$ is analyzed during aging in contact with the commonly used (KCMS-120) and sorption-active (EIO-120) cellulose paper in the case of development of partial discharges. (2 Refs)

[5]

Allan, D.; Blundell, M.; Boyd, K.; Hinde, D., "New Techniques for Monitoring the Insulation Quality of In-service HV Apparatus," IEEE Transactions on Electrical Insulation Vol. 27, No. 2, June 1992.

Treatment: X; (Experimental); T; (Theoretical)

Abstract: Aging HV substation plant presents a number of problems to maintenance and operational staff. In the current economic climate, it is desirable to keep this plant in service as long as possible. However, as age increases, the insulation quality decreases and the risk of disruptive failure due to insulation breakdown rises. To maintain a safe, reliable electricity supply system, while obtaining maximum plant life, knowledge of the insulation condition is essential. To maximize service life without endangering personnel or jeopardizing system security, close monitoring of aged insulation is therefore necessary. Conventional tests are often impractical. They are labor-intensive and require the plant to be taken off line. On this premise, new online monitoring techniques have been developed for use on HV systems. An online testing device was developed to measure partial discharge and dielectric loss angle (DLA) of in-service HV instrument transformers and is used as a fast screening device. A continuous DLA monitor for in-service transformer bushings and current transformers has also been developed and installed at a $132-\mathrm{kV}$ substation. These techniques considerably enhance HV plant maintenance programs and have a significant impact on future plant monitoring strategies. (1 Ref)

$* * * * * * * * * * * * * * * * * * * * * * * * * * * * * * * * * * * * * * * * * * * * * * * * * * * * * * * * * * * * * * * * * * * * * * * * * * * * * * * * * * * * * * * * * * * * * * * * * * * * * * * * *$

[6]

Alsheikhly, A.; Guzman, H.; Kranz, H.-G., "A New Diagnostic Tool Through Computer Simulation Calculation Using Expanded Partial Discharge Equivalent Circuit," Proceedings of the 4th International Conference on Conduction and Breakdown in Solid Dielectrics, IEEE, 1992.

Treatment: Theoretical (T)

Abstract: An equivalent circuit has been developed to simulate PD (partial discharge) single activities in solid insulation. Attention is given to the simulation of the PD in afflicted solid electrical insulation between two metal electrodes. The aim is to simulate in real-time the effect of PD in the nanosecond region (microscopic period) and its effect on the consequent signals in the mu s-region (macroscopical period) and the millisecond region. The simulation considers the nonlinearity of the discharge phenomena in the cavity as a voltage- and time-dependent resistance. The model also considers the measuring circuits, and takes into account the accumulation of charge at the dielectric electrodes of the cavity and in the area surrounding the footprints of the discharge. Analyzing the effect of each element of the circuit model, using circuit analysis, leads to much useful information and simplifies the explanation (from an engineering point of view) of the effect of the physics of the PD. This can be used as a basic diagnostic tool by observing the changes of the parameters due to deterioration. (3 Refs) 
[7]

Alsheikhly, A.; Kranz, H.-G., "A New Approach for a Basic Understanding of PD Phenomena," Proceedings, Seventh International Symposium on High Voltage Engineering, Dresden Univ. Technol, Dresden, Germany, 1991.

Treatment: Theoretical (T); Experimental (X)

Abstract: To understand the effect of partial discharges (PD) on different apparatus, special concern was given to the analysis of the physics of PD in an afflicted specimen containing only one PD source. The analysis shows that the PD signal is independent of the position of the gap within the afflicted solid insulation specimen. The authors point out the determination of so far unknown model parameters of PD phenomena. These are determined by computer aided simulation optimization, iteratively corrected by real measurements. (6 Refs)

[8]

Alsheilchy, A.; Kranz, H.G., "Determination of the Ratio of the PD Damaging Energy to the Measurable Input Energy for a PD Afflicted Solid Insulation, " Proceedings, International Conference on Partial Discharge, 1993.

Treatment: Theoretical (T), Experimental (X)

Abstract: One of the important parameters in PD measurements is the apparent charge (cumulative, or maximum apparent value) and its correlation to the respective applied voltage to the nominal voltage, and/or the phase angle of the applied frequency. One method is to determine the energy of the measurable PD signals and the correlate this value to the real damage process within the insulation. This method requires the knowledge of the electrical transferred energy within a void or inclusion, and its relation to the external measurable energy. This knowledge was determined experimentally under laboratory conditions in test objects with modeled voids and needs relatively long integral measurements. For simplicity and clarity solid insulation bulk with only one void which has one PD source was considered. To prevent confusion, and to ease the terminology, the term energy used further in this work means electrical energy only. (8 Refs)

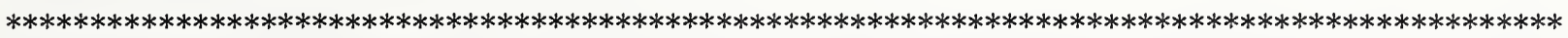

[9]

Arakelyan, V.G.; Daryan, L.A.; Lokhanin, A.K., "Chromatographic Technique for Diagnostics of HV Pulse Capacitors in Their Manufacture," Elektrichestvo No. 1, January 1992 (in Russian).

Treatment: A; (Applications); X; (Experimental)

Abstract: An investigation has been conducted to reveal the possibility of developing and using a diagnostic method for HV pulse capacitors during 'adoption-turn' in tests. The method is based on the chromatographic analysis of gaseous disintegration products (GDP) solved in oil. The GDP distribution over the volume of a capacitor has been investigated experimentally with no operational action and in three voltage modes: oscillation, repetitive pulses. The authors have obtained data showing the dynamics of gas concentration variation in 'damaged' capacitors. To identify diagnostic criteria the composition of GDP//S was studied during the process of capacitor dielectric deterioration with time, when it was exposed to partial discharges, heating and cavitation. For comparisons castor oil of different types and transformer oil were tested. An empirical dependency between acetylene concentration and the service life of capacitors has been established. The probability of no-failure operation for capacitors after rejection is more than 1.5 times higher as compared with that for the articles with no rejection practice. (5 Refs) 
[10]

Aksenov, Y.P.; Arsentiev, V.; Golovkov, M.; Pintal, Y.S.; Bromley, J.C.; Glodjo, A.; McDermid, W., "Measurement \& Location of Dielectric Anomalies in Field Aged XLPE Cables," Conference Record of the 1994 International Symposium on Electrical Insulation.

Treatment: Experimental (X)

Abstract: In order to adequately assess the condition of field aged XLPE cable it is necessary to select diagnostic test methods which are sensitive to each type of defect. The paper reports the results of a field test program to evaluate the condition of a number of aged XIPE cables operating at $12 \mathrm{kV}$ and $25 \mathrm{kV}$ line-to-line. Promising test methods include time domain reflectometry to detect and locate PD sources as well as other anomalies in the dielectric. These sites may be temporally enhanced as a result of selected over potential tests at a moderate level. Subsequent dissection has revealed extensive water trees and incipient failures in the detected locations. (5 Refs)

[11]

Austin, M.E.; Hill, D.J.T.; O'Donnell, J.H.; Pomery, P.J., "Photodegradation of Polyolefins," Proceedings of the 3rd International Conference on Properties and Applications of Dielectric Materials, IEEE, 1992.

Treatment: X; (Experimental)

Abstract: The Photo degradation behavior of a propylene/ethylene copolymer has been investigated and compared to the degradation of a polypropylene homopolymer. The materials contained small amounts of thermal stabilizers, but no photo-stabilizers. The development of carbonyl and hydroxyl oxidation species was followed by infrared spectroscopy, but this was not a sensitive detection method in the early stages of degradation. Mechanical measurements indicated that the performance of the copolymer deteriorated after only brief exposures to ultraviolet irradiation in an accelerated weathering cabinet. In contrast, the homopolymer showed no signs of mechanical degradation during a short induction period, but then degraded very rapidly. The induction period corresponded to the disappearance of the thermal stabilizers. Outdoor weathering results confirmed the trends predicted by artificial weathering; however, the predicted service lifetimes were underestimated by about $50 \%$. (7 Refs)

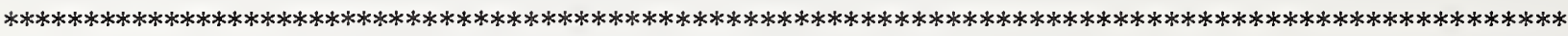

[12]

Banford, H.M.; Given, M.J.; Tedford, D.J., "A Space Simulation Chamber for Space Power Insulation," Conference Record of the 1992 IEEE International Symposium on Electrical Insulation, IEEE, 1992.

Treatment: Practical (P); Experimental (X)

Abstract: The authors describe an experimental facility which has been designed specifically for the study of electrical insulation in a simulated space environment. They consider vacuum, temperature, nuclear radiation and atomic oxygen. The facility consists of a stainless steel high-vacuum chamber with a sample mounting arrangement which allows sample temperatures to be varied between 80 and $420 \mathrm{~K}$. The materials being considered are Kapton and an epoxy resin formulation. Various electrical measurements are being undertaken and comprise primarily dielectric loss by frequency domain spectroscopy and prebreakdown current pulse activity under direct stress, while the provision exists for conductivity and breakdown measurements. Measurements are made in real time under vacuum, temperature, and low-dose-rate electromagnetic radiation following an aging procedure. (15 Refs) 
[13]

Banford, H.M.; Given, M.J.; Tedford, D.J., "Effect of Antioxidant Concentration and Radiation Dose on Oxidation Induction Time," Record of the 1992 IEEE International Symposium on Electrical Insulation, 1992. Treatment: Experimental (X)

Abstract: Oxidation induction time (OIT) provides a useful measurement of aging of electrical cable insulation. The technique is being refined for application to $1 \mathrm{E}$ electric cable in nuclear power plants. Exponential correlations have been found for OIT as functions of both radiation dose and antioxidant concentration for ethylene-propylene rubber (EPR) and cross-linked polyethylene (XIPE) cable materials. At constant dose rate, the antioxidant concentration was shown to decrease linearly with time, which is consistent with oxidation reaction kinetics. (7 Refs)

$* * * * * * * * * * * * * * * * * * * * * * * * * * * * * * * * * * * * * * * * * * * * * * * * * * * * * * * * * * * * * * * * * * * * * * * * * * * * * * * * * * * * * * * * * * * * * * * * * *$

[14]

Barsch, R.; Hofmann, J.; Schmuck, F., "Accelerated Ageing Tests and Diagnostic Methods of Housing Materials for Composite Insulators," Proceedings, Seventh International Symposium on High Voltage Engineering, Dresden Univ. Technol., Dresden, Germany, 1991.

Treatment: Experimental $(\mathrm{X})$

Abstract: The authors deal with the ageing procedures and diagnostic values of polymer surfaces. Experiences and results gained by a standardized salt fog procedure are discussed. A comparison to a modified rotating wheel procedure is shown. The suitability of flashover voltage and electrical partial discharge values to determine the polymer surface state is investigated and recommendations are deduced. ( 9 Refs)

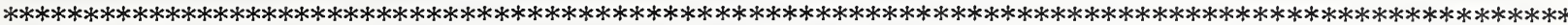

[15]

Bartnikas, R.; Novak, J.P., "On the Character of Different Forms of Partial Discharge and Their Related Terminologies," IEEE Transactions on Electrical Insulation, Vol. 28, No. 6, December 1993.

Treatment: Tutorial

Abstract: Experimentally obtained partial discharge pulse forms have been compared with those derived theoretically, using a mathematical model of a short gap. The calculations indicate that with overvolted short gaps, the apparent absence of the protracted ion current tail in the overall pulse form is due to the large excess of the electron current component generated by strongly enhanced cathode emission by the photo effect and other phenomena. Under conditions of high overvoltage the ion impact induced emission, the ion fluxes and, consequently, the ion current component are greatly reduced as compared to the electron current and the long ion current tail, representing not more than a few percent of the total current, passes undetected. Pulseless and pseudo-glow discharges are also considered and preferred terms to designate the different forms of partial discharges are suggested. (20 Refs)

[16]

Bernstein, S.; Marks, J., "Extruded Dielectric Cables: Density Measurements as a Diagnostic Tool," IEEE Electrical Insulation Magazine, Vol. 6, No. 3, May/June 1990.

Treatment: Tutorial Review

Abstract: None

Reviewer's comments: A brief summary article making reference to two comprehensive EPRI Reports, EL-6207, "Evaluation of Diagnostic Techniques for Cable Characterization" and EL-3154, "Estimation of Life Expectancy of Polyethylene-Insulated Cables." Tests were performed by IREQ.

The density measurements are made on specimens cut from the cable of interest, thus the method is not nondestructive and is not applicable to in-situ tests. 


\section{[17]}

Bernstein, B.S.; Brancato, E.L., "Aging of Equipment in the Electric Utilities," IEEE Transactions on Electrical Insulation, Vol. 28, No. 5, 1993.

Treatment: Practical (P)

Abstract: The authors point out that multiple-stress-induced aging occurs in all electrical equipment. However, the dominant aging mechanism may differ for each class of equipment. Electrical insulation in equipment employed by the electric utilities encompasses all types of polymers. Both thermoset and thermoplastic materials are employed. The nature of the insulation is designed to meet a variety of needs, depending on the equipment environment. For example, transformer insulation requires thermal resistance at moderate operating stresses, capacitors operate at high electrical stresses and without excessive thermal load, and cables require only moderate thermal resistance and operate at relatively low voltage stress. The utility network system, types of equipment, types of insulation used, and properties required of the electrical insulation are reviewed. The typical aging mechanism for each class of utility equipment is described, and the limits of any multifactor aging relationship's ability to predict a component's life are analyzed. (31 Refs)

\section{[18]}

Boggs, S.A., "Partial Discharge - Part II: Detection Sensitivity," IEEE Electrical Insulation Magazine, Vol. 5, No. 5, September/October 1990.

Treatment: Tutorial

Abstract: For almost all systems, the PD pulse originates with a duration of at most a few nanoseconds. However the signal detection outside the test object depends on the nature of the connection between the point of pulse generation and the external world. In this paper, we will consider our options for detecting and characterizing that signal. Important parameters to be considered include minimum detectable signal (PD sensitivity), circuit time constants which limit PD waveform characterization (where this may be desirable), and general applicability of the detection scheme. (7 Refs)

[19]

Boggs, S.A., "Partial Discharge III: Cavity-Induced PD in Solid Dielectrics," IEEE Electrical Insulation Magazine, Vol. 6, No. 6, November/December 1990.

Treatment: Tutorial

Abstract: The basic problem can be stated as 'How do we relate the magnitude of the measured, 'effective' PD to the size, shape, and position of the cavity within a solid dielectric"? For a range of geometries, we can develop analytic solutions; and for any system, a solution can be found with computer-based methods to calculate the electric field through a sample. With this paper, the series begins to move toward applications-specific content which will lead to a series of papers on PD testing to specific types of electrical apparatus, such as solid dielectric power cable, rotating machines, printed circuit boards, gas-insulated substations, etc. (9 Refs)

\section{[20]}

Borsi, H., "Digital Location of Partial Discharges in HV Cables," IEEE Transactions on Electrical Insulation, Vol. 27, No. 1, February 1992.

Treatment: Applications (A); Practical (P); Experimental (X)

Abstract: This paper deals with a new digital system for locating partial discharges (PDs) in high voltage (HV) cables under noisy conditions. After an introduction to different PD location methods and their limits, the possibility of PD location through the pulse separation method is introduced. Digital filtering performed with predictor filters is described. Extensive investigations are carried out to determine the effectiveness of these filters, as well as their limitations, in their use for PD and noise separation. The results concerning the application of filtering on PD and noise signals measured on an HV cable under noisy conditions are presented. (14 Refs) 
[21]

Borsi, H., "Dielectric Behavior of Silicone and Ester Fluids for Use in Distribution Transformers," IEEE Transactions on Electrical Insulation, Vol. 26, No. 4, 1990.

Treatment: Experimental (X)

Abstract: Investigations to determine the relevant electric and dielectric properties of certain insulating fluids which appeared most suitable from the viewpoint of environmental compatibility and inflammability are discussed. Two of these are silicone fluids based on linear polydimethyl siloxane (kinematic viscosity at $25^{\circ} \mathrm{C}$ is $50 \mathrm{~mm}^{2} / \mathrm{s}$ ) and an ester fluid based on penthaerythrithol tetraester. After a short description of the insulating fluids, the influence of aging on the breakdown and dissipation factor is determined. Furthermore, a comparison of the breakdown and aging behavior of fluid-paper composite dielectrics is made. The influence of partial discharge prestressing on the breakdown of the fluid-paper composite dielectric is shown. (12 Refs)

$* * * * * * * * * * * * * * * * * * * * * * * * * * * * * * * * * * * * * * * * * * * * * * * * * * * * * * * * * * * * * * * * * * * * * * * * * * * * * * * * * * * * * * * * * * * * * * * * * * * * * * * * * * * *$

[22]

Borsi, H., "New Method for Partial Discharges (PD) Location in High Voltage Cables under Noisy Condition," Proceedings, Seventh International Symposium on High Voltage Engineering, Dresden Univ. Technol., Dresden, Germany, 1991.

Treatment: Practical (P)

Abstract: The author deals with the methods of partial discharge measurement and location on high voltage cables. After a short description of the different methods of PD-location, a new system for locating partial discharges in high voltage cables under noisy conditions, based on digital filtering is introduced. The determination of the effectiveness of the digital filtering and its limitation is also discussed. In this part the efficiency of an adaptive predictor filter and a time selective working nonadaptive filter are compared. The effectiveness of the filtering and the caused measuring failure is demonstrated with PD and noises measured on a high voltage cable. (12 Refs)

\section{[23]}

Bozzo, R.; Coletti, G.; Hagi, A., "Pre-breakdown Phenomena in XLPE under Highly Divergent Field Conditions," Proceedings of the 4th International Conference on Conduction and Breakdown in Solid Dielectrics, IEEE, 1992.

Treatment: Experimental (X)

Abstract: Prebreakdown phenomena were studied in XIPE (cross-linked polyethylene) of the kind used in the fabrication of extruded power cables. Specimens having a point-plane electrode geometry, obtained by insertion of steel Ogura needles in rectangular blocks of XLPE, have been prepared by means of an ad hoc experimental procedure. A video recording technique made it possible to observe the treeing growth in real time. Experimental results are presented and discussed. Also discussed is a phenomenological model which considers a further descriptive parameter, $\mathrm{E}_{\mathrm{b}}$, regarded as the electric field at the surface of an ideal equipotential sphere corresponding to the treeing damage structure at the instants immediately proceeding the breakdown, neglecting the contribution of the space charge. (5 Refs) 


\section{[24]}

Bozzo, R.; Guastavino, F.; Cicciari, M.; Contin, A.; Montanari, G.C., "Stochastic Procedures for the Investigation of Tree Growth in Insulating Material for H.V. Applications," Conference Record of the 1994 IEEE International Symposium on Electrical Insulation.

Treatment: Theoretical (T), Experimental (X)

Abstract: The results of partial discharge measurements performed during treeing tests made on specimens of the insulating materials by the point-plane electrode system are processed by statistical operators. It is shown that the partial discharge height distribution well fits the two-parameter Weibull function at any time of the tree growth features, thus providing a statistical tool for growth, before starting of the breakdown leader. Moreover, the Weibull parameters are correlated with the tree-growth features, thus providing a statistical tool for partial discharge pattern recognition. Other statistical operators, already proposed in literature, are considered, that is skewness, kurtosis, cross-correlation. They are applied, in particular, to charge vs phase distributions, and show behavior characteristic of the examined phenomenon. (22 Refs)

[25]

Braun, J.M.; Sedding, H.G.; Stein, J., "Electrical Testing of Aged Station Cables," Proceedings of the American Power Conference, Vol. 1, 1993.

Treatment: Practical (P)

Abstract: Power, control, and instrumentation cables are critical components of power plant life cycle management program. A major challenge in applying electrical diagnostic tests to these unshielded cables is a lack of a well-defined, continuous ground plane. The authors demonstrate that for unshielded multi-conductor configurations, testing conductor-to-conductor is a realistic alternative. Results are presented on partial discharge measurements and breakdown tests carried out in the laboratory and in a plant environment. Good agreement was obtained between AC and DC breakdowns obtained in-situ on deteriorated 25 -year old $5 \mathrm{kV}$ cables tested conductor-to-conductor and the same measurements repeated in the laboratory in a shielded configuration. None of the conventional diagnostic measurements (e.g., DC insulation resistance and polarization index) proved sensitive to the progressive deterioration of plant cables aged thermally in the laboratory. Promising results are reported on changes in very low frequency dissipation factor with thermal aging of the insulation. (5 Refs)

[26]

Bressani, M.; Contin, A.; Rabach, G.; Razza, F.; Secco, M., "A Test Methodology, Based on Partial Discharge Analysis, for the Evaluation of a Solid Insulation System," Proceedings, Sixth International Symposium on High Voltage Engineering, 1989.

Treatment: Experimental (X)

Abstract: The paper deals with the evaluation of different turn insulation systems used in high voltage induction systems used in high voltage induction motors. An experimental methodology, bases on PDAD detection performed by computer-bases instrumentation, was adopted. Analysis and processing of acquired data provide an evaluation of the sample conditions and make possible a relative classification of the insulation systems under test. (4 Refs) 
[27]

Bruning, A.M.; Danikas, M.G., "Report on Continuing Work on Parallel and Nonparallel Electric Field Chemical Aging of Polymer Cavities," Proceedings of the 4th International Conference on Conduction and Breakdown in Solid Dielectrics, IEEE, 1992.

Treatment: Theoretical (T); Experimental (X)

Abstract: Fast pulse measurements were made in a system consisting of parallel electrodes with a cylindrical cavity embedded in polyethylene between them. Extremely fast discharge events can be detected in such cavities. The partial discharges recorded were of the streamer type. Variations in inception stress, albeit small ones, were found. The results also show that the smaller the cavity, the smaller the risetime and the smaller the discharge magnitude. These results suggest that notions such as 'discharge free insulation', and 'inception stress' should be used with caution, as they are very much dependent on the sensitivity of the detection apparatus used. (15 Refs)

[28]

Bruning, A.M.; Danikas, M.G., "Experiments on Polymer Cavity Currents above and below CIV," Proceedings of IEEE Conference on Electrical Insulation and Dielectric Phenomena October 1992.

Treatment: Experimental (X)

Abstract: The authors report work in progress on the hypothesis that currents in cavities of polymers, including those not detected by commercial partial discharge detectors, may cause chemical changes on the walls of cavities or at other inhomogeneities. These changes may lead to insulation chemical deterioration, with resulting premature failure. The authors report on refined test cell design, and operation in support of continuing the plasma-chemical investigations of A.M. Bruning et al. (1991). (9 Refs)

[29]

Bruning, A.M.; Campbell, F.J., "Aging in Wire Insulation under Multifactor Stress," IEEE Transactions on Electrical Insulation, Vol. 28, No. 5, October 1993.

Treatment: Theoretical (T), Experimental (X)

Abstract: A fundamentally based chemical-thermodynamic multifactor stress aging functional relation requiring experimentally based constants is developed, based upon various theoretical models. The specific example presented is that for $120 \mathrm{~V}$ aromatic polyimide insulated wire. The stresses of water, temperature, and mechanical strain are included and electrical stress is considered. The results of over 2000 specimens are fitted to the theoretical trends. For a single independent variable function, the resulting relation reduces to the classical Arrhenius curve. The three independent variable relations presented here is applied to data from laboratory aging experiments that simulate insulation deterioration occurring in actual aircraft service experience. The results used in age categorization of US Navy aircraft are generated from wire specimens taken from active aircraft. The paradigm does not use $a b$ initio based constants because of uncertainties in the theoretical development, two forms of which are presented. It is the aim of this presentation to provide a plausible, intuitively meaningful syllogism having elements transferable to other insulation materials/devices/systems. That transfer will require proper recognition of specific chemical mechanisms in the life calculation routine, constrained by practical secondary effects and the need of nonstandard statistics. (36 Refs) 
[30]

Burnay,S.G.;Hitchon, J.W., "Time-Temperature Superposition in Accelerated Radiation Aging of Elastomers," Transactions of the American Nuclear Society, Vol. 46, 1984.

Treatment: Experimental (X)

Abstract: Elastomers are widely used as sealing materials in nuclear applications where they are exposed to relatively low dose rates for long periods of time. In assessing the long-term behavior of these seals, accelerated aging tests need to be used to estimate the seal lifetimes under service conditions. Experimental data on a polyurethane elastomer and a fluoropolymer described here show the applicability and some of the limitations of time-temperature superposition in radiation aging of these materials.

$* * * * * * * * * * * * * * * * * * * * * * * * * * * * * * * * * * * * * * * * * * * * * * * * * * * * * * * * * * * * * * * * * * * * * * * * * * * * * * * * * * * * * * * * * * * * * * * * * * * * * * * * * * * * * *$

[31]

Burnay, S.G.; Hitchon, J.W., "Prediction of Service Lifetimes of Elastomeric Seals During Radiation Ageing," Journal of Nuclear Materials, Vol. 131, No. 2-3, April 1985.

Treatment: Experimental (X)

Abstract: Measurements have been made on fluoropolymer seals of leakage rates, sealing force and compression set over a limited range of temperature and irradiation conditions to compare these techniques for their effectiveness in determining seal lifetimes. The results obtained indicate that the use of compression set tests in the routine assessment of seal performance is justified. Compression set measurements have been made on a polyurethane and a fluoropolymer over a range of temperature and radiation dose rates. The time-temperature superposition principle has been used to determine that thermal and dose rate shift factors $a_{\mathrm{T}}, \mathrm{a}_{\mathrm{R}}$ and activation energy $E_{a}$ for both materials. Determination of the functional dependence of $q, k$ and $E$ on the dose rate enables realistic lifetime predictions to be made even when dose rate effects and temperature-radiation synergism are present. (16 Refs)

$* * * * * * * * * * * * * * * * * * * * * * * * * * * * * * * * * * * * * * * * * * * * * * * * * * * * * * * * * * * * * * * * * * * * * * * * * * * * * * * * * * * * * * * * * * * * * * * * * * * * * * * * * * * * * *$

[32]

Burnay, S.G., "The Assessment of Service Lifetimes of Elastomeric Seals in a Nuclear Environment," Proceedings, International Conference on Operability of Nuclear Systems in Normal and Adverse Environments. OPERA 89, Paris, 1989.

Treatment: Practical (P), Experimental (X)

Abstract: A considerable amount of experimental data has previously been obtained on the behavior of a specific elastomer under conditions of elevated temperature $\left(150\right.$ to $\left.300^{\circ} \mathrm{C}\right)$ and high dose rate $(0.03$ to $3 \mathrm{~Gy} / \mathrm{s})$. The data from these accelerated tests have been used to develop a predictive model for assessing the behavior of elastomeric seals under service conditions. The author reports an experimental validation of the predictions of the model under irradiation conditions well outside the temperature and dose rate range used to determine the model parameters. In addition the effect of the presence of water vapor during irradiation has been examined. (1 Ref)

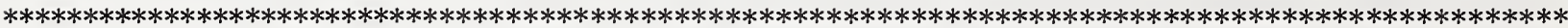

[33]

Burnay, S.G., "The Assessment of Service Lifetimes of Elastomeric Seals in a Nuclear Environment," Proceedings, International Conference on Operability of Nuclear Systems in Normal and Adverse Environments. OPERA 89, Paris, 1989.

Treatment: Practical (P), Theoretical (T), Experimental (X)!

Abstract: In their quest to extend the active lives of nuclear plant, operators and engineers need reliable estimates of the lifetimes of components under reactor conditions. The effect of high radiation fields on polymeric materials, used in components such as seals, cable jacketing and electrical insulation, is difficult to predict because of the variation in chemical makeup. The author describes the development of models of polymer behavior and the testing techniques used to predict the lifetimes of these versatile materials. ( 0 Ref) 
[34]

Cacciari, M.; Contin, A.; Rabach, G.; Montanari, G.C., "Diagnosis of Practical Insulation Systems by Partial Discharge Measurements in the Presence of Multi-discharge Phenomena," Proceedings of the 1993 IEEE Conference on Electrical Insulation and Dielectric Phenomena, 1993.

Treatment: Theoretical (T), Experimental (X)

Abstract: The shape analysis of multiple partial discharge (PD) phenomena is addressed to the representation of the cumulative PD height distribution in Weibull plot. It is shown that a multiple-Weibull distribution can fit PD data obtained from measurements performed on stator bars when two PD phenomena are superimposed. Pattem identification and clustering is thus achieved, so that each PD phenomenon can be investigated as a function of measurement voltage and aging time. The effectiveness of the Weibull representation as a diagnostic tool is therefore derived. (3 Refs)

\section{[35]}

Capponi, G.; Schifani, R., "Measurement of Partial Discharge in Solid Dielectrics with a

Microprocessor-based System," IEEE Transactions on Electrical Insulation, Vol. 27, No. 1, February 1992. Treatment: Practical (P)

Abstract: The authors discuss briefly the basic aspects of partial discharge (PD) measuring techniques with special emphasis on the problem of detecting the amplitude of discharge pulses having transient decaying sinewave shapes. After a short account of the recent multichannel pulse-height analysis techniques of collected data and of the use of a computerized system for calculating multiple discharge parameters, a new digital system for PD measurement and computer data processing is presented. (7 Refs)

[36]

Capponi, G.; Schifani, R., "Application of a Peak Detection Algorithm for the Shape Analysis of Partial Discharges Amplitude Distribution," Conference Record of the 1994 International Symposium on Electrical Insulation, 1994.

Treatment: Theoretical (T) and Experimental (X)

Abstract: The Partial Discharges (PD) height distribution are processed by using digital signal processing techniques. When several PD phenomena are simultaneously active, they can combine their own patterns and produce plurimodal distribution. In order to locate the peaks in the mixture (where they start, end, and attain their maxima), an automatic peak detection algorithm is developed. The results of using this algorithm for the detection of multi-PD phenomena are discussed in the case of PD measurements performed on practical insulation systems. The proposed algorithm seems to be a very useful tool as a preprocessor for further automated statistical elaboration. (10 Refs)

Reviewer's comment: The two examples cited concern rotating machines insulation.

[37]

Chan, J.C.; Duffy, P.; Hiivala, L.J.; Wasik, J., "Partial Discharge - Part VIII: PD Testing of Solid Dielectric Cable,' IEEE Electrical Insulation Magazine, Vol. 7, No. 5, September/October 1991.

Treatment: Tutorial

Abstract: In view of the stringent quality requirements for solid dielectric cable, a wide range of quality assurance techniques is applied. PD testing is by far the most effective non-destructive test for screening and rejecting poor quality cables, especially when the measured PD levels clearly exceed $5 \mathrm{pC}$ requirement and results are not confounded by external noise. Additional destructive, non-electrical tests provide an essential supplement to high voltage withstand and PD tests. (20 Refs) 
[38]

Changchang, W.; Heng, G.; Dehend, Z.; Kexiong, T., "The Study of Current Transducer System for On-line Monitoring Partial Discharge in Electrical Equipment," Proceedings, Sixth International Symposium on High Voltage Engineering, 1989.

Treatment: Experimental (X)

Abstract: The current transducer in a key unit for on line monitoring partial discharge in electrical equipment and has been studied in this paper. The principle of transducer design has been given. The frequency-selective characteristic must be considered first of all. After choosing the transducer parameters properly, the resonance frequency $\mathrm{f} 2$ ' in low frequency band of monitoring system is approximately equal to the resonance frequency $\mathrm{f} 2$ of transducer secondary circuit. It will be quite simple to design the current transducer and choose its parameter. An on line monitoring system has been developed. Some results of detection of partial discharge in transformers with the system have been presented. (5 Refs)

$* * * * * * * * * * * * * * * * * * * * * * * * * * * * * * * * * * * * * * * * * * * * * * * * * * * * * * * * * * * * * * * * * * * * * * * * * * * * * * * * * * * * * * * * * * * * * * * * * * * * * * * * *)$

[39]

Coletti, G.; Guastavino, F., "A Contribution to the Evaluation of Power Generators Insulation

Ageing Due to Long Term Service," Energia Elettrica, Vol. 68, No. 1, 1991.

Treatment: Experimental (X)

Abstract: An evaluation of the insulating system status of two different large power generators having a service longer than 30 years is presented. Both insulations were based on mica splittings: one used a thermosetting resin, while the other one had a thermoplastic compound. A purposely devised testing program was carried out both on semicoils (and on smaller samples) taken from the generator windings which had been in long term service and on reference semicoils kept stored for the same time period. The testing program involved visual, acoustic and microscope examinations, partial discharges, loss tangent and depolarization current measurements, a dielectric proof test and thermo-physical analyses. The relevant results enable to advance qualitative assessments, on the ageing mechanisms noted, which can contribute to a wider diagnostic evaluation of the winding insulation status. In parallel, it has also been possible to evaluate the capabilities of the single testing procedures adopted to discriminate between service aged and non-aged insulation systems. (4 Refs)

[40]

Coletti, G.; Guastavino, F., "An Experimental Testing Procedure to Study the Resistance to Partial Discharges of Thin Polymeric Films," Proceedings, Nordic Insulation Symposium NORD-IS 92, Nygrens Ljuakopla AB, Vasteras, Sweden, 1992.

Treatment: Experimental (X)

Abstract: The results of an experimental study about a testing procedure to evaluate the performances of thin polymeric films subjected to the action of partial discharges are presented. The main problems met in the study are outlined and the criteria adopted in the design of the test cell and in the choice of test parameters are illustrated. The reported preliminary results show possible influence of the electrical ageing effects on the films time-to-breakdown and can be of interest for the correct evaluation of different thin polymer films. (1 Ref) 
[41]

Contin, A.; Rabach, G., "Identification and Detection of Slot Discharges During Accelerated Ageing Tests," Proceedings of the 1992 IEEE Conference on Electrical Insulation and Dielectric Phenomena, 1992.

Treatment: Experimental (X)

Abstract: The Partial Discharges Amplitude Distributions (PDAD) analysis can be usefully applied in the detection and identification of slot discharges activity during accelerated ageing tests. A sequential thermal, mechanical and electric stress was applied to a $10 \mathrm{U}$-shape frame simulating complete stator slots, in order to reproduce slot discharges in a relatively short time. By plotting the detected cumulative distributions on a Weibull paper, the slot discharges are identified by their distinctive, pattern even though the inception of the phenomena may be mixed up with other discharge patterns. These results confirm the validity of the PDAD shape analysis approach as a possible tool to classify the detected phenomena both in laboratory and during p.d. measurements in HV generators stator windings. (4 Refs)

[42]

Danikas, M.G., "The Definitions Used for Partial Discharge Phenomena," IEEE Transactions on Electrical Insulation, Vol. 28, No. 6, December 1993.

Treatment: Tutorial

Abstract: In the following we comment on a variety of definitions related to partial discharge (PD) phenomena. Although a wealth of PD data exists, there is no general agreement to this date as to the definitions of the various regimes of PD. A certain confusion exists which may be due to the multitude of PD manifestations. Here, an attempt is being made to elucidate some aspects of the PD definitions. We do not claim that this study is an exhaustive one but rather an incentive to further research in this direction. Related problems needing more work are referred to at the end of this Communication. (7 Refs)

[43]

Dejean, H.; Dejean, P.P.F.; Foulon-Belkacemi, N.; Goldman, M.; Goldman, A., " New Electrical Method of Identification of Polymer Ageing Kinetics," Proceedings of the International Conference on Partial Discharge, IEE, Michael Faraday House, Stevenage, UK, 1993.

Treatment: T; (Theoretical); X; (Experimental)

Abstract: We used a corona discharge test cell and an electronic device to measure the current under the streamer impact to monitor on line the ageing of dielectric polymer foils. Average current monitoring, under corona discharge proved to be a simple method for the diagnostic and the accelerated ageing of polymer samples. The three period are always present, but differences of polymers chemical composition induce variation of the shape of the plot of the average current versus time. This means that the chemical composition (proportion of additives) of a sample can be checked without any other tests. The different periods of the accelerated ageing are directly detected by an electric measurement. (2 Refs) 
Dejean, P.; Foulon, N.; Goldman, M.; Dejean, H., "Chemical Aspects of the Ageing of Solid Insulating Materials Submitted to Partial Discharges," Proceedings of the 4th International Conference on Conduction and Breakdown in Solid Dielectrics, IEEE, New York, NY, USA, 1992.

Treatment: Experimental (X)

Abstract: The authors attempt to correlate the characteristics of the electrical signals due to partial discharges (PD) with the chemical aspects of the ageing of the insulating material subjected to these discharges. The samples are 19- $\mu \mathrm{m}$-thick foils of polyethylene terephthalate, low-density polyethylene, and polypropylene. The PD development both in time and in space is related to the electrical pulse shape and to the chemical composition of the surface subjected to PD. The pulse shape can be related to the ageing of the insulating material. Several ageing steps appear. The surface wettability increases at the very beginning of exposure to PD. Changes of the surface morphology are studied using electron scanning microscopy. The by-products of chemical reactions due to PD have been analyzed by infrared micro-spectroscopy. The production of carboxylic aid by PD and the effect of this product and water on the ageing processes are also discussed. ( 3 Refs)

[45]

Dissado, L.A.; Fothergill, J.C., "Electrical Degradation and Breakdown in Polymers," Peter Peregrinus, Stevenage, UK, 1992.

Abstract: As well as advancing the scientific and engineering understanding of electrical degradation and breakdown in polymers, this book forms a comprehensive and international review of the state-of-the-art. Topics include: water and electrical treeing; charge transport; 'classical' and filamentary thermal, electromechanical, electronic and partial discharge breakdown models; the stochastic nature of breakdown and statistical characterization techniques; and engineering considerations for breakdown testing and degradation assessment. Although the book is primarily aimed at scientists and engineers practicing in the field, a broad introductory section has been included to cater for a wide range of readership including those who are new to the subject area. This comprises a description of the nature of the polymers, basic solid-state physics and an introduction to degradation and breakdown. (939 Refs)

$* * * * * * * * * * * * * * * * * * * * * * * * * * * * * * * * * * * * * * * * * * * * * * * * * * * * * * * * * * * * * * * * * * * * * * * * * * * * * * * * * * * * * * * * * * * * * * * * * * * * * * * \pi$

[46]

Dissado, L.A., "Discharges and the Formation of Tree-shaped Breakdown Structures," Proceedings of the International Conference on Partial Discharge, IEE, Michael Faraday House, Stevenage, UK, 1993.

Treatment: T; (Theoretical)

Abstract: The picture of the electrical tree process that has emerged from this stochastic model is one of a discharging skeletal structure embedded within a space-charge region of its own creation. The space-charge controls the discharging pattern (spatially and temporally) and hence indirectly the discharge induced avalanche damage. Minor variations of the trapped space-charge density will lead to preferred directions for new channel formation, and provide a physical explanation for the random choice of the stochastic model, Regarding space-charge fields as contributing a negative feedback into the non-linear damaging process, treeing can be seen to be a consequence of a near-equilibrium situation. Conversely when the space-charge effect is small under a rapidly rising driving force, runaway in the form of a single puncture ensues. (10 Refs) 
[47]

Domun, M.K.; MacKinley, R.R.; Miller, R., "The Effects of Voltage and Frequency on the Partial Discharge Characteristics of HV Paper Cables," Proceedings, Sixth International Symposium on High Voltage Engineering, 1989.

Treatment; Experimental (X)

Abstract: None

Reviewer's comment: The objective of the ECRC research program was to develop a method of predicting remaining life by (a) detection and location of discharges in installed cables and (b) a knowledge of the relation between partial discharge and service life derived from accelerated life tests. The problem was the interpretation of the results. Discharge location could only be carried out on installed cables by energizing the cables with a dc ramp power supply. The results could not be satisfactorily correlated with those obtained at $50 \mathrm{~Hz}$. Measurements were also carried out during accelerated life tests on samples using the Robinson-type discharge detector, model 3 or 5 (DD5), developed in the 1950's. The selection of a discharge magnitude from a large spectrum of pulses appearing on a small CRO screen is subjective and can vary by a factor of 8 to 1 . This paper describes the work carried out to determine the effects of voltage and frequency of the power supply on partial discharge characteristics of 'solid' medium-voltage paper cables. Includes a brief discussion of filters to eliminate noise and bring sensitivity to $1 \mathrm{pC}$.

(7 Refs)

[48]

Du, Z.; Mashikian, M.S., "Self-Learning Digital Filter for the Field Location of Partial Discharge in Cables," Conference Record of the 1994 International Symposium on Electrical Insulation, 1994.

Treatment: Experimental (X)

Abstract: The resolution and robustness of a cable PD locating instrument, based on time-domain reflectometry are critically affected by noise present in a field environment. The permanent background noise encountered during field tests has been shown to be mainly due to amplitude modulation radio signals. The filter, in conjunction with a signal averaging routine, has been successfully used to reduce noise and enhance the PD signal obtained from the cable in a field environment. Examples are provided to demonstrate the ability of the filter to significantly improve the signal-to-noise ratio and effectively extract PD signals from field recordings. (6 Refs)

$* * * * * * * * * * * * * * * * * * * * * * * * * * * * * * * * * * * * * * * * * * * * * * * * * * * * * * * * * * * * * * * * * * * * * * * * * * * * * * * * * * * * * * * * * * * * * * * * * * * * * * * * * * * * * * * *$ [49]

Ebinuma, Y.; Ogishima, M.; Aihara, M.; Haga, K., "Insulation Measurement of 22 Approximately $33 \mathrm{kV}$ XLPE Insulated Cable by Very Low Frequency High Voltage," Showa Electric Wire and Cable Review, Vol. 43, No. 2, 1993 (In Japanese).

Treatment: New Developments (N); Practical (P); Experimental (X)

Abstract: A method which uses very low frequency (VLF) high voltages has been studied for the diagnosis of 22-33 kV XLPE power cable insulation. The authors developed a novel VLF high voltage generator which supplies high power with no noise. The generator is applied to the measurement of partial discharge and dielectric loss tangent for several power cables, and it is confirmed that the VLF method is effective for measurement of insulation deterioration. (8 Refs) 
Egiziano, L.; Femia, N.; Garamella, G.; Lupo, G.; Tucci, V., "Characterization of Composite Organic Materials for Field Stress Control of HV Cables Terminations," Proceedings of the 4th International Conference on Conduction and Breakdown in Solid Dielectrics, IEEE, 1992.

Treatment: Practical (P); Experimental (X)

Abstract: Results are presented concerning the characterization of both electrical properties (volume resistivity, permittivity, $\tan \delta$ ) and mechanical properties (mass density, tensile strength, elongation, etc.) of cross-linked polyolefin stress control tubes (SCT). The authors also examine the chemical compatibility of such materials with the impregnation oil used in paper impregnated cables; results concerning the above properties obtained after an accelerated aging test in oil at $100^{\circ} \mathrm{C}$, according to ASTM D471/2, are reported. In order to correlate the behavior of materials with that of components, partial discharge characteristics and impulse withstand voltages for extruded cable terminations manufactured with unaged and 4-th oil aged SCT are compared. (3 Refs)

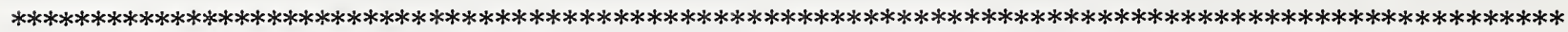
[51]

Ehara, Y.; Koizumi, N.; Kishida, H.; Ito, T., "Characteristics of Humidity on Partial Discharge Deterioration," Proceedings of the Symposium on Electrical Insulating Materials, 1993, Inst. of Elec. Eng. of Japan, 1993. Treatment: X; (Experimental)

Abstract: Deterioration in insulating materials due to partial discharge are complexity. Several experimental investigations have been reported to several effect on various conditions as a shape of a void and an atmospheric condition using an artificial void. However there are many causes still not cleared, an effect of moisture is one of these causes. The object of this work is to investigate condition of the insulator deterioration on polymer materials using various humidity in a void.

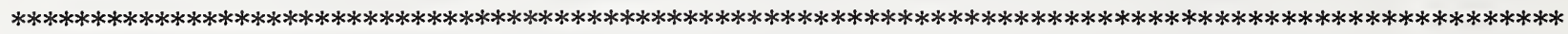

[52]

Fantana, N.L.; Bohme, H., "Dynamical Model for Electrical Aging of a Solid Dielectric," European Transactions on Electrical Power Engineering, Vol. 3, No. 6, 1993.

Treatment: Theoretical (T)

Abstract: The possibility of gaining a qualitative insight into long-time phenomenon in dielectric materials, using a dynamical model, is investigated. The authors assume a simplified microstructure of the material and a set of rules which apply iteratively. The rules describe some basic features of the aging phenomena under partial discharge. Stochastic aspects were modeled by using random number generators. Simulation was carried out for various starting microstructures regarding number size and position of initial voids and for different applied voltage. (15 Refs)

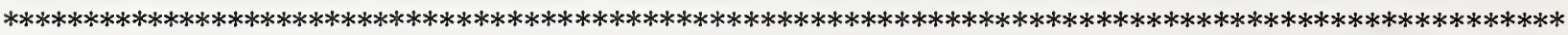
[53]

Florkowska, B.; Wlodek, R., "Pulse Height Analysis of Partial Discharge in Air," IEEE Transactions on Electrical Insulation, Vol. 28, No. 6, December 1993.

Treatment: X; (Experimental)

Abstract: The pulse height distribution (PHD) functions of partial discharges (PD) generated by ac voltage in air have been investigated. The electrode systems used allowed the investigation of single-source PD and/or multiple-source discharges. Because voltage and the electrode configuration alter the PHD functions of even a single PD source, the overall voltage effect on multiple source discharges is rather complicated. The results indicate that the PHD functions of the multiple source discharges are the superposition of the distribution functions of the discharges and the component sources acting alone. Knowledge of the PHD functions of the typical PD sources together with some kind of deconvolution technique could help to interpret the results of PD measurements performed on more complex, real insulation systems and, perhaps, identify the main sources of PD in those systems. (12 Refs) 


\section{[54]}

Fruth, B.; Florkowski, M.; Gross, D., "Partial Discharge Signal Generation, Transmission and Acquisition," Proceedings, International Conference on Partial Discharge, 1993.

Treatment: Experimental (X)

Abstract: Partial discharges (PD) play an important role in the ageing or breakdown scenario of solid, liquid and gaseous insulation systems. Their presence may indicate defects which reduce lifetime or reliability of an HV apparatus. If the partial discharge "signals" are correctly interpreted a risk evaluation may be done. Precondition for a correct interpretation of PD measurements are the understanding of the PD physics (i.e. physical models for the partial discharge process) and of the signal propagation (or transmission) in sometimes quite complex networks of HV apparatus plus the choice of a measurement procedure which is capable of predominantly revealing the partial discharge physics. (3 Refs)

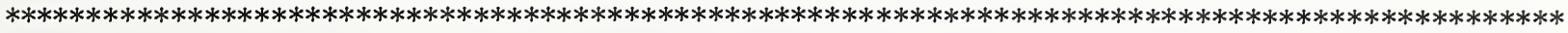

[55]

Fruth, B.; Niemeyer, L., "The Importance of Statistical Characteristics of Partial Discharge Data," IEEE Transactions on Electrical Insulation, Vol. 27, No. 1, February 1992.

Treatment: Practical (P); Theoretical (T); Experimental (X)

Abstract: A digital partial discharge (PD) measuring concept which is designed to acquire not only conventional PD charge magnitudes but also statistical characteristics of PD signals which contain most significant information on insulation defects is described. The latter fact is explained by a physical discharge model for discharges within voids in a dielectric. The potential of combining the new measurement concept with a physical interpretation is demonstrated by measurements on artificial defects in laboratory experiments as well as on real HV insulation systems. (10 Refs)

[56]

Fuhr, J.; Fruth, B.; Niemeyer, L.; Konigstein, D.; Hassig, M.; Gutfleisch, F., "Generic Procedure for Classification of Aged Insulating System," Proceedings of the 3rd International Conference on Properties and Applications of Dielectric Materials, IEEE, 1991.

Treatment: X; (Experimental)

Abstract: The authors describe a generic procedure for the evaluation of aged insulating systems of different types of HV (high-voltage) apparatus. This procedure is based on practical experience gained by on-site and on-line PD (partial discharge) measurements and supported by theoretical simulation of PD-generating defects. (5 Refs)

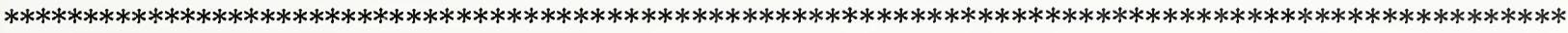

[57]

Fukunaga, K., "A New Partial Discharge Detection Method for Live UHV/EHV Cable Joints," Electrical Engineering in Japan, Vol. 113, No. 4, June 1994.

Treatment: Experimental (X)

Abstract: Partial discharge (PD) detection on live UHV/EHV power cables and accessories is one of the most important techniques to prevent cable systems from serious difficulties caused by slight errors in cable joining. A new PD detection method is proposed in this paper. A resonance-type partial discharge (REDI) sensor is developed for detecting PDs occurring inside the joints of live XIPE insulated power cable. This sensor picks up the high-frequency components of PD current pulses on the surface of live cables, hence the output signals can clearly be observed at the noiseless area (for example, 10-60 MHZ). This new method was applied to the initial AC breakdown tests of UHV/EHV power cables with three different types of joint. The PD pulse sequence was detected before their breakdown in all case. The charge quantity and the number of pulses increased tremendously just before the breakdown. In addition, the phase of the PD pulse against the applied voltage (phi-q characteristics) changes with time or with the progress of deterioration. According to these experimental results, the REDI sensor can be applied to the insulation diagnosis of live power cable joint. ( 8 Refs) 
[58]

Fukunaga, K.; Tan, M.; Takehana, H.; Takahashi, T.; Yoshida, S., "New Partial Discharge Detection Method for Live Power Cable Systems," Proceedings of the 3rd International Conference on Properties and Applications of Dielectric Materials, IEEE, 1991.

Treatment: Experimental (X)

Abstract: A novel partial discharge detector, the REDI (resonance-type high-frequency partial discharge) sensor, is developed for picking up the high-frequency components of partial discharge (PD) current pulses from live cable systems. This sensor was applied to initial AC breakdown tests of practical joints of XIPE (cross-linked polyethylene) insulated cables, and PD could be clearly observed in all cases (the minimum apparent charge was $5 \mathrm{pC}$ with $275 \mathrm{kV}$ cables). The phase characteristics of PD against the applied voltage changed just before the breakdown. (4 Refs)

[59]

Giddings, J.; Simmons, M.; Hilder, D., "Practical Experience of Partial Discharge Measurement and Location on Power Cables," Proceedings, International Conference on Partial Discharge, 1993.

Abstract: The paper present a historical review of partial discharge measurement techniques. Much practical engineering experience has been gained by both the cable manufacturers and measurement equipment manufacturers. Requirements for successful operation described in the paper include the screened room option, open area testing, pulse discrimination, non-inductive link, good housekeeping, higher voltage testing, and special precautions for long cables (several kilometers). (4 Refs)

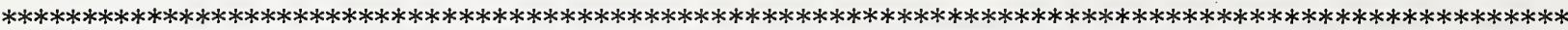

[60]

Gjaerde, A.C., "Multi Factor Ageing of Epoxy Resin," Proceedings, Nordic Insulation Symposium NORD-IS 92, Nygrens Ljuakopla AB, Vasteras, Sweden.

Treatment: Experimental (X)

Abstract: Electrical insulation is subjected to several stresses in practical applications. Stresses which result in irreversible destructive processes, ageing, limit the life of the insulation system. The main ageing factors are electrical, thermal, mechanical and environmental stress. When several factors act simultaneously the ageing produced is not necessarily the algebraic sum of the ageing the individual factors would have caused if they were applied sequentially. It is the main aim of this work to investigate the synergy effects of temperature and voltage including also the effect of partial discharges. (4 Refs)

[61]

Gjaerde, A.C.; Sletbak, J., "Influence of Partial Discharges on Void Gas Pressure," Proceedings of the International Conference on Partial Discharge, IEE, Michael Faraday House, Stevenage, UK, 1993.

Treatment: T; (Theoretical); X; (Experimental)

Abstract: The development of void gas pressure has been measured at different levels of voltage and thermal stress. The void gas pressure typically exhibits a fluctuating behavior in the beginning of ageing and then subsequently decreases at a constant rate that increases for increasing voltage stress. It is larger at $50^{\circ} \mathrm{C}$ then at room temperature. A characteristic PD-pattern was observed to develop after a certain ageing time dependent on the temperature level. The characteristic PD pattern could to some extent be explained as an effect of indirect interaction. (7 Refs) 
[62]

Gluchowski, S.; Juchniewicz, J., "The Interplay of Treeing Forms and Aging Phenomena," Proceedings of the 3 rd International Conference on Properties and Applications of Dielectric Materials, IEEE, 1991.

Treatment: Theoretical (T)

Abstract: The effect of electrical tree structure on the energy spectrum of partial discharges is examined. This is shown for an exemplary electrical tree. It is argued that the dependence could be used, in reverse, to establish the dynamics of the aging process during electrical tree propagation. The nature of the energy dependence of partial discharges is illustrated for branchlike and bushlike trees, and an attempt is made to demonstrate the scaling method of approach to such processes. (6 Refs)

[63]

Grünewald, P.; Weidner, J.R., "On-line PD Analysis in Power Plants - A Successful Tool for Early Fault Detection," Proceedings, International Conference on Partial Discharge, 1993.

Treatment: Applications (A); Practical (P)

Abstract: Although partial discharge (PD) monitoring techniques are primarily applied for detecting internal discharges in polymer insulating materials, basically the same detection methods can also be used in a slightly modified form for online monitoring and for early fault detection in power plants. Faults in high-voltage equipment are often revealed by high-energy partial discharges or arcing. The resulting high-frequency pulses can be detected and analyzed by an online monitoring system. Such a system enables the sudden failure of vital equipment (generator, transformers) with severe consequential damage to be averted at an early stage. Thus improving the cost-effectiveness of the power plant. (0 Ref)

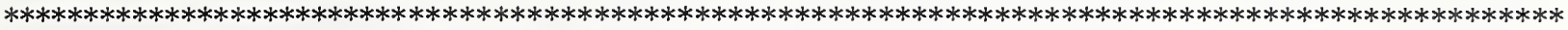

[64]

Gryazin, V.A.; Zavarzina, V.V.; Rozhkov, V.M., "Influence of Pressure on the Breakdown of Small Air Gaps," Elektrotekhnika Vol. 63, No. 11, Translated in Soviet Electrical Engineering Vol. 63, No. 11, 1992. Treatment: Experimental (X)

Abstract: The dependence of the breakdown voltage in small air gaps (less than $0.5 \mathrm{~mm}$ ) on the air pressure in the range $0.1-100 \mathrm{kPa}$ has been determined for copper electrodes without special treatment or conditioning. The agreement of the breakdown curves for two different electrode systems at pressures of no less than $0.6 \mathrm{kPa}$ indicates the reliability of the results and permits their recommendation, for example, for the calculation of the voltage at which partial discharges appear in the insulation of electrical devices operating at normal and reduced air pressure. In the proposed system for determining breakdown, the current is large in the period when electrical breakdown is developing, but the steady current is small. This permits reduction not only in the degree of damage to the electrodes but also in the power of the voltage source. Therefore, this system may be recommended for widespread use in measuring the electrical strength of any dielectrics. (8 Refs) 


\section{[65]}

Guastavino, F.; Guerra, G., "Optimization of Partial Discharge Testing Techniques," Proceedings of the 4th International Conference on Conduction and Breakdown in Solid Dielectrics, IEEE, 1992.

Treatment: Experimental (X)

Abstract: The authors consider the behavior of dielectric films subjected to surface partial discharges (PDs) under AC voltage (power frequency) in cells containing a gas gap in a series with a film. The recurrent formation of PDs in the gap creates damage which can lead to breakdown. It had been suggested previously that the damage to thin polymer films during tests of this kind can be related to synergic factors: the action on the film surface of the discharges and the effect of electrical aging in the bulk of the film present during the discharge time windows. In order to clarify the effect of the electrical aging factor on the duration of the films during PD testing it was necessary to devise a way to separate the contribution of the two factors, maintaining the conditions driving the first factor and changing the stress present on the film during discharge periods, when the air gap is short-circuited. The initial assumption that the damage to thin dielectric films during surface PD tests can be related to the two above-mentioned synergic factors was confirmed. ( 2 Refs)

$* * * * * * * * * * * * * * * * * * * * * * * * * * * * * * * * * * * * * * * * * * * * * * * * * * * * * * * * * * * * * * * * * * * * * * * * * * * * * * * * * * * * * * * * * * * * * * * * * * * *$

[66]

Gubanski, S.M.; Montanari, G.C.; Motori, A., "TSDC Investigations of the Thermally and Electro-Thermally Aged Cable Models," Conference Record of the 1994 International Symposium on Electrical Insulation.

Treatment: Experimental (X)

Abstract: Classical TSD and fractional polarization analyses were carried out on unaged and aged XLPE cable models from $-120^{\circ} \mathrm{C}$ to $120^{\circ} \mathrm{C}$ and three relaxation processes were found. A low temperature process, identified as $\beta$ relaxation and ascribed to the polar groups attached to the polymer chains in the amorphous region, gets stronger with duration of the aging and can be mainly ascribed to an increase in carbonyl group concentration. The second polarization process that exhibits itself by a strong TSD peak at a temperature range $50-80^{\circ} \mathrm{C}$ and is only present in the spectra of aged samples, is believed to be caused by a charge relaxation. The high temperature peak, present above $100^{\circ} \mathrm{C}$, can be related to melting of crystalline phase in the polymer. This peak should also be related to a charge polarization process. Fractional depolarization measurements allowed for a precise description of elementary processes (activation energies and preexponential factors). (12 Refs)

[67]

Gulski, E.; Kreuger, F.H., "Diagnostics of Insulating Systems Using Statistical Tools," Conference Record of the 1992 IEEE International Symposium on Electrical Insulation.

Treatment: Experimental (X)

Abstract: In this paper computer-aided analysis of partial discharges (PD) using conventional discharge detection (bandwidth about $400 \mathrm{kHz}$ ) was studied. It has been found the shape of phase-position distributions contains mush information on the origin and type of discharge. These shapes are therefore analyzed, using statistical operators like skewness, kurtosis, cross correlation factor, etc.. Tests of discharges in artificial models in gases and solid materials have shown in the past that several statistical are characteristic for actual discharge sources. The combination of 15 statistical operators can form the finger print of a discharge. To use these finger prints for the recognition of unknown defects an algorithm called recognition rate was developed. This technique was used to reveal the origin of discharges in actual objects like current transformer, cable and gas insulated switchgear. The promising results of the recognition rate have shown that the origin of the discharges in technical objects can be traced by using computer-aided discharge analysis. (2 Refs) 
[68]

Hadid, A.; Laurent, C.; Mammeri, M.; Clavreul, R.; Duchateau, F.; Berdala, J., "An Investigation into Electrical Ageing of Insulating Polymers by Detection of Charge Injection under Alternative Divergent Field," Journal de Physique (Applied Physics, Materials Science, Fluids, Plasma and Instrumentation), Vol. 4, No. 1, January 1994 (In French).

Treatment: Experimental (X)

Abstract: Our aim is to understand the electrical ageing of insulating polymeric materials under $\mathrm{AC}$ voltage and in discharge-free situation, i.e. in the absence of any pre-existing gaseous cavities in the bulk of the dielectric. In this report, we use a needle electrode molded into the insulant to simulate defects producing local field enhancement. An experimental technique for measuring the charge flow injected by the needle into the dielectric under AC voltage is described. The transition between the discharge-free electro-luminescent state to micro-partial discharge state (early electrical tree propagation phase) is investigated with a sensitivity reaching $0.01 \mathrm{pC}$. Optical diagnosis is carried out simultaneously. Special emphasis is given to synthetic insulation of power cable. Low-density polyethylene is used as a dielectric with molded metallic needle electrode. Semi-conducting electrodes prepared from the shield of a cable are also used in this investigation. Statistics on times to tree inception show that the needle tip cannot be considered as a homogeneous injecting surface. The conclusion is double: (I) the onset field for massive charge transfer derived from the measured curvature radius of the needle is not the absolute value and (ii) the discussion of the results obtained by a needle test must include a Weibull statistical analysis with determination of the location parameter. (18 Refs)

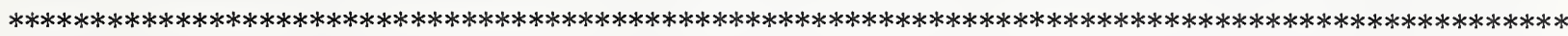

[69]

Hanson, B.A.; Reynolds, A.B., "Effect of Aging on Breakdown Voltage of Artificially Damaged Cable," Proceedings of the 1993 IEEE Conference on Electrical Insulation and Dielectric Phenomena, 1993.

Treatment: X; (Experimental)

Abstract: The effect of flaws and thermal and radiation aging of flaws on electrical breakdown of low-voltage cable was studied. AC breakdown voltages of XLPE and EPR cables were measured for both damaged and undamaged cable. Three types of flaws were studied: scrapes, transverse cuts, and longitudinal cuts. Some cables were radiation aged up to $1 \mathrm{MGy}$ and others were thermally aged at $130^{\circ} \mathrm{C}$ for up to 50 days. Results to date indicate little effect of aging on breakdown voltage and a linear decrease in breakdown voltage with decreasing thickness beneath scrapes and transverse cuts below some threshold thickness. Calculated electrical field distributions at breakdown indicate that breakdown occurs by partial discharge in pores. (7 Refs)

[70]

Hantouche, C., "Partial Discharges on Power Capacitors," IEEE Transactions on Electrical Insulation, Vol. 28, No. 6, December 1993.

Treatment: X; (Experimental)

Abstract: Partial discharges measurements in power capacitors have been carried out using digital technique. The advantages of the use of digital technique are discussed. The digital equipment design is presented. Test result on industrial all-film power capacitors with high capacitance values are presented together with measurements of the PDIV before and after the endurance tests. (7 Refs) 


\section{[71]}

Hasegawa, T.; Kimura, K.; Shibuya, Y., "Construction of Expert System Prototype for Degradation Diagnosis and Measurement System Using Personal Computer Application for Degradation Diagnosis of PD Statistical Parameter Using Phase Information," Transactions of the Institute of Electrical Engineers of Japan, Part A, Vol. 113-A, No. 5, 1993 (In Japanese).

Treatment: Practical (P); Theoretical (T); Experimental (X)

Abstract: We have constructed a prototype of PD measurement and expert system for degradation diagnosis using personal computer(PDM/ES-I). PDM/ES-I consists of three parts: PD measurement system (PDM), PD pulse data analyzing system (PDDANS) and degradation diagnosis system (DDS). PDM allows one to obtain reproducible $\mathrm{PD}$ pulse data with the phase information in an alternating voltage cycle and the number of the alternating cycles. For CIGRE Method-II (CM-II) electrode system using $0.1 \mathrm{~mm}$ thick polyethylene film (LDPE), temporal change of PD data is measured with PDM/ES-I up to breakdown of the sample (LDPE). We found from the experimental results that five new statistical PD parameters monotonously have varied with aging time. We also found that PD pulses occurrence distributions have correlation with aging time. Finally, we propose a model for a PD mechanism in which the statistical time lag of the discharge is dependent on over voltage of a void gap and the residual voltage depends upon the charge of partial discharges. (18 Refs)

[72]

Hasegawa, T.; Kimura, K.; Shibuya, Y., "Effect of Applied Voltage Frequency on Swarming Pulsive Microdischarges in Closed Voids," Electrical Engineering in Japan, Vol. 113, No. 3, 1993.

Treatment: Experimental (X)

Abstract: The extinction of the partial discharge (PD) pulse has frequently been observed in an epoxy specimen with a closed void during voltage endurance tests using a CIGRE Method-II electrode. The individual discharge pulse becomes so small that the discharges cannot be detected by conventional pulse detection methods. Such discharges are known as "swarming pulsive microdischarges" (SPMD). In this paper, SPMD characteristics are investigated by varying the frequency of the applied voltage from 0.1 to $240 \mathrm{~Hz}$. As a result, the SPMD are found to occur less frequently as the frequency is lowered. To seek this cause, one-shot voltages were applied repeatedly at constant intervals. By varying the interval from 0.02 to $100 \mathrm{~s}$, the PD of an electrically aged specimen was measured. It was revealed that the discharge magnitude increases as the interval becomes longer. The onset of SPMD was found to depend on the preceding discharge. (12 Refs)

$* * * * * * * * * * * * * * * * * * * * * * * * * * * * * * * * * * * * * * * * * * * * * * * * * * * * * * * * * * * * * * * * * * * * * * * * * * * * * * * * * * * * * * * * * * * * * * * * * * * *$ [73]

He, Q.; Kemp, I.J.; MacKinlay, R., "On Data Analysis and Processing of Partial Discharge Pulses Using Software Orientated Techniques," Proceedings, Sixth International Conference on Dielectric Materials, Measurements and Applications, IEE, London, UK, 1992.

Treatment: Applications (A); Practical (P)

Abstract: The detection of partial discharge activity from the solid insulating systems of high voltage plant is well-recognized as a measurement whose interpretation can prove valuable in the assessment of insulation integrity. Partial discharge detectors have traditionally been configured to display the pulses from the partial discharges superimposed on the AC power cycle. Knowledge of these pulse amplitudes, their phase distribution, polarity and overall number per cycle can be used, often in conjunction with the knowledge of how these parameters vary with applied voltage and, at a fixed applied voltage, with time, to provide a valuable insight into the nature, extent and location of degradation sites within the solid insulating system. Given the plethora of parameters to be measured and presumed necessity for accuracy and objectivity, it is not surprising that digital technology has been utilized to this end and many such systems are now being reported in the literature. Indeed, the data manipulating power of such systems is now producing results which indicate that more complex pattern changes can be analyzed to provide increasing sophisticated assessments relating to insulation integrity. (5 Refs) 
[74]

Henriksen, M.; Holboll, J.T.; Rygal, R., "An Improved Method/Setup for Extended Testing after the CIGRE Method II," Conference Record of the 1992 IEEE International Symposium on Electrical Insulation, 1992. Treatment: Practical (P); Experimental (X)

Abstract: The authors describe an improved version of the CIGRE Method II test technique used for testing the resistance of insulating materials to partial discharges (PDs). The method was extended to continuous PD measurements and pulse analyses. It was sound that parameters such as selective fuse protection of the different test objects, and the sample production and preparation, among others, were of the utmost importance for the end results of this test. Results of using the system on epoxy with and without fillers are presented. Based on these results, the critical points of the method are discussed. The application of the system showed typical behavior of the discharges and lifetimes that was strongly dependent on the filler type. (4 Refs)

[75]

Hikita, M.; Komori, F.; Nishiguchi, N.; Mizutani, T., "Phase-resolved and Time-Sequential Partial Discharge Pulse Measurements in a Metal-Void-Insulator System Using a Personal Computer," Journal of Physics D (Applied Physics) Vol. 27, No. 6, June 1994.

Treatment: Experimental (X)

Abstract: We have developed a partial discharge measurement and analysis system using a personal computer, which allows one to obtain reproduced partial discharge pulse data with the phase information in an applied alternating current voltage and the number of cycles. For the CIGRE method II electrode system using $0.1 \mathrm{~mm}$ thick polyethylene film, temporal changes of partial discharge characteristics were measured up to breakdown of the sample. The average inception phase theta ${ }_{\text {inc }}$ was proposed as a new statistical partial discharge parameter, which was obtained by making use of the capability of the time-sequential partial discharge data acquisition of our system; theta $\mathrm{inc}_{\text {in }}$ is defined as the average of theta ${ }_{\text {inc }}$ of the number of cycles in a measurement; theta inc $_{\text {is a }}$ phase at which the first partial discharge pulse occurs in the half cycle after the polarity reversal of the previous partial discharge pulses. The experimental results revealed that the partial discharge pulse occurrence phase distribution (phi -q-n distribution) exhibited a good correlation with ageing time. It was suggested that theta ${ }_{\text {inc }}$ is a candidate signal for diagnosis of insulation performance of the system from the initial to middle degradation stage. We also discuss the physics of the temporal change of the phi-q-n distribution and theta inc $_{\text {as }}$ the ageing process proceeded. (20 Refs)

[76]

Holboll, J.T.; Henriksen, M., "Partial Discharge Patterns and Surface Deterioration in Voids in Filled and Unfilled Epoxy," Conference Record of the 1992 IEEE International Symposium on Electrical Insulation, 1992.

Treatment: Experimental (X)

Abstract: Results are presented from analyses of pulses from partial discharges (PDs) in single spherical voids in filled and unfilled epoxy plastic and related to the observed surface deterioration. The filler types used were dolomite, alumina, and silica. Long-time aging tests including pulse phase/height analyses were performed over a period of $2400 \mathrm{~h}$ and showed very characteristic discharge patterns for each material combination. A unique behavior with regard to changes of pulse repetition rate and maximum apparent charge was observed for PD in alumina- and silica-filled epoxy. The void surfaces were investigated by scanning electron microscopy for voids exposed to PD as well as voids without discharges. Different kinds of surface deterioration were found. An attempt was made to establish a relationship between aging phenomena as exhibited by void surface changes and discharge patterns. (6 Refs) 
[77]

Homma, H; Takahashi, T.; Taniguchi, T.; Izumi, K., "Evaluation of Surface Degradation of Polymer Insulating Materials Related to Leakage Current," Proceedings of the 21 st Electrical Electronics Insulation Conference and Electrical Manufacturing and Coil Winding 1993, IEEE, 1993.

Treatment: T; (Theoretical); X; (Experimental)

Abstract: We performed artificial aging tests using test rods made of Silicone Rubber (SR) and Ethylene Propylene Diene Monomer (EPDM), based on the Rotating Wheel Dip Test (RWDT) method and the Salt Fog Chamber Test (SFCT) method, and evaluated aspects of surface degradation. It is concluded that the surface degradations of polymer insulating materials are directly related to the partial discharge and the cumulative charge of leakage current on the surface of test specimens is useful in evaluating degradation aspects. (1 Ref)

\section{[78]}

Hoof, M.; Patsch, R., "Analyzing Partial Discharge Pulse Sequences - A New Approach to Investigate Degradation Phenomena," Conference Record of the 1994 International Symposium on Electrical Insulation. Treatment: Experimental (X)

Abstract: This paper presents a new method of partial discharge data analysis for the investigation of space charge and degradation phenomena in high voltage insulation systems. The basic principles of the PulseSequence-Analysis are illustrated and the characteristic differences with regard to standard procedures that have been established during the past few years are outlined. A description is given of an electronic partial discharge acquisition system, which is designed on a plug-in interface board for a standard Personal Computer to perform long term measurements of all discharge parameters required for the PSA. Electrical treeing in polyethylene is used to demonstrate the usefulness of the PSA method. It is shown the information on space charge phenomena and the development of the local degradation can be obtained by considering correlations between consecutive discharge pulses. (7 Refs)

[79]

Hoof, M.; Patsch, R., "Pulse-sequence Analysis: A New Method for Investigating the Physics of PD- Induced Ageing," IEE Proceedings Science, Measurement and Technology, Vol. 142, No. 1, January 1995.

Treatment: Practical (P); Experimental (X)

Abstract: A new method is presented of partial discharge data analysis for the investigation of space charge and degradation phenomena in high-voltage insulation systems. The basic principles of the pulse- sequence-analysis (PSA) are illustrated and the characteristic differences with regard to standard procedures that have been established during the past few years are outlined. A description is given of an electronic partial discharge acquisition system, which is designed on a plug-in interface board for a standard PC to perform long-term measurements of all the discharge parameters required for the succeeding analysis. Electrical treeing in polyethylene is used to demonstrate the usefulness of the method. It is shown that information on the physics of treeing phenomena especially with regard to the influence of local space charges and their build-up and decrease over time as well as the development of the local degradation can be obtained by considering correlations between consecutive discharge pulses. Some experimental results from different stages of the electrical tree growth are analyzed and their meaning with regard to the local microscopic phenomena inside the tree or in the vicinity of the tree tips discussed. (8 Refs) 
[80]

Ishida, T.; Mizumo, Y.; Nagao, M.; Kosaki, M., "Computer Aided Partial Discharge Analysis System for Detection of Swarming Pulsive Microdischarges," Proceedings, International Conference on Partial Discharge, 1993.

Treatment: Theoretical (T)

Abstract: When diagnosing internal partial discharge (PD) degradation phenomenon, one must be cautious about swarming pulse microdischarges (SPMD). However, that details of main factors on appearance of SPMD are not clear yet. As one of the reasons, there was no way to measure SPMD quantitatively. So we developed computer aided partial discharge analyzing system (CAPDAS) which can evaluate SPMD, and introduced a new PD parameter, the SPMD ratio, for quantitative analysis of SPMD. It becomes clear that the enhanced appearance of initial electrons in internal void promotes the change of normal PDs into SPMD. This paper focuses on development of PD analyzing system for SPMD and on clarification of the factors affecting the occurrence of SPMD. (7 Refs)

$* * * * * * * * * * * * * * * * * * * * * * * * * * * * * * * * * * * * * * * * * * * * * * * * * * * * * * * * * * * * * * * * * * * * * * * * * * * * * * * * * * * * * * * * * * * * * * * * * * * * * * * * * * * *$

[81]

Ivanov, S.I.; Svirachev, D.M.; Pechenyakova, V.P.; Petrov, Ch.V.; Dobreva, E.D., "Surface Modulation of Polyimide in a Gas Discharge: Post-effect," Bulgarian Journal of Physics, Vol. 19, No. 1-2, 1993.

Treatment: Experimental (X)

Abstract: The evolution of a polyimide surface treated in a corona discharge for $0.3 \mathrm{~s}$ has been investigated. The relaxation was followed from the 12 th minute up until 500 hours after discontinuation of the plasma treatment. The acquired adhesivity of the treated surface gradually decreases during ageing, and this is expressed by decrease of the cosine of the wetting angle. The decrease with time of the adhesivity acquired from the treatment follows a law expressed as the sum of two exponents. This is explained in terms of deactivation of two types of adhesive states generated from the action of the corona discharge. The first adhesive state has a lifetime of 17 hours and relative content 0.16 . The second adhesive state lasts longer -- it has a lifetime of 3140 hours and a relative content of 0.81 . (7 Refs)

[82]

Jianaing, L.; Jinping, Y., "Intelligent Partial Discharge Measurement Device," Conference Record of the 1994 International Symposium on Electrical Insulation, 1994.

Treatment: Experimental (X)

Abstract: This paper introduces an entirely new intelligent partial discharge measurement device, which integrates with the computer $\mathrm{A} / \mathrm{D}$, time series control and the filter amplifier circuit for analog signals. It has four independent $\mathrm{A} / \mathrm{D}$ channels. The highest sampling frequency is $20 \mathrm{MHz}$ and data storage is $512 \mathrm{k}$. This device can be used for detecting partial discharge in electrical apparatus by means of acoustical and electrical methods. The waveform and parameters of partial discharges can be shown immediately. The real response form of any discharge impulse within one cycle can be observed on the screen. It can give $\mathrm{Q}-\mathrm{V}, \mathrm{Q}-\psi, \mathrm{Q}-\phi, \mathrm{Q}-\mathrm{N}$ relations and spectrum through FFT; also it can carry our correlation analysis and determine the discharge type which it compares with the standard wave by searching the wave in the one cycle. All the signals taken and waveforms can be stored on disks for review and further analysis. Discharge faults of two large transformers were found in field measurements of PD by use of this device. (6 Refs) 


\section{[83]}

Kahle, M., "Use of Combined Methods for Location and Identification of PD-sources in Electrical Insulation," Proceedings of the Symposium on Electrical Insulating Materials, Inst. of Electrical Engineers of Japan, Tokyo, 1993.

Treatment: X; (Experimental)

Abstract: High voltage equipment is influenced in life time and reliability by a great number of factors. Hot spots and PD, however, play the most serious role. Although the existing PD measuring methods are at an elevated standard the results of prognoses are not satisfying. A step forward could be the combination of different methods to overcome some weak points of one or the other method and to use the effects of increasing the recognition probability by eliminating interferences of different kinds. (7 Refs)

$* * * * * * * * * * * * * * * * * * * * * * * * * * * * * * * * * * * * * * * * * * * * * * * * * * * * * * * * * * * * * * * * * * * * * * * * * * * * * * * * * * * * * * * * * * * * * * * * * * * * * * * * * * * * * * *$

[84]

Kako, Y.; Watanabe, S.; Higashimura, Y.; Matsunobu, K., "Internal Partial Discharge Resistance of Sulfur Cured Rubber," Transactions of the Institute of Electrical Engineers of Japan, Part A, Vol. 113-A, No. 10, 1993 (In Japanese).

Treatment: Applications (A); Experimental (X)

Abstract: Because of the strong activity of atomic oxygen produced by partial discharges, it is very difficult for organic insulating materials to withstand it. In order to prevent the insulation deterioration due to partial discharges, it is practical to minimize the partial discharges in insulation or to use inorganic materials combined with organic materials. The authors discovered about 30 years ago that rubber shows excellent PD resistance in some conditions, and this paper shows that sulfur cured rubber shows excellent PD resistance, whereas pure rubber and peroxide cured rubber does not. Through the PD resistance test for thermoplastic rubber with each element of sulfur curing agents, it has been clarified that the most important combination of elements is that of sulfur, $\mathrm{ZnO}$ and double bond of polymer. And in this case, it seems probable that some chemical bonds of sulfur with rubber are produced since there is no bloom of sulfur on cured sample. An inorganic film is formed on the surface of samples after internal partial discharges, and it may perform partly as the protective film for deterioration due to discharges, but the main cause must exist in the action of the newly produced sulfur bond, and it is the most important subject of future research to clarify this mechanism. (10 Refs)

[85]

Kako, Y.; Watanabe, S.; Higashimura, Y.; Matsunobu, K., "Improvement of Partial Discharge (PD) Resistance of Epoxy Resin by Using Sulfur Containing Additives," Transactions of the Institute of Electrical Engineers of Japan, Part A, Vol. 113-A, No. 10, 1993. (In Japanese)

Treatment: Applications (A); Experimental (X)

Abstract: In the field of high voltage engineering, it has been desirable for a long time to improve the internal PD resistance of epoxy resin without lowering other properties. Recently, the authors discovered that some sulfur compound as curing agents or simple additives improved the PD resistance of rubber markedly, and this time they have tried to apply this fact to the case of epoxy resin. As was expected, some sulfur compounds containing SS-bond suppress the deterioration of epoxy resin due to internal partial discharges, and the larger the molecular weight of organic group combining to the SS-bond, the longer the effective life of additives. Moreover, in order to make full use of these additives, it is very important to restrict moisture in the insulation system. From this study, the authors have proposed the chemical formulation of suppressive effect of additives for deterioration of epoxy resin due to internal partial discharge. (13 Refs) 
[86]

Kang, D.S.; Lee, W.Y.; Kim, Y.J., "A New Measurement Technique of Partial Discharge Phase Angle Distribution," Proceedings of the 1993 IEEE Conference on Electrical Insulation and Dielectric Phenomena, 1993.

Treatment: (X)

Abstract: Several experiments have been aiming at finding useful diagnostic parameters from partial discharge spectra by applying new measurement techniques. The work described was designed to measure a new partial discharge parameter named Dynamic Stagnation Voltage, which may be a useful diagnostic concept in predicting remaining life and assessing insulation health, by frequency spectrum analyzer and multichannel analyzer. (3 Refs)

$* * * * * * * * * * * * * * * * * * * * * * * * * * * * * * * * * * * * * * * * * * * * * * * * * * * * * * * * * * * * * * * * * * * * * * * * * * * * * * * * * * * * * * * * * * * * * * * * * * * * * * * * * * * * * * * *$

[87]

Karady, G.G.; Oliva, J.R; Domitz, S.; Meketa, R., "Advanced Digital Instrumentation for Partial-Discharge Measurement," Electric Power Systems Research, Vol. 25, No. 3, December 1992.

Treatment: X; (Experimental)

Abstract: A new computer based partial-discharge (PD) measuring system was successfully tested in the laboratory in long duration tests on dielectric materials and capacitors. The system measures each current pulse generated by partial discharge during a predetermined time. The pulses are digitized by a 200 megasample/s real-time waveform digitizer and stored in a fast memory unit. The data obtained are transferred to a personal computer for analysis. This system records a large number of pulses without dead time and produces statistical information related to amplitude, polarity, energy and charge content of the PD-generated current pulses. The operation, analysis and display of results are controlled by software. The software can easily be modified to obtain different evaluation methods. This gives flexibility to the new PD detection system and allows its use as a design tool. The operation of the system is automatic, no human supervision is required. Long duration tests of ceramic capacitors were performed to validate the operation of the diagnostic system. One result indicates that the aging of the tested capacitors changes the charge distribution curve, which was obtained by the statistical analysis of current pulses. The distribution curve shifts towards higher levels of charge as the capacitors deteriorate. This result agrees with the experimental data reported in the literature. The system is particularly suitable for aging studies on dielectric materials under different test conditions. (12 Refs)

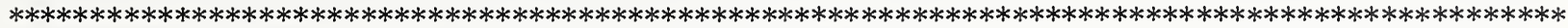

[88]

Karapetyan, M.; Khachatryan, A. S.; Bortnik, I. M., "The Short Term and Long Term Electric Strength of Polymeric Composition Materials under DC and AC Stresses," Izvestiya ANSSSR: Energetika Transport, No. 1, January-February 1991 (in Russian)

Treatment: A; (Applications); T; (Theoretical)

Abstract: For polymeric composite materials with weakly and sharply nonuniform fields results of electric strength investigations with interelectrode distances from 2 to $10 \mathrm{~mm}$ and smooth rise of voltage, electric ageing for $20000 \mathrm{~h}$ are presented. Partial discharge rate dependence on electric field strength are obtained. Tests were carried out under DC and $\mathrm{AC}(50 \mathrm{~Hz})$ voltages. High electric strength of composite materials under direct voltage long term action and its smooth rise will reduce sizes of insulation nodal points of high voltage apparatus. (12 Refs) 
[89]

Katsuta, G.; Toya, A.; Muraoka, K.; Endoh, T.; Sekii, Y.; Ikeda, C., "Development of a Method of Partial Discharge Detection in Extra-High Voltage Cross-Linked Polyethylene Insulated Cable Lines," IEEE Transactions on Power Delivery, Vol. 7, No. 3, July 1992.

Treatment: Experimental (X)

Abstract: Deterioration in the insulation performance of extra-high voltage XIPE (cross-linked polyethylene) cables is believed to be attributable to the deterioration caused by partial discharges. After using an XIPE cable to investigate the behavior of partial discharges under various adverse conditions, the authors succeeded in developing a highly sensitive novel method of measuring partial discharge in XILPE cable lines. Partial discharges in a $275 \mathrm{kV}$ XLPE cable live line have been measured using this method. As a result, a detection sensitivity of $1 \mathrm{pC}$ has been achieved. (23 Refs)

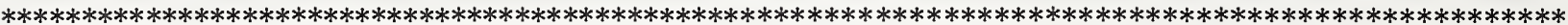

[90]

Kärner, H.C., "Solid Dielectrics in HV Systems," Proceedings, Sixth International Symposium on High Voltage Engineering, 1989.

Treatment: Tutorial review

Abstract: This paper describes stresses and properties of solid dielectrics applied in HV insulating systems. For most important material and applications electrical, thermal, mechanical and environmental stresses and their influence on dominating properties are explained, accompanied by an outline on future developments. (25 Refs)

[91]

Kemp, I.J., "Developments in Partial Discharge Plant-Monitoring Technology," Proceedings, Inter-national Conference on Partial Discharge, 1993.

Treatment: Technology review

Abstract: None

Reviewer's comment: The paper presents a review of several methods for in-plant monitoring, with reference to original papers. These methods include acoustic detection of PD activity, optical detection of PD activity, chemical detection of PD activity, and electrical detection of PD activity. The author concludes that electrical detection of individual PD events must be at the center of future diagnostic strategies. (45 Refs)

\section{[92]}

Komatsubara, M.; Ishii, M., "Evaluation Methods on Polymer Materials for Surface of Outdoor Insulators, Electrical Engineering in Japan, Vol. 112, No. 5, 1992.

Treatment: Experimental (X)

Abstract: Measurements were conducted on silicon rubber (SR), EPDM, PMMA and polyethylene (PE). The influence of irradiation with a mercury lamp was detected through measurements of contact angle, formation time of water film, and mass analysis of released gases under irradiation of an electron beam. Measurement of the contact angle by using polar and nonpolar liquids revealed that silicon rubber (SR) was the most resistant against UV radiation. SR also showed recovery of hydrophobicity after UV irradiation. Measurement of the current flowing across the surface of materials exposed to artificial fog showed good agreement to the measurement of contact angle. Infrared absorption spectroscopic analysis enabled the intensity of oxidation of highly UV-deteriorated organic insulating materials to be detected. Radicals on the surface of specimens were specified from the result of mass analysis of released gases. From these results, the nature of deterioration of organic insulating materials irradiated by $\mathrm{UV}$ is discussed. (11 Refs) 
[93]

Komori, F.; Nishiguchi, N.; Hikita, M.; Mizutani, T., "Construction of Prototype On-line Expert System for Insulation Degradation Diagnosis of Polymeric Insulation Material Suffering Partial Discharge (PD)," Proceedings of the 4th International Conference on Conduction and Breakdown in Solid Dielectrics, IEEE, 1992.

Treatment: Practical (P); Experimental (X)

Abstract: The authors have constructed a prototype of an online PD pulse measurement and expert system (PDM/ES-I) using a personal computer for insulation degradation diagnosis of materials suffering partial discharge (PD). For 0.1-mm-thick LDPE (low-density polyethylene) film, using the CM-II electrode system and PDM/ES-I, they measured the temporal changes of $\Phi$-q-n characteristics of PD pulses and analyzed 33 kinds of statistical PD parameters up until breakdown. They found that five new statistical PD parameters correlated with aging time. PD pulse occurrence distribution also proved to have a correlation with aging time. Diagnosis was made under the same conditions with either a diagnosis system using statistical parameters or one using pattern recognition. Both permitted an exact determination of the degree of degradation at a given aging time, predicting the breakdown residual life of the CM-II electrode system using LDPE. (6 Refs)

\section{[94]}

Komori, F.; Nishiguchi, N.; Hikita, M.; Mizutani, T., "Degradation Diagnosis and Estimation of Residual Life of Insulating Material Using Pattern Recognition of Phase Angle Resolved Partial Discharge Pulse Occurrence Distribution," Transactions of the Institute of Electrical Engineers of Japan, Part A, Vol. 113-A, No. 8, 1993. Treatment: Practical (P); Experimental (X)

Abstract: Constructs a prototype of partial discharge (PD) pulse measurement and degradation diagnosis expert system (PDM/ES-I) using a personal computer for insulation degradation diagnosis of materials suffering from PD. For $0.1 \mathrm{~mm}$-thick low density polyethylene (LDPE) with CIGRE Method II electrode system, temporal change of phase-angle-resolved PD pulse occurrence distribution was measured with PDM/ES-I. The authors applied the so-called "pattern recognition" of the PD pulse distribution to diagnosis of insulation degradation and assessment of residual life. Experimental results revealed that in spite of large scattering of time to breakdown, i.e. life, from 5 to 43 hours, all the tested samples exhibited similar evolution of the profile of PD pulse occurrence distribution with increasing aging time. The PD pattern measured at a given aging time was compared with five standard normalized PD patterns which had been registered in advance as five representative degradation stages from initial degradation category to final one. The degradation stage determined by the pattern recognition (PR) method proved to vary from the initial degradation category to final one in a correct turn. Consequently, the PR method permitted an exact determination of the degree of degradation at a given aging time. In other words, the PR method was capable of predicting the residual life of LDPE with a CM-II electrode system. (12 Refs)

\section{[95]}

Komori, F.; Nishiguchi, N.; Hikita, M.; Mizutani, T., "Detection of Electrical Tree Initiation and Assessment of Shape of the Developing Tree Using Pattern Recognition of Partial Discharge Occurrence Phase Distribution," Proceedings, International Conference on Partial Discharge, 1993.

Treatment: Experimental (X)

Abstract: We have constructed a PD pulse measurement and degradation diagnosis system (PDM/ES-I) of materials suffering partial discharge using a personal computer. We applied PDM/ES-I to electrical tree degradation in low density polyethylene. The PD pattern measured at a given aging time was compared with five standard normalized PD patterns which had been registered in advance as five representative degradation stages. Consequently, the pattern recognition method proved to allow an exact determination of the time when the tree was initiated. In addition, the result of assessment agreed well with the observed tree shape. (4 Refs) 
[96]

Kong, A.; Lawson, J.; Bristol, R.; Landinger, C., "Evaluation of Field Aged HMWPE Insulated Distribution Cables," Proceedings of the 1991 IEEE Power Engineering Society Transmission and Distribution Conference, 1991.

Treatment: Practical (P); Experimental (X)

Abstract: The evaluation of large quantities of field aged high molecular weight polyethylene (HMWPE) cables removed from the Pacific Gas \& Electric Company system and subjected to extensive electrical and physical testing performed by the Hendrix Wire and Cable Company is described. The electrical tests conducted were AC and DC breakdowns, corona extinction and volume resistivity (VR). The physical tests included semiconducting shield adhesion. Microscopic studies were conducted for semiconducting shield protrusions, void and contamination count, and treeing. The results of the electrical and physical testing are reported. The correlation between $\mathrm{AC}$ breakdown strength (ACBD) and treeing is presented. Discussions also include comparisons of electrical characteristics of cables from wet and dry conduits. The data presented contribute to a better understanding of failure mechanisms and factors affecting cable life. (15 Refs)

[97]

König, G.; Feser, K., "A New Digital Filter to Reduce Periodical Noise in Partial Discharge Measurements," Proceedings, Sixth International Symposium on High Voltage Engineering, 1989.

Treatment: Experimental (X)

Abstract: New filters can be designed due to the progress in digital signal processing. They offer the possibility to deal with all kind of interferences. This paper will introduce an adaptive filter algorithm which automatically recognizes all external periodical interferences and eliminates them. The filtering is done in the frequency domain after a Fast Fourier Transform (FFT). The main advantage of this filter is that it is self adaptive to all periodical disturbances at a measuring location during a calibration procedure. This filter algorithm is applied to partial discharge measurements under On-Site conditions. The results with this new design are shown and compared to measurements with conventional detectors. The filter suppresses all periodical interferences very effectively while maintaining all information to classify the discharges as obtained by a broadband detector. ( 9 Refs)

\section{[98]}

König, G.; Kopf, U.; Feser, K., "Methods to Improve On-site Partial Discharge Measuring Instruments," Proceedings, Seventh International Symposium on High Voltage Engineering, Dresden Univ. Technol, Dresden, Germany, 1991.

Treatment: Theoretical (T); Experimental (X)

Abstract: The faults in power systems can result from the long term ageing of the high voltage insulation of system components. The partial discharge (PD) measurement technique is a very powerful tool to detect even small insulation failures which may cause trouble in the further use of an apparatus. Normally, these measurements are carried out in shielded laboratories at the manufacturers plant to prove the quality of the products. But it is also desired to perform such PD measurements at installed equipment in service, like power transformers, switchgear or cables, to control the quality of the insulation after field assembly or during service. Under these onsite conditions the sensitivity of the PD measurement is reduced by various effects. To detect even small insulation defects in service, interferences above a certain level have to be recognized and afterwards suppressed. The authors describe two possibilities to reduce the influence of these disturbances. Both methods are based on the increased performance in digital signal processing achieved in the last few years. (6 Refs) 
[99]

Kreuger, F.H.; Gulski, E.; Krivda, A., "Classification of Partial Discharges," IEEE Transactions on Electrical Insulation, Vol. 28, No. 6, 1993.

Treatment: Tutorial

Abstract: For a long time, classification of partial discharges was performed by eye, by studying discharge patterns at the ellipse of an oscilloscope screen. The introduction of digital processing techniques allowed automation of the recognition procedure. These procedures are reported and applied to a number of actual HV constructions which suffer from partial discharges. The results of these tests show that a quite satisfactory recognition of discharges takes place. (14 Refs)

[100]

Kreuger, F.H.; From, U., "Time Resolved Measurements of Partial Discharges in Gaseous Voids," Proceedings of Nordic Insulation Symposium. NORD-IS 94, June 1994.

Treatment: Experimental (X)

Abstract: Time resolved measurements of the discharge current at DC have been made on PE samples containing gaseous voids. This enables the study of the discharge mechanism. The discharge mechanism changes after prolonged discharge activity. The registration of the pulse width and pulse height have been used to distinguish between discharges of the 'Townsend-like' type and the 'streamer-like' type. At low test voltages the 'Townsend-like' discharge mechanism has been observed to be dominant. At higher test voltages 'streamer-like' discharges have been observed as well. The transition mechanism requires a different explanation compared to AC voltage. (4 Refs)

\section{[101]}

Krivda, A.; Gulski, E., "Influence of Aging on Classification of Partial Discharges in Cavities," Japanese Journal of Applied Physics, Part 1 (Regular Papers \& Short Notes) Vol. 33, No. 10, October 1994.

Treatment: Experimental (X)

Abstract: In this work the effect of aging on discharge patterns from cavities in polyethylene (PE) is investigated. Two aspects were taken into account-aging due to discharges and the location of the cavity (dielectric or electrode bounded). Discharge patterns were analyzed using a previously developed technique involving statistical parameters. This tool successfully discriminated various aging stages and cavity types. No difference was found between discharge patterns of dielectric- and electrode-bounded cavities in the first minutes from the beginning of measurement. Clear recognition of dielectric- and electrode-bounded cavities in the conditioned and aged stage was achieved. For discharge patterns with asymmetry between the positive and the negative half of the voltage cycle, the ability of statistical parameters to follow changes in the defect location in a test object was proven. (12 Refs) 
Kurrat, M.; Peier, D., "Wideband Measurement of Partial Discharges for Fundamental Diagnostics," Proceedings, Seventh International Symposium on High Voltage Engineering, Dresden Univ. Technol, Dresden, Germany, 1991.

Treatment: Experimental (X)

Abstract: Several measurable quantities are used to study partial discharges (PD), such as apparent charge, PD energy or pulse height and phase angle distributions. These integral quantities give only a little information about the discharge processes. In contrast, the PD current is directly correlated with the charge carrier movement, caused by the discharge processes. Time resolved measurements of the PD current therefore yield information about these processes. The measurement of the original PD current requires special wideband PD test circuits. A measuring circuit with a bandwidth of $1 \mathrm{GHz}$ and a maximum test voltage of $15 \mathrm{kV}$ is presented. Preliminary measured partial discharge currents in gaseous voids in polyethylene are shown and the characteristic time development is discussed. (5 Refs)

$* * * * * * * * * * * * * * * * * * * * * * * * * * * * * * * * * * * * * * * * * * * * * * * * * * * * * * * * * * * * * * * * * * * * * * * * * * * * * * * * * * * * * * * * * * * * * * * * * * * * * * * * *$

[103]

Laghari, J.R.; Sarjeant, W.J., "Energy-storage Pulsed-power Capacitor Technology," IEEE Transactions on Power Electronics, Vol. 7, No. 1, January 1992.

Treatment: Practical (P)

Abstract: Fundamentals of dielectric capacitor technology and multifactor stress aging of all classes of insulating media that form elements of this technology are addressed. The goal is the delineation of failure processes in highly stressed compact capacitors. Factors affecting the complex aging processes such as thermal, electromechanical, and partial discharges are discussed. Diagnostic measurement techniques available and those being developed to determine material degradation affecting available life and failure probability of capacitors are presented. (24 Refs)

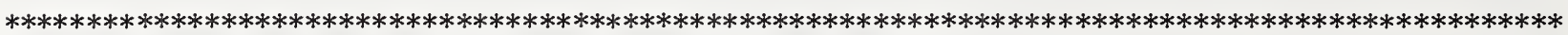
[104]

Laghari, J.R., "Complex Electrical Thermal and Radiation Aging of Dielectric Films," IEEE Transactions of Electrical Insulation, Vol. 28, No. 5, October 1993.

Treatment: Tutorial review

Abstract: A review of the effects of electrical, thermal and radiation stresses, singularly or simultaneously, on dielectric films is carried out. The types of accelerated aging under these stresses and the statistical methods used to evaluate the experimental data for life, including the two-parameter Weibull and the log normal distributions, are described briefly. The experimental life models currently used for aging are discussed. Recent data on the complex electrical/thermal/radiation aging of dielectric films is described. (71 Refs)

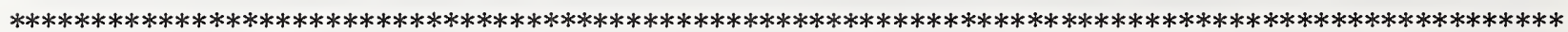

[105]

Lamarre, L.; Morin, R.; Fournier, D., "Partial Discharge Measurements in Underground Distribution Cable Joints," Proceedings of the International Conference on Partial Discharge, IEE, Michael Faraday House, Stevenage, UK, 1993.

Treatment: G; (General Review); T; (Theoretical)

Abstract: PD diagnosis was then the chosen approach to increase the level of confidence regarding work on underground cables and accessories. However, a decision threshold (under which no work should be allowed) remains to be established. This paper reports on a series of accelerated aging tests designed to find an actual value for this threshold; using a portable PD detector developed by our company, workers will be helped in making a decision whether or not to go ahead, by taking into consideration the suggested threshold values found in the lab. (2 Refs) 
[106]

Lasky, J.S.; La Bozetta, R., "EPR Power Cables Rated $105^{\circ} \mathrm{C} / 140^{\circ} \mathrm{C}$," Proceedings, 1993 Rural Electric Power Conference, IEEE, 1993.

Treatment: Experimental (X)

Abstract: A cable insulation system based on EPR insulation and EPR-based semiconductive layers was introduced over 25 years ago. The possibility of raising the rating of this system was evaluated. The results show it is completely justifiable to rate the EPR system at $105^{\circ} \mathrm{C}$ for continuous and $140^{\circ} \mathrm{C}$ for emergency service. Thermal-oxidative aging data are analyzed, and a comparison with older insulations is given. The behavior of power factor and the AC dielectric strength of cable made with this EPR through multiple cycles and after continuous exposure to the elevated temperatures were measured. Comparisons of the resulting data with measurements made at the current $90^{\circ} \mathrm{C} / 130^{\circ} \mathrm{C}$ temperatures are given. The insulation's physical properties after exposure to the proposed higher temperature and the screen resistivities after cyclic and continuous exposure to current and proposed temperatures were measured. Deformation of the EPR versus temperature and measurement of impulse strength after temperature exposures are discussed. Examples of ampacity increases available, suitability of jacketing materials, and moisture resistance of the EPR system are described. (0 Ref)

[107]

Laurent, C.; Mayoux, C., "Partial Discharge - XI. Limitations to PD as a Diagnostic for Deterioration and Remaining Life," IEEE Electrical Insulation Magazine, Vol. 8, No. 2, March-April 1992.

Treatment: Practical (P); Experimental (X)

Abstract: The correlation of partial discharge (PD) measurements with insulation degradation and failure is addressed. The limitations inherent to such diagnostics as applied to solid insulating systems are examined. The discussion is based on simple experimental facts and the physics of discharge within solid dielectrics. It is concluded that meaningful evaluation of PD measurements in terms of the rate of degradation or remaining life is impossible in the absence of a microscopic description of the defect.

(9 Refs)

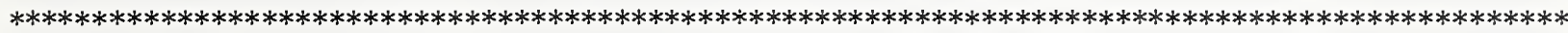

[108]

Laurent, C.; Mayoux, C., "From Initiation to Propagation in Electric Treeing," Proceedings of the IEE International Conference on Partial Discharge, IEE, Michael Faraday House, Stevenage, UK, 1993.

Treatment: G; (General Review); T; (Theoretical)

Abstract: Our aim is to understand the electrical ageing of insulating polymeric materials in the absence of pre-existing gaseous cavities in the bulk of the dielectric. We used a needle electrode molded into the insulant with the aim to produce local field enhancement. The transition between the discharge-free to micro-partial discharge state (early electrical tree propagation phase) is investigated with a sensitivity reaching $0.01 \mathrm{pC}$. Correlation is made between length of tree and amplitude of discharges before any branching of the initial tree channel. The physics of discharge in such small volume is discussed. (6 Refs)

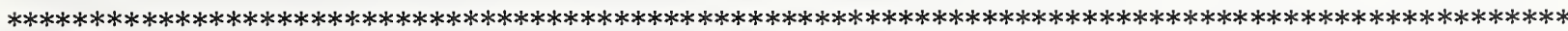

[109]

Lefkowitz, S.; Burnay, S., "A New Approach to Managing Cable Ageing (Nuclear Plants)," Nuclear Engineering International, Vol. 39, No. 485, December 1994.I

Treatment: Practical (P), Experimental (X)

Abstract: Maintenance of the electrical portion of nuclear plants is usually based on the "if it ain't broke, don't fix it" concept. However, there is now the possibility of a new approach using a combination of laboratory-developed life prediction models and in-plant cable condition monitoring. This work discusses cable conditioning monitoring and life modeling. (0 Ref) 
[110]

Leijon, M.; Ming, L.; Bengtsson, T., "PD - Source Identification in Solids," Conference Record of the 1992 IEEE International Symposium on Electrical Insulation.

Treatment: Experimental (X)

Abstract: It is of great importance not only to detect but also to localize and identify the source of partial discharges (PD). If the PD source type can be identified, it is possible to give a more reliable estimate of the potential damage that could be caused. In this paper we present some general arguments for the acoustic mode density in cavities of different dimensionality: flat, hole or spherical. This knowledge may be utilized to identify the shape and size of a discharging cavity in solid insulators using acoustic technique. ( 8 Refs)

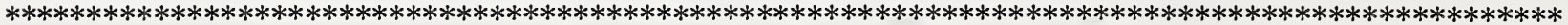

[111]

Lemke, E.; Schmiegel, P., "Analysis of Dielectric Properties on the Basis of a Non-conventional Measuring Procedure," Proceedings, 6th International Conference on Dielectric Materials, Measurements and Applications, IEE, London, UK, 1992.

Treatment: Practical (P); Experimental (X)

Abstract: The authors' work deals with a new procedure for evaluation of the properties of dielectric materials. It is based on a modified bridge circuit for measurement the total charge of partial discharges under AC stresses. In order to apply this method for practical investigations on HV components, a prototype of a dielectric analyzer (DIANA) was developed. Preliminary test results showed that knowledge on dielectric behavior of electrical insulation can be increased essentially by the new method, compared to the classical power loss factor measurement. Because of the time resolved display of the capacitive and resistive voltage vector even nonlinear phenomena may be detected. (4 Refs)

[112]

Lundgaard, L.E., "Partial Discharge - XIV. Acoustic Partial Discharge Detection - Practical Application," IEEE Electrical Insulation Magazine, Vol. 8, No. 5, September-October 1992.

Treatment: Applications (A); Practical (P)

Abstract: The finer points of acoustic partial discharge (PD) detection systems and their common applications are treated. The PD source, propagation path of the waves, the acoustic sensor, and system noise are described. The design of acoustic PD instrumentation, the location of discharges, and the detection and evaluation of signals are discussed. Applications to outdoor insulation, medium-voltage air-insulated switchgear, capacitors, transformers, and cables are covered. (20 Refs)

[113]

MacKinley, R.R., "Partial Discharge Measurements at Low Frequencies on High Voltage Cables in Service Within the UK Utilities," Proceedings, Sixth International Symposium on High Voltage Engineering, 1989. Treatment: Experimental (X)

Abstract: This research program was set up with the idea of determining the useful remaining life of the installed high voltage cables in the UK utilities. Principally the program investigated paper insulated cables up to and including $33 \mathrm{kV}$. However, the methods described here apply equally well to polymeric cables in the same voltage range. Using a simple time of flight technique for detection and location of partial discharges within the cable insulation, a method has been successfully developed which can draw a 'map' of the magnitude and position of the partial discharge activity on an installed cable. (3 Refs) 
[114]

Mammeri, M.; Laurent, C.; Salon, J., "Influence of Space Charge Buildup on the Transition to Electrical Treeing in PE under AC Voltage," IEEE Transactions on Dielectrics and Electrical Insulation, Vol. 2, No. 1, February 1995.

Treatment: Practical (P); Experimental (X)

Abstract: Our investigation is focused on the understanding of electrical aging in polymeric materials under 50 $\mathrm{Hz} \mathrm{AC}$ voltage. In this report, a needle electrode molded into the insulant to simulate defects producing local field enhancement is used. Special emphasis is given to low density polyethylene. The transition between the discharge-free electroluminescent state to micro-partial discharge (PD) state (early electrical tree propagation phase) is studied with a sensitivity reaching $0.01 \mathrm{pC}$. Optical diagnosis is carried out simultaneously. At the moment of tree initiation, electrical discharges from 0.04 to $0.1 \mathrm{pC}$ occur in the positive half cycle. A very small electrical tree of $5 \mu \mathrm{m}$ was observed. Using the phase angle of the first measurable PD with respect to the applied voltage offers additional information helping to understand tree initiation. Then a correlation between the magnitude of electrical discharges and the characteristic traces of local breakdown (electrical tree) is reported. We proposed an interpretation based on the similarity with grounding tree experiments in which the initiation of a local breakdown is mainly due to a strong Poisson field radiated by a space charge region in the vicinity of the needle tip. (12 Refs)

\section{[115]}

Martzloff, F.D.; Simmon, E.; Steiner, J.P.; Van Brunt, R.J., "Detection of Incipient Defects in Cables by Partial Discharge Analysis," NISTIR 4487, 1992.

Treatment: Theoretical (T), Experimental (X)

Abstract: As one of the objectives of a program aimed at assessing test methods for in-situ detection of incipient defects in cables due to aging, a laboratory test system was implemented to demonstrate that the partial discharge analysis method can be successfully applied to low-voltage cables. Previous investigations generally involved cables rated $5 \mathrm{kV}$ or higher, while the objective of this program focused on the lower voltages associated with the safety systems of nuclear power plants. The defect detection system implemented for this project was based on commercially available signal analysis hardware and software packages, customized for the specific purposes of the project. The test specimens included several cables of the type found in nuclear power plants, including artificial defects introduced at various points of the cable. The results indicate that indeed, partial discharge analysis is capable of detecting incipient defects in low-voltage cables. There are, however, some limitations of technical and non-technical nature that need further exploration before this method can be accepted in the industry. (92 Refs)

\section{[116]}

Mashikian, M.S.; Palmieri, F.; Bansal, R.; Northrop, R.B., "Location of Partial Discharges in Shielded Cables in the Presence of High Noise," IEEE Transactions on Electrical Insulation, Vol. 27, No. 1, February 1992. Treatment: Practical (P); Experimental (X)

Abstract: Updated information on a partial discharge location system intended to pinpoint the location of defects and/or faults on a shielded buried underground cable is presented. The system is based on the principle of reflectometry. Its salient characteristics include the following two features: (a) an ability to pinpoint the location of a partial discharge source not only along the cable length, but also along the surface of the trench where it is buried; and (b) the ability to operate in a high noise environment. Recent field and laboratory data obtained on noise and techniques for its mitigation are discussed in some detail. These techniques include analog/digital notch filters for the elimination of AM broadcast noise and an adaptive digital filtering scheme which incorporates the transfer function of the cable for added accuracy. ( 8 Refs) 
[117]

Mason, L.R.; Doyle, T.E.; Reynolds, A.B., "Effect of Antioxidant Concentration and Radiation Dose on Oxidation Induction Time," Proceedings of the 1992 IEEE International Symposium on Electrical Insulation, 1992.

Treatment: Experimental (X)

Abstract: Oxidation induction time (OIT) provides a useful measurement of aging of electrical cable insulation. The technique is being refined for application to $1 \mathrm{E}$ electric cable in nuclear power plants. Exponential correlations have been found for OIT as functions of both radiation dose and antioxidant concentration for ethylene-propylene rubber (EPR) and cross-linked polyethylene (XLPE) cable materials. At constant dose rate, the antioxidant concentration was shown to decrease linearly with time, which is consistent with oxidation reaction kinetics. (7 Refs)

$* * * * * * * * * * * * * * * * * * * * * * * * * * * * * * * * * * * * * * * * * * * * * * * * * * * * * * * * * * * * * * * * * * * * * * * * * * * * * * * * * * * * * * * * * * * * * * * * * * * * * * * * * * * * * * * * * * * * *$

[118]

Mason, L.R.; Doyle, T.E.; Reynolds, A.B., "Oxidation Induction Time Correlations with Radiation Dose and Antioxidant Concentration in EPR and XIPE Polymers," Journal of Applied Polymer Science, Vol. 50 No. 9, December 5, 1993.

Treatment: A; (Applications); X; (Experimental)

Abstract: Oxidation induction time (OIT), as measured by differential scanning calorimetry, is useful in assessing the extent of degradation in polymeric materials. Values of OIT for typical EPR and XLPE polymer insulation materials used for electric cable insulation in nuclear power plants were measured as a function of both radiation dose and antioxidant concentration after accelerated aging. Irradiations were performed at the University of Virginia Cobalt Irradiation Facility. OIT was found to decrease exponentially with increasing radiation dose and with decreasing antioxidant concentration for both ethylene-propylene rubber (EPR) and cross-linked polyethylene (XIPE) insulations. It was determined experimentally that, when polymers are subjected to a constant radiation dose rate, antioxidant concentration decreases linearly with time, and it was shown that this variation is consistent with theoretical autoxidation kinetics. (12 Refs)

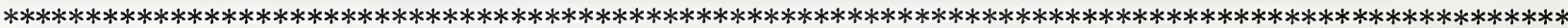

[119]

Mazroua, Amira A.; Salama, M.M.A.; Bartnikas, R. "PD Pattern Recognition with Neural Networks Using the Multilayer Perceptron Technique," IEEE Transactions on Electrical Insulation, Vol. 28, No. 6, December 1993.

Treatment: X; (Experimental)

Abstract: The partial discharge (PD) pattern recognition capability of a neural network, employing the multilayer perceptron technique with data input based on five discharge pulse form parameter, was examined. Simple discharge sources, consisting of artificially created cylindrical cavities with metallic and dielectric electrodes, were employed. The PD pattern discrimination capability was tested using cavities of equal depth but with different electrodes, and cavities of varying depths but with similar electrodes. (21 Refs) 


\section{[120]}

Mazroua, A.A.; Bartnikas, R.; Salama, M.M.A., "Neural Network System Using the Multi-Layer Perceptron Technique for the Recognition of PD Pulse Shapes Due to Cavities and Electrical Trees," IEEE Transactions on Power Delivery, Vol. 10, No. 1, January 1995.

Treatment: Applications (A); Practical (P)

Abstract: A neural network system, utilizing the multi-layer perceptron approach has been applied to distinguish between power cable insulation partial discharge pulse shapes that are characteristic of cavities and electrical trees. The neural network was found to be capable of recognizing the differences in PD pulses produced by single cavity and electrical tree discharge sources. It also could differentiate between the discharge pulse forms emanating from electrical trees of different lengths; likewise, it was able to recognize changes in the shape of the discharge pulses with time due to aging effects. However, as these recognition capabilities relate only to comparisons of single discharge sources on a one-to-one basis, the application of neural networks to PD pulse shape recognition on actual power cables, where a number of different discharge sources may be discharging simultaneously, is quite premature at this time without more detailed exploratory work on complex discharge patterns. (12 Refs)

[121]

Mazzanti, G.; Montanari, G.C.; Simoni, L., "Multistress Endurance Characterization of EPR Cable Models," Conference Record of the 1994 International Symposium on Electrical Insulation.

Treatment: Experimental (X)

Abstract: The results of life tests performed on EPR cable models aged by combined thermal-electrical stresses are reported, showing electrical and thermal life lines, intersections of the life surface with the planes at constant stress. The Combined Analysis Method is used to obtain more information on the behavior of the tested cable in a wide voltage and temperature range. Parameters useful for insulation characterization and cable design are derived. (20 Refs)

[122]

Miri, S.M.; Privette, A., "A Survey of Incipient Fault Detection and Location Techniques for

Extruded Shielded Power Cables," Proceedings of 26th Southeastern Symposium on System Theory, IEEE, 1994.

Treatment: Review

Abstract: The existing techniques for the detection and location of incipient faults (e.g. electrical trees) in extruded shielded power cables are reviewed. Only the techniques developed for field applications are included. The advantages and disadvantages of each technique are evaluated from the point of view of a power engineer. The desired features of an ideal incipient fault detection and location system are identified. Guided by these features, directions for future research in this area are suggested. The authors discuss partial discharge measurement and time-domain reflectometry. (14 Refs) 
[123]

Miri, S.M.; Privette, A., "Electrical Conduction and Breakdown in Heat-resistive Polyparabanic Acid Films," Proceedings of the 4th International Conference on Conduction and Breakdown in Solid Dielectrics, IEEE, 1992.

Treatment: Experimental (X)

Abstract: The characteristics of electrical conduction and electrical breakdown in heat-resistant Polyparabanic Acid (PPA) films were measured, and the correlation between them is discussed. All samples were aged at $453 \mathrm{~K}$ for $12 \mathrm{~h}$. Electric strength was measured with DC and pulse voltages. Aging of samples for the breakdown measurement was the same as for the conduction measurement. Electrical conduction and electrical breakdown of PPA films show a significant dependence on the chemical structure. The results are explained in terms of thermal breakdown due to Joule heating by hopping conduction. (3 Refs)

$* * * * * * * * * * * * * * * * * * * * * * * * * * * * * * * * * * * * * * * * * * * * * * * * * * * * * * * * * * * * * * * * * * * * * * * * * * * * * * * * * * * * * * * * * * * * * * * * * * * * * * * * * * * * * *$

[124]

Mopsik, F.I., "The Use of Time-Domain Dielectric Spectroscopy to Evaluate the Lifetime of Nuclear Power Station Cables," NISTIR 4486, 1992.

Treatment: Experimental (X)

Abstract: None

Reviewer's comments: The reports presents a summary of the Time-Domain Dielectric Spectroscopy (TDS) he developed earlier, together with a general discussion of radiation effects on polymers and the application of TDS to dielectric measurement on aged samples. Test results are given for cable specimens aged in a now decommissioned plant environment, and specimens of a prototype cable aged with heat and with radiation. Effects of the aging process on the bulk properties of the insulation are clearly visible on the plots of dielectric characteristics, but these effects, unless correlated with accepted, conventional methods for assessment of aging with respect to end-of-life condition, cannot by themselves provide an indication of approaching end of life.

[125]

Morshuis, P.H.F.; Kreuger, F.H., "The Spatial Distribution and Electrical Parameters of Partial Discharges in Polyethylene Insulation During Ageing," Proceedings of the 4th International Conference on Conduction. Treatment: Experimental (X)

Abstract: The change of discharge parameters obtained from large bandwidth electrical and optical measurements is related to ageing phenomena in polyethylene voids. Discharge-pulse shape, ignition voltage, and spatial distribution were monitored in disc-shaped polyethylene voids for $100 \mathrm{hrs}$. Optical and electrical results are related to the mechanism of the discharge and the dimensions of the void. Primarily discharge pulse height, discharge pulse width, and discharge repetition rate are important parameters describing the ageing process. These parameters changed drastically during ageing as layers of discharge by-products were deposited on the void surfaces and pits were formed. The creation of pits was linked to the occurrence of a discharge regime with minute pulses of high repetition rate and a decreasing ignition voltage. These minute discharges were therefore regarded as a sign of advanced degradation of the dielectric. (11 Refs) 
[126]

Morshuis, P.H.F., "Time Resolved Discharge Measurements," Proceedings, International Conference on Partial Discharge, 1993.

Treatment: Experimental (X)

Abstract: This paper gives a short introduction in time-resolved discharge measurements and elucidates this detection method with the results obtained from measurements with a $1 \mathrm{GHZ}$ bandwidth on polyethylene samples under prolonged discharge activity. The test samples consisted of three sheets of polyethylene with a hole in the central sheet, thus creating a disc-shaped void. It was found that the shape of the discharge pulses changed significantly after prolonged voltage application (hours). The start of severe degradation can be recognized in the shape of the discharge pulses. (11 Refs)

[127]

Morshuis, P.H.F., "Partial Discharge Mechanisms in Voids Related to Dielectric Degradation," IEE Proceedings Science, Measurement and Technology, Vol. 142, No. 1, January 1995.

Treatment: Practical (P)

Abstract: The usefulness of time-resolved measurements is shown for the study of degradation processes of insulating materials associated with partial discharges. Using an optimized test set-up the different stages in the degradation process can be recognized. The possibilities for using the time-resolved method in practice are discussed. A promising combination of classic and time-resolved measurements is presented and clarified by the first results obtained with the discharge analyzing system TEAS. (12 Refs)

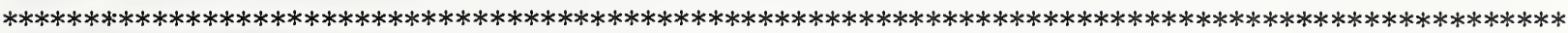

[128]

Motori, A.; Montanari, G.C.; Gubanski, S., "Effect of Temperature and Time on the Dissipation Factor of Power Cable Junctions," Proceedings of the 1993 IEEE Conference on Electrical Insulation and Dielectric Phenomena, IEEE, 1993.

Treatment: X; (Experimental)

Abstract: For the industrial diagnostic methods, it is important to find a physical parameter of an insulating material which could be affected by time and/or temperature - the so called aging effect. It has been observed that the physical and chemical changes caused by time and/or temperature influence the complex permittivity. We have carried out systematic measurements of dielectric constant and dielectric absorption of field assembled power cable junctions aged by temperature cycling over a wide range. We shall report experimental results of dielectric properties for power cable junctions in the frequency range $10^{-4} \mathrm{~Hz}$ to $1 \mathrm{~Hz}$. Evidence of decreasing dissipation factor with time for short aging time and increasing after long aging time is presented. Our results show that the measurement of the dissipation factor and the relaxation frequency in the low frequency region is an useful way to estimate the degradation of the power cable junctions. We intend to discuss theoretical models linking dielectric parameters with physico-chemical and thermal degradation of the power cable junctions. (6 Refs) 
[129]

Motori, A.; Montanari, G.C.; Gubanski, S., "Investigation of Relaxation Processes in Thermally-aged XLPE Cable Models," Proceedings of the 1993 IEEE Conference on Electrical Insulation and Dielectric Phenomena, IEEE, 1993.

Treatment: X; (Experimental)

Abstract: Still of great interest are XIPE that their properties and measurement techniques (which provides aging diagnosis) are investigated. In the paper, the outcome of thermally stimulated discharging currents (TSDC) and DC isothermal charging/discharging currents measurements, implemented on pretreated and thermally-aged cables are introduced and discussed. Specifically, relaxation processes are referred to and connected to the chemical-physical changes caused by aging in the insulation. Results show that correlations between intensity changes and temperatures location of TSDC peaks with aging and the changes of other properties were established. (7 Refs)

$* * * * * * * * * * * * * * * * * * * * * * * * * * * * * * * * * * * * * * * * * * * * * * * * * * * * * * * * * * * * * * * * * * * * * * * * * * * * * * * * * * * * * * * * * * * * * * * * * * * * * * * * *$

[130]

Motori, A.; Sandrolini, F.; Montanari, G.C.; Loggini, M., "Electrical Properties for Detection of Thermal Aging in XLPE Cable Models," Proceedings of the 3rd International Conference on Properties and Applications of Dielectric Materials, IEEE, 1991.

Treatment: Experimental (X)

Abstract: The electrical behavior (DC conductivity and AC properties) of XLPE (cross-linked polyethylene) cable models aged under thermal stress is investigated as a function of aging time. Charging and discharging currents as well as the dielectric constant and loss factor of specimens aged at different times and temperatures were measured from 55 to $90^{\circ} \mathrm{C}$ and $10^{-2}$ to $10^{5} \mathrm{~Hz}$ AC properties. Significant variations of DC conductivity and AC losses with aging time and temperature are pointed out. Cable models thermally aged above $100^{\circ} \mathrm{C}$ revealed a strong increase of DC electrical conductivity with aging time. The same behavior, i.e., increase with aging time at 100 and $130^{\circ} \mathrm{C}$, is exhibited by dielectric constant and loss factor. The observed increase of electrical conductivity and dielectric losses supports the build-up of thermo-oxidative processes in thermally-aged specimens. (11 Refs)

$* * * * * * * * * * * * * * * * * * * * * * * * * * * * * * * * * * * * * * * * * * * * * * * * * * * * * * * * * * * * * * * * * * * * * * * * * * * * * * * * * * * * * * * * * * * * * * * * * * * * * * * * * * *$

[131]

Murata, K.; Yasuda, S., “The Latest Technique of Portable Oil-dissolved Gas Analyzer for

Distribution Oil-immersed Transformer," Transactions of the Institute of Electrical Engineers of Japan, Part B, Vol. 112-B, No. 3, March 1992 (In Japanese).

Treatment: Applications (A); Practical (P)

Abstract: As an advanced diagnosis technology for the oil-immersed transformer, the authors describe the outline of oil-dissolved gas analysis, partial discharge measurement, insulation resistance measurement, dielectric dissipation factor measurement, insulation oil characteristics measurement, and insulating paper deterioration diagnosis. The authors describe the recent trends of portable diagnosis equipment for the distribution oil-immersed transformer, the functions and specifications of the portable analyzer, its configuration and principles, and the precision of its analysis. The authors also refer to applications of the oil-dissolved gas analysis method including abnormality diagnosis and deterioration diagnosis. (6 Refs) 
[132]

Naboka, B.G.; Besprozvannykh, A.V.; Gladchenko, V.Y., "Diagnostics of High-Voltage Insulation Using Multichannel Analyzers," Electrical Technology, No. 2, 1991, UK.

Treatment: Theoretical (T)

Abstract: The pulse characteristics of partial discharges (apparent charge, frequency, average current, etc.) alone do not allow estimation of the quality of high-voltage solid insulation. The authors discuss the role of voids in partial discharges and then discuss methods of diagnosing the results of partial discharge measurements. (6 Refs)

[133]

Nakanishi, Y.; Nakatani, Y.; lizumi, M.; Kasuya, M., "Partial Discharge Detection by AE Sensors for Prefabricated Joints for XLPE Cables," Electrical Engineering in Japan Vol. 113, No. 8, December 1993.

Treatment: Experimental (x)

Abstract: This paper describes detection by the $\mathrm{E}$ (acoustic emission) sensor of partial discharge in a prefabricated joint, one of the accessories for XIPE power cables which is composed of factory-formed parts. Since the prefabricated joints can be installed in a short time, an increasing number of such joints has been used on power transmission lines. However, the interface between the parts of prefabricated joints tends to exhibit weak points because of a structure peculiar to this type of joint. The E sensor is provided for practicability in comparison with conventional electrical defect detection methods. In the course of the present study, a method for locating a defect using multiple signals from the E sensors was developed and its validity was evaluated by the dielectric breakdown test. (7 Refs)

[134]

Nattrass, D.A., "Partial Discharge Measurement and Interpretation," IEEE Electrical Insulation Magazine, Vol. 4, No. 3, May/June 1988.

Treatment: Tutorial

Abstract: None

Reviewer's comments: A 12-page article presenting a review of the interpretation of PD patters as displayed in the elliptical mode, for 11 examples of defects. The dielectric structures investigated are shown as sheets of insulating materials sandwiched between electrodes to illustrate the diagnostic options. No direct application to cable monitoring methods is cited. (49 Refs)

[135]

Nemamcha, M.; Grosse, J.P.; Gosse, B.; Marteau, C., "Monitoring of Partial Discharges in Capacitor Models with Impregnated Polypropylene Films," Proceedings of the 4th International Conference on Conduction and Breakdown in Solid Dielectrics, IEEE, 1992.

Treatment: Experimental (X)

Abstract: Experiments were made using an aromatic hydrocarbon (benzyltoluene) and a saturated hydrocarbon (n-decane) as capacitor impregnant, to compare their behavior in high fields. The results are used to determine the voltage to apply to these impregnated capacitor models during accelerated electrical aging without discharge occurrence. The measurements indicate that, during an aging test at $4.1 \mathrm{kV}$, no discharges occur in the capacitor models until the models broke down. When the test was stopped before breakdown, and the applied voltage on the aged model was slowly raised, the model broke down for 5.5-6 kV; no discharges were detected before that. Thus, evaluation of the discharge threshold voltage shows that, even for low applied voltages without discharges, an aging process exists in impregnated insulation. It can be enhanced by dissolved $\mathrm{O}_{2}$, temperature, and the electric field (up to a very high value), and causes the breakdown of the model. Liquids used for impregnated capacitors are known for their good gas absorbing properties, which can be evaluated using a normalized method (Pirelli test). It is shown that the same liquids have a high threshold voltage for discharge detection. (5 Refs) 


\section{[136]}

Nemeth, E., "Measuring the Voltage Response, a Diagnostic Test Method of Insulating," Proceedings, Seventh International Symposium on High Voltage Engineering, Dresden Univ. Technol., Dresden, Germany, 1991. Treaiment: Experimental (X)

Abstract: A short survey of the principles of diagnostic testing of HV insulations is given. Measuring the voltage response is a relative new diagnostic testing method for $\mathrm{HV}$ insulations. A comparison is made between the new and the older testing methods. Experiences are described, obtained by the new method on diagnostic tests of $10 \mathrm{kV}$ impregnated-paper cable lines and of $6 \mathrm{kV}$ PVC insulated cables. By the new testing method, it is possible not only to select cables with a poor condition of insulation, but to distinguish whether the deterioration of the cable insulation was caused by thermal ageing or by moistening. ( 8 Refs)

$* * * * * * * * * * * * * * * * * * * * * * * * * * * * * * * * * * * * * * * * * * * * * * * * * * * * * * * * * * * * * * * * * * * * * * * * * * * * * * * * * * * * * * * * * * * * * * * * * * * * * * *$

[137]

Nensi, T.; Davies, A.E.; Vaughan, A.S.; Swingler, S.G., "Electrical Ageing of Low-Density Polyethylene Cable Insulation," Proceedings of the 1992 IEEE Conference on Electrical Insulation and Dielectric Phenomena, 1992.

Treatment: $(\mathrm{X})$

Abstract: Low Density Polyethylene (LDPE), in both thermoplastic and cross linked forms is now widely used for the insulation of high voltage cables. These high voltage systems are operated at stresses well below the measured short term electric strength of the polymer so that predicted life expectancy is high. Field data has shown, however, that localized electric breakdowns can occur prematurely with failure times ranging from hours to years. In a survey to elucidate the contributing factors in cable failures Mintz examined 73 cables and concluded that 30 percent of service failures could be assigned to internal defects present in the polyethylene, although the assignment was somewhat arbitrary since the fault area was completely destroyed. The internal defects identified in the vicinity of the failures included voids, contaminants and ambers. The possible importance of internal defects in service failures has led to improvements in manufacturing techniques and quality control to reduce void sizes and levels of contamination. In addition a considerable amount of work has been undertaken to understand the effect of critical voids and metal contaminants on the mechanisms of failure and breakdown strength. In this paper we report the results of an experimental investigation to examine the influence of controlled defects on the long term degradation mechanisms and life expectancy of polyethylene insulation. Spherical conducting heads have been introduced into LDPE samples which have been aged at three different frequencies. Comparisons have also been made with control samples without any conducting beads. (6 Refs)

[138]

Niemeyer, L., "The Physics of Partial Discharges," Proceedings, International Conference on Partial Discharge, 1993.

Treatment: Theoretical (T)

Abstract : Partial Discharges (PD) in insulation systems comprise a large variety of physical phenomena ranging from low level surface emission, over glow discharges, leakage currents along weakly conducting insulator surfaces, sub-critical avalanche activity, electrical tree inception and growth, to streamers, leaders, sparks and arcs. This paper will be restricted to pulsed PD associated with streamers in gases. For this class of discharges, a classification scheme and a generic approach for their physical modeling will be presented and it will be shown, that such models allow to derive relations between measured PD data, defect characteristics, and design and test parameters as important tools for PD interpretation. (15 Refs) 
Nikolopoulos, P.N.; Agoris, D.P.; Sakkas, G.H., "Comparative Consideration of Aging and Breakdown of Pressboard Dielectric Stressed Either by Impulse or by Alternating Voltages under the Influence of Partial Discharges," Proceedings, Seventh International Symposium on High Voltage Engineering, Dresden Univ. Technol., Dresden, Germany, 1991.

Treatment: Experimental (X)

Abstract: The results of comparative investigations on aging and breakdown of pressboard dielectric specimens of $1 \mathrm{~mm}$ and $2 \mathrm{~mm}$ thickness, immersed in transformer oil, when stressed by impulse $1,2 / 50 \mu$ s positive and negative polarity, as well as by alternating $(50 \mathrm{~Hz})$ voltages are presented. Applied voltage values were higher than partial discharge inception voltage. Partial discharge evolution was monitored during impulse and alternating voltage stressing conditions. The life duration of pressboard dielectric when repetitive impulses were applied, as well as when it was stressed by constant value alternating voltages has been measured for various voltage values and relevant curves have been drawn. (6 Refs)

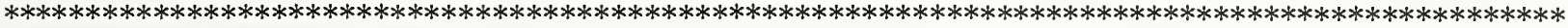

[140]

Noriaki, N.; Komori, F.; Hikita, M.; Mizutani, T., "Detection of Electrical Tree Initiation and Assessment of Shape of the Developing Tree Using Pattern Recognition of Partial Discharge Occurrence Phase Distribution," Transactions of the Institute of Electrical Engineers of Japan, Part A, Vol. 113-A, No. 7, 1993 (In Japanese). Treatment: Practical (P); Experimental (X)

Abstract: We have already constructed a prototype of partial discharge (PD) measurement and degradation diagnosis system (PDM/ES-I) for insulating materials using a personal computer. In this report, we applied PDM/ES-I to electrical tree degradation phenomena; we developed a system to detect when an electrical tree is initiated and to assess the shape of the electrical tree by making use of the so-called Electrical Tree Detection System using Pattern Recognition, which is abbreviated as ETESPAR. We also developed a system to observe the treeing shape; the tree observation system (TOS) consisting of a microscope and an image processor can record temporal change of the shape of tree. Measurements of PD distribution pattern were made. Using ETESPAR, we tried to determine the time of the tree initiation and to assess the developing tree shape for a polyethylene sample with needle vs. plane electrode. The PD pattern measured at a given aging time was compared with five standard normalized PD patterns which had been registered in advance as five representative tree degradation stage. It has been found that ETESPAR allowed an exact determination of time when the tree was initiated. In addition, the result of the assessment by ETESPAR agreed well with the tree shape and degradation stage for the insulating material using pattern recognition of the PD pulse occurrence phase distribution. (10 Refs)

$* * * * * * * * * * * * * * * * * * * * * * * * * * * * * * * * * * * * * * * * * * * * * * * * * * * * * * * * * * * * * * * * * * * * * * * * * * * * * * * * * * * * * * * * * * * * * * * * * * * * * * * * * * * * * * *$ [141]

Oda, T.; Wang, S.-N.; Maruyama, Y.; Ichiyanagi, N.; Tanaka, H., "Thermally Stimulated Discharge Current Observation of Cross-linked Polyethylene," Proceedings of the 3rd International Conference on Properties and Applications of Dielectric Materials, Vol. 1, IEEE, 1991.

Treatment: Experimental (X)

Abstract: As cross-linked polyethylene (XLPE) is the most typical and suitable insulating material for electric power cables, various studies on its physical properties have been reported where a thermally stimulated discharge current (TSDC) observation method was found to be very effective for understanding chemical contamination and structural change, such as additive effects and $\mathrm{X}$-ray radiation damage. The authors observed such TSDC of charged XIPE films or an actual power cable from room temperature (about $20^{\circ} \mathrm{C}$ ) to $100^{\circ} \mathrm{C}$ to understand the $\mathrm{AC}$ stressing effect. Corona charging and typical $\mathrm{DC}$ field charging in hot air, $\mathrm{SF}_{6}$, or oil were tested to make charged samples. In gas, the degradation effects caused by AC stressing were identified by the TSDC as a heterocurrent peak shift from 60 to $80^{\circ} \mathrm{C}$. However, in the oil test, the annealing effect is found to be dominant for the TSDC and a pure field stressing effect is not recognized. (2 Refs) 
[142]

Ohno, H.; Katsuta, G.; Sakaguchi, R.; Ebinuma, Y.; Sasaki, N.; Nagaoka, A., "Development of Partial Discharge Location Method of Power Cable," Transactions of the Institute of Electrical Engineers of Japan, Part B, Vol. 112-B, No. 8, 1992 (In Japanese). Also, in English, in Electrical Engineering in Japan, Vol. 113, No. 8, December 1993.

Treatment: Practical (P)

Abstract: Insulation deterioration of a power cable can be measured by the method of partial discharge. If a large partial discharge is detected in a cable, the cable is concluded to be defective and the partial discharge is located to find the position of the defect. However, partial discharge location methods have the disadvantages that they require much skill for their operation and are inferior with regard to sensitivity and accuracy. To solve these problems, the authors have developed a locating method using a two-phase cable and an automatic partial discharge locator which automatically localizes the generating site of the discharge immediately after making partial discharge measurements. They have made field measurements on separately lead-covered cables and other cables with this locator in order to test its accuracy and reliability, and the device was found to be both effective and useful. (8 Refs)

$* * * * * * * * * * * * * * * * * * * * * * * * * * * * * * * * * * * * * * * * * * * * * * * * * * * * * * * * * * * * * * * * * * * * * * * * * * * * * * * * * * * * * * * * * * * * * * * * * * * * * * * * * *$

[143]

Ohno, M.; Yoshida, S.; Takehana, H.; Tan, M.; Fukunaga, K., "Measurement of Partial Discharge on Live Power Cables Using a High Frequency Component Detection Method Partial Discharge Sensor for Live Power Cable Systems," Fujikura Technical Review, No. 21, January 1992.

Treatment: Practical (P)

Abstract: Partial discharge (PD) detection on live power cables and accessories is one of the most important techniques for monitoring cable systems against serious damage caused by slight inaccuracies in jointing the cables. This new partial discharge detection method uses a high-pass filtering sensor attached to the PVC cable jacket at the end of a joint. The sensor picks up the 30 to $60 \mathrm{MHZ}$ (noiseless area) component of PD pulses on the surface of live cables. This method was applied to initial AC breakdown tests of practical joints. PD pulses were clearly detected, and extremely large signals were observed just before the breakdown in all tests. (11 Refs)

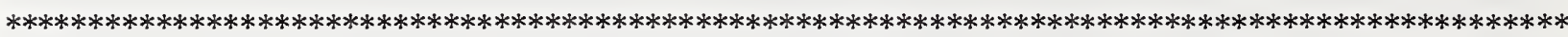

[144]

Okamoto, T.; Tanaka, T., "Partial Discharge Pattern Recognition for Three Kinds of Model Electrodes with a Neural Network," Proceedings, International Conference on Partial Discharge, 1993.

Treatment: Experimental (X)

Abstract: Partial Discharge (PD) signals have been studied for a long time as one of the significant high voltage test parameters and therefore many research works have been done on the sophistication of the PD measurements and data processing methods. PD characteristics can be derived from pulse data through statistical treatment of the data. With the aids of computer measurement systems, the $\phi-q$ distribution characteristics and the $\phi-q-n$ distribution characteristics have been proposed. Those characteristics ass the voltage phase angle information to the conventional PD measurements. This paper describes PD data processing as input signal for the neural network and the capability of the neural network system to recognize PD signals using four kinds of electrode systems. (9 Refs) 
[145]

Osvath, P.; Zahn, H., "Evaluation and Location of Partial Discharge in Plastic-Insulated High Voltage Cables," Proceedings, CABLEWIRE - 91. 3rd International Seminar on Cables, Conductors and Winding Wires, 1991, Indian Electr. Electron. Manuf. Assoc, Bombay, India.

Treatment: Experimental (X)

Abstract: High operational safety and a long service life, which are synonymous with high dielectric strength allied to moderate ageing ('strength consumption'), are ultimately the most important quality criteria of a high-voltage cable. International quality assurance standards amply cover the combination of partial discharge and voltage withstand tests, which is specified as a highly informative nondestructive specimen test procedure. Here, the authors describe how, for quality assurance, and especially for freshly manufactured high-polymer insulated HV cables, the detection and location of partial discharge (PD) are essential, for which purpose only sufficiently sensitive PD measurement at background noise levels below $2.5 \mathrm{pC}$ can adequately meet the special requirements for plastic-insulated cables. (12 Refs)

[146]

Pfeiffer, W., "Partial-discharge Testing of Components for Low-voltage Equipment," IEEE Transactions on Electrical Insulation, Vol. 26, No. 2, 1991.

Treatment: Practical (P); Experimental (X)

Abstract: The present test methods and requirements for solid insulation are discussed. It is demonstrated, that those tests and thickness requirements cannot guarantee safe performance of solid insulation throughout the whole equipment life. Moreover, such tests may cause severe damage is applied as a sampling or a routine test. As a replacement, the partial discharge test is proposed. Its applications for testing of transformers, optocouplers, coatings and similar arrangements is demonstrated. It is shown that this test method in combination with conditioning is appropriate for nondestructive testing of solid insulation. (21 Refs)

[147]

Phung, B. T.; Blackburn, T. R.; James, R. E., "Use of Artificial Neural Networks in Discriminating Partial Discharge Patterns," Proceedings, Sixth International Conference on Dielectric Materials, Measurements and Applications, IEE, Michael Faraday House, Stevenage, UK, 1992.

Treatment: A; (Applications); X; (Experimental); N; (Numeric/Statistical)

Abstract: Application of digital methods in partial discharge (PD) measurements and analysis has become one of the most active research areas in insulation diagnostics. The concept involves the quantization and recording of basic discharge parameters associated with each individual PD pulse. This study has provided some useful insights into the practical implementation of ANNs to discriminate the partial discharge patterns. Experimental results indicated a high degree of success in classifying patterns generated by the presence of artificial voids in solid insulation. Correct discrimination was achieved in spite of the low resolution in the input patterns. The use of the CDA measurement system together with more efficient training laws enables fast response which is necessary for practical applications. (9 Refs) 
[148]

Pietsch, R., "Integral and Spectral Investigations of Luminescence Light During Electrical Aging in Polyethylene," Proceedings, Seventh International Symposium on High Voltage Engineering, Dresden Univ. Technol., Dresden, Germany, 1991.

Treatment: Experimental (X)

Abstract: An extended optical and electrical measurement system for the investigation of electrical aging processes in polymers under high AC stress is presented to study the electroluminescence (EL) and partial discharge (PD) effects in normal and degassed samples in a needle-plane arrangement. The light is detected simultaneously with a very sensitive photomultiplier tube (PMT) and a grating spectrograph (SP). General aspects and sensitive phase analysis of the EL light, dependent on the applied voltage and specimen temperature, is presented. Variations of the needle tip radius demonstrate the influence on the inception voltage both for EL and PD effects. Within a restricted voltage interval the light intensity as function of the voltage could be explained with Fowler-Nordheim injection. First results gained with the SP during measurable PD show that the light intensity as a function of the applied voltage changes with the wavelength. (9 Refs)

\section{[149]}

Qi, Z.N.; Wan, Z.H.; Chen, Y.P., "A Comparative DSC Method for Physical Aging Measurement of Polymers," Polymer Testing, Vol. 12, No. 2, UK, 1993.

Treatment: Experimental (X)

Abstract: A method of comparative DSC is proposed for the study of physical aging. The essentials of the comparative DSC technique consists of comparing the entalpy relaxation behavior of an aged sample with a quenched sample as reference. The accuracy of comparison is improved because of simultaneous measurement of the sample and reference which makes the noise of the apparatus subtractive. This technique has been applied to study the influence of cross linking on the kinetics of entalpy relaxation of epoxy resins. (8 Refs)

$[150]$

Ramsey, N.W., "The Influence of Manufacture on Post-irradiation Thermally Stimulated Conductivity in Polyethylene, Proceedings of IEEE Conference on Electrical Insulation and Dielectric Phenomena, 1992. Treatment: Experimental (X)

Abstract: It is pointed out that the significance of thermally stimulated conductivity in polyethylene following its exposure to directly or indirectly ionizing radiation is that it can be measured and related to the amount of energy absorbed by the polyethylene from the radiation. Measurement of the apparent increase in conductivity is straightforward. Following exposure to radiation, raising the temperature will produce an immediate increase in current flowing through a specimen and the current will shortly fall to the value it had before irradiation. In an attempt to investigate how the manufacturing process might influence the properties of a material, a selection of eight Sclair resins designed for rotomolding were obtained. Variations in crystallinity and the presence of additives, which are used to prevent oxidation and UV-induced deterioration, are assumed to be important factors in affecting the desired behavior. (5 Refs) 
[151]

Reynolds, P.R., "A Review of the Current Status of Partial Discharge Studies, Proceedings, Sixth International Symposium on High Voltage Engineering, 1989.

Treatment: Tutorial review

Reviewer's comment: The author's concluding remark reads: "One obvious trend is the continuation of the use of measurement systems based on fast analog-to-digital converters and digital processing. These will permit the on-line use of increasingly sophisticated software to improve signal-to-noise ratios, recognize patterns and provide expert assistance. However, for those methods to become fully effective we need computing devices which will operate at very high speed and provide mass storage, all at economic prices. Once such devices are available the resonant-coupled type of detector, which has dominated partial discharge detection from the 1930's until the present, will finally become obsolete". The paper is a general review, outdated in 1995 but showing historical perspective. (0 Ref)

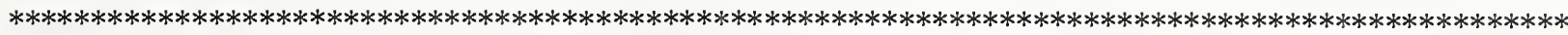

[152]

Robinson, G., "Low-frequency Loss Spectra and Ageing in Paper-Insulated Cables," Proceedings, Third International Conference on Power Cables and Accessories, IEE, London, UK, 1993.

Treatment: Experimental (X)

Abstract: This paper is concerned with a method for the assessment of degradation in underground paper-insulated power cables. One advantage of the proposed method is that less energy, and so lighter equipment, is needed to produce a transient than to sustain an alternating current in a long buried cable. Another is that the intrinsic loss at working voltage is derived independently of partial discharge activity (this is recorded and analyzed more effectively by separate pulse counting methods). And finally, the measurement yields a spectrum of loss values over a broad frequency range, which affords more physical insight than a single-frequency measurement. The purpose of the present work is to develop the method for use with $11 \mathrm{kV}$ and $33 \mathrm{kV}$ cables, and to demonstrate the enhanced value of the low frequency spectrum in assessing ageing. (4 Refs)

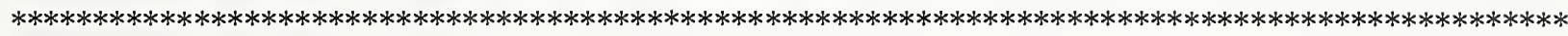

[153]

Ryder, D.M., "Interpretation of Partial Electrical Discharge Measurements with Insulation Damage and Ageing," Proceedings of the 1993 IEEE Conference on Electrical Insulation and Dielectric Phenomena, 1992.

Treatment: Tutorial, Experimental (X)

Abstract: Partial discharge measurements can be related to aging and dielectric damage in a research environment but can be very difficult to interpret in service on complicated structures. The research information that can be passed on to the engineer cannot be definitive and therefore, must be used in combination with experience, a knowledge of the materials used, and the characteristics of the measuring instruments. It is unlikely that any one measurement technique will be adequate and in anything other than very simple configurations, the ability to predict the remaining life is extremely difficult. This paper presents evidence of various stages of solid dielectric deterioration and the effect of these processes on the partial discharge measurements. The processes that can cause confusion in the interpretation of results are identified and an engineering option is proposed. (5 Refs) 
Satish, L.; Gururaj, B.I., "Use of Markov Models for Partial Discharge Recognition," IEEE Transactions on Electrical Insulation, Vol. 28, No. 2, April 1993.

Treatment: Theoretical (T), Tutorial

Abstract: The importance of partial discharge (PD) measurements for diagnosis of defects in insulation systems is well known. The image patterns obtained in these measurements contain features whose analysis leads to identification of the PD cause. These features are the phase position and amplitudes of PD pulses appearing on the image pattern (usually displayed on elliptic time base on conventional detectors). There is a close similarity between PD signals and speech. Both are time-varying and similar in behavior. Hidden Markov models (HMM) have been very successful in modeling and recognizing speech. Hence, an attempt was made to employ them to classify PD image patterns. Basis for selection of model and training parameters and the obtained results are discussed. It is shown that successful recognition of PD image patterns using HMM is possible. The ability of HMM to classify some actual PD image patterns has also been ascertained. (13 Refs)

\section{[155]}

Schichler, U.; Borsi, H.; Gockenbach, E., "Problems and New solutions for Partial Discharge Measurement on High Voltage Cables under Noisy Conditions," Conference Record of the 1994 International Symposium on Electrical Insulation.

Treatment: Experimental (X)

Abstract: This paper reports about problems and new solutions concerning partial discharge (PD) measurement on high voltage cables under noisy conditions. In addition to the problems of PD measurement on high voltage cables in laboratories there are many problems for on-site PPD measurement caused by ambient noises. Some suitable solutions according to these problems are introduced. The decoupling of the measuring signal is realized successfully with a Rogowski coil and a special cylindrical voltage sensor. A personal computer receives the digitized measuring signal and enables a digital signal processing. The necessary noise rejection is accomplished by well matched analog course filters and digital filter algorithms, which suppress continuous noise signals. Experimental investigations carried out in the laboratory and on a layer cable track show us the effectiveness of the presented PD measuring system under noisy conditions. (11 Refs)

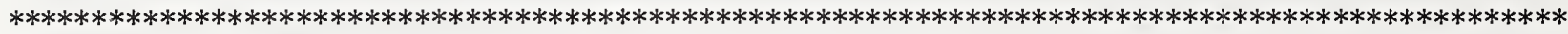

[156]

Schnettler, A.; Peier, D., "A New Computer-aided Partial Discharge (PD) Measuring System for Dielectric Diagnosis," Proceedings, Seventh International Symposium on High Voltage Engineering, Dresden Univ. Technol., Dresden, Germany, 1991.

Treatment: Practical (P); Product Review (R)

Abstract: For dielectric diagnosis of high voltage apparatus, a computer-aided partial discharge (PD) measuring instrument is developed. By connection with a personal computer, this system allows one to monitor the PD activity of a test device. In particular, the system records the apparent pulse charge $q_{a}$, the PD polarity and either the PD frequency in dependence on the phase angle of the alternating voltage and the pulse height or the PD pulse distance during the test cycles. The obtained PD can be shown both as a three dimensional diagram including PD quantity, phase angle, and pulse height and as several two dimensional graphs. In first attempts both in online PD measurements and in PD monitoring, the efficiency of this instrument was demonstrated. The authors deal with the development of the computer-aided PD measuring instrument DIGITEM. Both the hardware and software configuration are described. Subsequently first trials are presented and results discussed with regard to dielectric diagnosis. ( 9 Refs) 
[157]

Shalimov, V.V.; Bespalova, E.B.; Zorin, G.A.; Kandibolotskaya, T.B., "Stability of Layered Materials Against Electric Discharges," Zhurnal Tekhnicheskoi Fiziki Vol. 63, No. 9, 1993. Translated in: Technical Physics, Vol. 38, 1993.

Treatment: Theoretical (T)

Abstract: The use of thin-film plastic composite materials for forming systems for insulating electric machines requires that their radiation resistance and ability to function under electric discharge conditions be improved. The production of thin-film electrically insulating materials with satisfactory characteristics that ultimately provide reliable operation of power equipment requires a detailed study of the physical and chemical processes that degrade the properties of these materials during long-term operation of electrical machines, control of these aging processes by the proper selection of the components of composite materials with the required characteristics, and the development of the optimum construction technology. The destructive action on dielectrics due to atmospheric discharges, including partial discharges, is due to combined action on the surface layer of the insulating material by electron and ion bombardment, thermal shock, ultraviolet radiation, and chemical products of the gas discharge. These factors are also largely responsible for the erosional destruction of the dielectric itself; for polymer materials the time required for their destruction is determined by the intensity of the partial discharges and inversely proportional of the average current. Data on the rates of destruction of thin film materials by electrical discharges make it possible to classify these materials according to their stability against gas discharge. The authors studied the rate of erosion of thin film materials (polyimides, layered polyimide-fluoroplastics, polyimides with $\mathrm{SiO}_{2}$ layers, polyethylene terephtalate) by atmospheric discharge. (11 Refs)

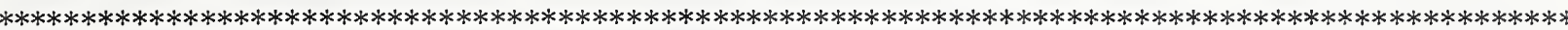
[158]

Shawn Addington, J.; Ellis, E.; Elshabini-Riad, A.; Su, W.; Riad, S.M., "Environmental and Lifetime Testing of Low-loss Dielectric Materials at Low Frequencies," Proceedings of the 1992 International Symposium on Microelectronics (SPIE Vol. 1847), Int. Soc. Hybrid Microelectron, Reston, VA, 1992.

Treatment: Experimental (X)

Abstract: The objective of this paper is to study the effects of operating temperature, relative humidity, and aging, on the complex dielectric constant of low-loss dielectric materials at low frequencies (100 kHz and $1 \mathrm{MHZ}$ ). The materials include a polymer (Pyralux), and a low temperature co-fireable tape ceramic (LTCC) material (Green Tape). The results indicate that both the dielectric constant and the dissipation factor of the polymer increase upon an increase in the temperature, as well as the humidity. Results for the tape ceramic indicate a similar trend with respect to temperature, but show a decrease in the values upon an increase in the humidity. In order to determine the effects of aging on the complex dielectric constant of these materials, additional polymer and tape ceramic laminates were evaluated after natural aging (through storage in a desiccant chamber under vacuum) and forced aging (through thermal cycling). These results indicate that the dielectric constant and dissipation factor are increasing over time for the polymer, and decreasing over time for the tape ceramic. Finally, results of some high frequency electrical characterization (up to $10 \mathrm{GHZ}$ ) are also presented. (5 Refs) 
[159]

Shihab, S.; Moorty, S.; Cheng, X.; Rao, V., "Partial Discharge Measuring System for On-Line Condition Monitoring of High Voltage Equipment," Proceedings of the 1992 IEEE Conference on Electrical Insulation and Dielectric Phenomena, 1992.

Treatment: $(\mathrm{X})$

Abstract: Partial Discharges (PD) can occur in any insulation used in high voltage power equipment. The sites where PD occur may deteriorate with time and eventually the total failure of equipment may take place. Many techniques have been developed for PD measurement and detection. However most conventional PD detectors used today have several limitations when it comes to on-line/on-site monitoring. At the Royal Melbourne Institute of Technology, a PD measuring and monitoring system utilizing current transducers based on the Rogowski-coil principle and a fast digitizer has been developed. This system does not make use of the conventional PD detector techniques. The sensors are non-intrusive and superior to the conventional PD detector methods. The PD measurement system is suitable for on-line/on-site monitoring. This paper details the development of the sensor and the PD investigation using this PD measurement system. (3 Refs)

$* * * * * * * * * * * * * * * * * * * * * * * * * * * * * * * * * * * * * * * * * * * * * * * * * * * * * * * * * * * * * * * * * * * * * * * * * * * * * * * * * * * * * * * * * * * * * * * * * * * * * * * *$ [160]

Shobha, R.; Nema, R.S., "Internal Partial Discharge and Breakdown Characteristics of Thin Polypropylene Films," Proceedings of the 1993 IEEE Conference on Electrical Insulation and Dielectric Phenomena, 1992. Treatment: X; (Experimental)

Abstract: Partial discharges (PD) cause failure of polypropylene (PP) film high voltage capacitors. Usually, they occur in cavities or gas pockets and these may be reduced in sizes as a result of system impregnation done in low pressures. In the study, the effect of cavity dimensions with diameters of $0.9 \mathrm{~mm}$ to $3.2 \mathrm{~mm}$ and depth of $40 \mu \mathrm{m}$ to $200 \mu \mathrm{m}$ on the various PD characteristics and related breakdown of thin PP films are analyzed. (4 Refs)

$* * * * * * * * * * * * * * * * * * * * * * * * * * * * * * * * * * * * * * * * * * * * * * * * * * * * * * * * * * * * * * * * * * * * * * * * * * * * * * * * * * * * * * * * * * * * * * * * * * * * * * * *$

[161]

Sigmond, R.S., "Fast Image Converter and Slow Computer Simulation Studies of Partial Discharge Models," Proceedings, International Conference on Partial Discharge, 1993.

Treatment: Experimental (X)

Abstract: The paper discusses some results obtained by nanosecond electrical and optical measurements on a physical model of a PD void, and demonstrates the use of a simple circuit simulation program to interpret PD pulse measurements on a $50 \mathrm{~Hz}$ time scale. The physical model is a sandwich of three foils of polypropylene. A computer simulation as two random-breakdown capacitors gave a realistic rendering of the observed PD distribution in phase and its change with void surface wear. (4 Refs)

$* * * * * * * * * * * * * * * * * * * * * * * * * * * * * * * * * * * * * * * * * * * * * * * * * * * * * * * * * * * * * * * * * * * * * * * * * * * * * * * * * * * * * * * * * * * * * * * * * * * * * *$

[162]

Sigmond, R.S.; Sigmond, T.; Goldman, A.; Goldman, M., "On the Role of Water in the Aging of Polymers in Air-insulated Electrical Systems," IEEE Transactions on Electrical Insulation, Vol. 26, No. 4, 1990.

Treatment: Theoretical (T); Experimental (X)

Abstract: The direct interaction between coronas and insulating surfaces is examined, including the generation of water by corona oxidation of the polymer. The authors then report on recent measurements of indirect corona/polymer interaction, by corona exposure of distilled water with submerged polymer samples. It is shown that corona discharges in ambient air will form a water layer on any exposed polymer surface, both by bringing water to the surface made hydrophilic by the corona and by producing water from the polymer itself, by oxidation. Water exposed to air coronas becomes acid and oxidizing, and causes marked aging effects on polymer surfaces. Thus, any model of the action of air corona discharges on polymer surfaces must include the presence and effects of an intermediary aqueous electrolyte surface layer. (11 Refs) 


\section{[163]}

Steiner, J. P., "Partial Discharge - Part IV: Commercial PD Testing," IEEE Electrical Insulation Magazine, Vol. 7, No. 1, January/February 1991

Treatment: Tutorial

Abstract: PD measurements for quality assurance require not only a detector, but an entire system coordinated to maximize the measurement sensitivity for the specific type of apparatus under test. Commercially available PD detectors are described here, along with their important characteristics. Ancillary test components, which complete an integrated test system, are discussed. Finally, examples are provided on some commercial applications. (20 Refs)

[164]

Steiner, J.P.; Ward, B.H., "Partial Discharge Measurements and Pulsed Resonant Wave Excitation," Conference Record of the 1992 IEEE International Symposium on Electrical Insulation, 1992.

Treatment: Practical (P); Experimental (X)

Abstract: A transient technique, referred to as the pulsed resonant wave technique, for in situ testing of extruded polymeric cable is discussed. A small, cost-effective power supply is used for energizing large capacitance specimens. This power supply has many of the benefits of testing at power line frequencies and none of the drawbacks of the other current methods, which are discussed for comparison. A digital noise reduction technique that mitigates the effects of interference is also used. (15 Refs)

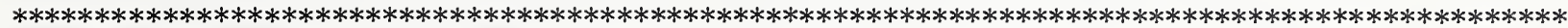

[165]

Stone, G.C.; Kuffel, J., "Digital Recording Techniques for Electrical Insulation Measurements," IEEE Electrical Insulation Magazine, Vol. 5, No. 3, May/June 1989.

Treatment: Tutorial

Author's Abstract: None

Reviewer's comments: An 8-page review article discussing the challenges and future of electrical insulation measurements from the point of view of selection of instrumentation. Offers an interesting historical perspective but no specific information applicable to cable condition monitoring methods. (9 Refs)

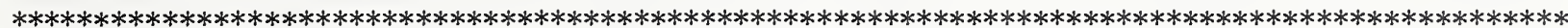

[166]

Stone, G.C., "Partial Discharge. VII. Practical Techniques for Measuring PD in Operating Equipment," IEEE Electrical Insulation Magazine, Vol. 7, No. 4, July-August 1991.

Treatment: Practical (P); Experimental (X)

Abstract: Online partial-discharge (PD) tests for monitoring the condition of the solid dielectric insulation in high-voltage equipment are discussed. Sources of external electrical noise are identified, as are attributes of PD and noise that are helpful in drawing distinctions between them. Methods for distinguishing between PD and noise are described. They are based on pattern recognition, time and frequency domain characteristics, or pulse time-of-flight analysis. Several on-line PD measuring systems for rotating machines, substation equipment, and high-voltage cables are presented. (38 Refs) 
Strobel; J. M.; Lyons, C. S., "Aging of Corona-treated Polypropylene Film," Proceedings, 49th Annual Technical Conference - ANTEC '91 In Search of Excellence Annual Technical Conference, Soc. of Plastics Engineers, Brookfield, CT, 1991.

Treatment: X; (Experimental)

Abstract: A discussion is presented of the aging of corona-treated polypropylene. It is shown that corona-treated PP has many functionalities available for specific interactions, while unmodified PP is relatively inert. There is no real mechanism for interaction between the highly polar corona- oxidized materials and the highly non-polar bulk PP regions. Hence, the corona-oxidized materials may simply lie atop the bulk PP. Although not thermodynamically stable, the LMWOM and underlying oxidized PP may simply lack a mechanism for significantly lowering surface energy. ESCA results do not show changes in surface chemical composition as a function of aging for any corona-treated PP. The minimal changes observed in the wettability of aged, corona-treated PP are probably due to reorientation of oxidized functionalities within the ESCA sampling depth of ca. 2-5 nm. (2 Refs)

[168]

Su, Q., "An Adaptive Filtering Method for Noise Suppression in Partial Discharge Measurements," Proceedings of the 1993 IEEE Conference on Electrical Insulation and Dielectric Phenomena, 1993.

Treatment: Theoretical (T), Experimental (X)

Abstract: The proposed adaptive filtering method, using the terminal calibration pulse as a reference signal, is capable of suppressing both periodic and random noises in partial discharge (PD) measurements. Coherence between calibration and PD pulses has been confirmed by theoretical analysis and laboratory tests. Signal distortion of the adaptive filter is minimized, which is significant for PD locations on the HV equipment with winding structures.

$* * * * * * * * * * * * * * * * * * * * * * * * * * * * * * * * * * * * * * * * * * * * * * * * * * * * * * * * * * * * * * * * * * * * * * * * * * * * * * * * * * * * * * * * * * * * * * * * * * * * * * *$ $\{169\}$

Suh, K.S.; Cooke, C.M., "Electrical Damage of Metallized Film Capacitors," Transactions of the Korean Institute of Electrical Engineers, Vol. 40, No. 6, 1991.

Treatment: Experimental (X)

Abstract: Damage in film capacitors has been investigated, using FTIR and ESCA, aiming to elucidate the nature of electrode removal and the possibility of base films being damaged. Tests were conducted to investigate the effect of long-term thermal aging at elevated temperatures. Unsuccessful clearing or grape-clustering processes can induce long-term degradation which involves chemical and morphological changes. Major changes are oxidation and decrease in surface crystallinity possibly arising from the corona discharge. An immediate deterioration of biaxially oriented polypropylene film (BOPP) may occur when air trapped between the film layers induces an extensive autocatalytic oxidative degradation. This type of immediate damage may result in premature failure at an early stage of qualification test. A permanent removal of electrode materials was observed in the main erosion area. (13 Refs) 
[170]

Tanaka, H.; Ichiyanagi, N.; Iwata, Z., "A Study on Breakdown Phenomena in XLPE Power Cable," Proceedings of the 1992 IEEE Conference on Electrical Insulation and Dielectric Phenomena, 1992.

Treatment: $(\mathrm{X})$

Abstract: In recent years, XLPE cables have been widely introduced, and remarkable progress has been achieved in this area; at present, research is underway with the objective of utilizing long-distance XLPE cables in the $500 \mathrm{kV}$ class. In this context, the factors exerting adverse effects upon insulation breakdown must be elucidated in order to further improve the reliability of cables. In order to clarify the breakdown factors involved in $\mathrm{AC}$ and lightning impulse voltages, the authors have developed Pre-breakdown Detection Method as well as tests for application of these techniques, and have discovered a number of interesting facts concerning the factors determining the insulation breakdown of XLPE cables, which are described in further detail. (8 Refs)

[171]

Tanaka, T.; Okamoto, T.; Nakanishi, K.; Miyamoto, T., "Aging and Related Phenomena in Modern Electric Power Systems," IEEE Transactions on Electrical Insulation, Vol. 28, No. 5, 1993.

Treatment: Bibliography (B); General, Review (G); Practical (P)

Abstract: Recent progress in the research and development of electrical insulation for modern electric power systems is reviewed. Cross-linked polyethylene cables, gas-insulated switchgear, composite insulators and oil-immersed transformers are covered. A number of aging processes are presented and analyzed. Typical aging processes are considered to be due to tree formation, partial discharge, electrochemical processes and thermochemical processes. Almost all causes of aging have been itemized and have been phenomenologically verified. Several other theoretical aspects that need to be clarified are identified. (89 Refs)

[172]

Tanaka, T., "Partial discharge pulse distribution pattern," IEE Proceedings Science, Measurement and Technology, Vol. 142, No. 1, January 1995.

Treatment: Theoretical (T)

Abstract: Statistical data analysis has been recently requisite for partial discharge (PD) study. This has been enabled by the recent development of microprocessors or the downsizing of computers. It is important to pay more attention to profiles of a packet of PD pulses on the voltage phase angle. Statistical parameters such as skewness and kurtosis have been intensively investigated for PD analysis. More recently, the neural network algorithm has been utilized especially to discriminate PD signals from noise signals for insulation diagnosis. (8 Refs) 
[173]

Tsutsumi, Y.; Yonekura, T.; Kikuchi, T., "Cluster Pulse Criteria for Recognition of Partial Discharge," Electrical Engineering in Japan, Vol. 113, No. 7, December 1993.

Treatment: Theoretical (T); Experimental (X)

Abstract: Statistical calculating programs simulating cable insulation partial discharge appearance are developed and applied to evaluations of criteria for discrimination of the partial discharges from noise. According to the simulation, clusters of sequential pulses appear at the partial discharge inception voltage, and have never been utilized at the usual pattern recognition of the partial discharges. Two original indexes that are a pair pulse rate and a maximum sequential pulse rate are defined to describe the time sequential features of the partial discharge and their signal distinguishable capabilities from noise are evaluated. A new logical index describing the signal distinguishable capability of the usual phi -q pattern of the partial discharges from noise also is proposed and compared with those of cluster pulses. The maximum sequential pulse rate gives most sensitive criteria in the bounds of calculating conditions. A $66 \mathrm{kV}$ cross-linked polyethylene power cable with an artificial defect is used to detect cluster pulses. By adding twice as many noise pulses as measured partial discharge pulses, the usual phi -q pattern criteria becomes powerless, but cluster pulse criteria are still informative for the recognition of the partial discharges. (17 Refs)

\section{[174]}

Unsworth, J.; Li, Y.; Gao, B., "Dynamic Mechanical Thermal Analysis and Dielectric Studies of Physical Ageing in an Epoxy Composite," Materials Forum, Vol. 16, No. 2, 1992.

Treatment: Experimental (X)

Abstract: A dynamic mechanical thermal analyzer (DMTA) and a continuous dielectric measurement system were used to monitor the physical ageing process (annealing) of air-quenched epoxy composite samples. Dynamic storage modulus $\mathrm{E}^{\prime}$ was found to increase continuously with time, reaching a plateau during the ageing, and the initial rate of change of E' was found to be temperature-dependent. Similar behavior of dielectric loss and dielectric constant during ageing was observed with continuous dielectric measurement. It is concluded that the DMTA technique is not only highly sensitive to property changes occurring during the ageing; it is also sensitive to the change of ageing rate due to the variation of ageing temperatures. The advantages of using the DMTA technique to characterize the physical ageing process are discussed. (7 Refs)

\section{[175]}

Van Brunt, R.J.; Cernyar, E.W., "Influence of Memory Propagation on Phase-Resolved Stochastic Behavior of AC-Generated Partial Discharges," Applied Physics Letters, Vol. 58, No. 23, June 1991.

Treatment: Experimental (X)

Abstract: Using measurements of phase-restricted conditional partial-discharge pulse-amplitude and phase distributions, it is shown for the first time that the stochastic properties of a dielectric-barrier type of partial discharge generated by an $\mathrm{AC}$ voltage are significantly influenced by memory associated with charge deposited on the dielectric surface by preceding discharge events. This memory effect must be considered in any attempt to interpret results of phase-resolved partial-discharge measurements. (12 Refs) 
[176]

Van Brunt, R.J.; Cernyar, E.W., "Influence of Phase-to-Phase Memory Propagation on the Stochastic Behavior of AC-Generated Partial Discharges," Proceedings of the 1993 IEEE Conference on Electrical Insulation and Dielectric Phenomena, 1993.

Treatment: Experimental (X)

Abstract: It is shown in the present work that the phase-resolved stochastic behavior of ac-generated PDs is strongly influenced by phase-to-phase memory propagation, where the "memory" is associated with charging of dielectric surfaces by successive discharge events. The memory effects are revealed for the first time from measurements of phase-restricted conditional partial-discharge amplitude and phase-of-occurrence distributions that show, for example, that the most probable phase-of-occurrence of a PD pulse on one half-cycle of the applied voltage is dependent on the total charge deposited by PDs on the dielectric surface during the previous half-cycle. The effects of memory uncovered here are implied by previous descriptions of the PD phenomenon when account is taken of statistical variability in the charging of the dielectric surface. (14 Refs)

[177]

Van Brunt, R.J.; von Glahn, P., "Nonstationary Behavior of Partial Discharge During Insulation Aging," Proceedings of the International Conference on Partial Discharge, IEE, Michael Faraday House, Stevenage, UK, 1993.

Treatment: T; (Theoretical)

Abstract: There are two purposes for this work. The first is to present an example of a case where a pulsating partial-discharge (PD) phenomenon exhibits non-stationary behavior associated with discharge-induced 'aging' of a dielectric material. The observed nonstationary behavior, which manifests itself by a time-dependence in the statistical characteristics of PD pulses, illustrates the difficulties to be encountered in defining meaningful PD pulse 'patterns' that can be used for reliable defect site identification. The second purpose is to point out possible difficulties in relating measured PD pulse-height distributions to measured average PD current which are relevant to the calibration of PD measurement systems. (5 Refs)

$* * * * * * * * * * * * * * * * * * * * * * * * * * * * * * * * * * * * * * * * * * * * * * * * * * * * * * * * * * * * * * * * * * * * * * * * * * * * * * * * * * * * * * * * * * * * * * * * * * * * *$

[178]

Van Brunt, R.J.; Cernyar, E.W., "Stochastic Analysis of AC-Generated Partial-discharge Pulses from a Monte-Carlo Simulation," Proceedings of IEEE Conference on Electrical Insulation and Dielectric Phenomena, 1992.

Treatment: Theoretical (T)

Abstract: A Monte-Carlo simulation of AC-generated partial-discharge (PD) pulses is described which can properly account for effects of phase-to-phase memory propagation. The results of the simulation have been tested by determination of various unconditional and conditional pulse amplitude phase-of-occurrence, and integrated charge distributions. The stochastic behavior of the simulated pulses is shown to be similar to that found experimentally for AC-generated PD in point-to-dielectric discharge gaps. (9 Refs) 
Van Brunt, R.J., "Stochastic Properties of Partial-discharge Phenomena," IEEE Transactions on Electrical Insulation, Vol. 26, No. 5, October 1991.

Treatment: Theoretical (T); Experimental (X)

Abstract: The author presents a bibliography and survey of the literature concerned with theory and measurement of the stochastic behavior of pulsating partial-discharge (PD) phenomena that can occur when insulation is subjected to electrical stress. The types of PD phenomena considered include AC and DC generated electron avalanches, pulsating positive and negative corona in gases, and PD that occur in liquid media and in the presence of solid dielectric surfaces. The basic physical mechanisms of discharge initiation, growth, and memory propagation that determine the probability distributions for pulse occurrence times and pulse amplitudes are discussed. Consideration is also given to special problems associated with the measurement and interpretation of data on the various statistical properties of PD phenomena. (345 Refs)

\section{[180]}

Van Brunt, R.J.; Misakian, M.; Kulkarni, S.V.; Lakdawala, V.K., "Influence of a Dielectric Barrier on the Stochastic Behavior of Trichel-Pulse Corona," IEEE Transactions on Electrical Insulation, Vol. 26, No. 3, June 1991.

Treatment: Theoretical (T); Experimental (X)

Abstract: The influence of a solid polytetrafluorethylene (PTFE) dielectric barrier on the stochastic behavior of negative (Trichel) pulse corona discharges in air is examined. This behavior is revealed from measurement of conditional and unconditional corona pulse-amplitude and pulse-time--separation distributions. The results indicate that the presence of a dielectric surface on the anode effectively reduces the electric field at the point electrode, but does not affect the occurrence of Trichel pulses, provided the point-to-plane gap spacing is greater than a critical value $d_{c}$ which depends on the area of the dielectric and the applied voltage. As the gap spacing approaches $d_{c}$, the effect of dielectric-surface charging by the corona introduces measurable memory effects indicated by correlations between pulse amplitude and time separation from the previous pulse. For spacings less than $d_{c}$, detachable corona-pulse activity is quenched by the presence of a quasi-permanent surface charge on the dielectric. (28 Refs)

\section{[181]}

Van Brunt, R.J.; Cernyar, E.W.; von Glahn, P.; Las, T., "Variations in the Stochastic Behavior of Partial-discharge Pulses with Point-to-dielectric Gap Spacing," Conference Record of the 1992 IEEE International Symposium on Electrical Insulation, 1992.

Treatment: Experimental (X)

Abstract: The stochastic behavior of AC-generated partial-discharge (PD) pulses in a point-to-dielectric air gap has been thoroughly characterized from direct measurements of various conditional and unconditional phase-restricted pulse-height and phase-of-occurrence distributions. A stochastic analyzer was used to examine changes in the stochastic behavior of PD pulses that occur when the gap distance between a point electrode and a solid planar dielectric surface is varied. The results reveal significant pulse-to-pulse and phase-to-phase memory propagation at all gap spacings. The observed memory effects are seen to be important in controlling the initiation and growth probabilities of partial-discharge pulses at any given phase of the applied voltage. (12 Refs) 
[182]

Van Brunt, R.J.; Cernyar, E.W., "System for Measuring Conditional Amplitude, Phase, or Time Distributions of Pulsating Phenomena," Journal of Research of the National Institute of Standards and Technology, Vol. 97, No. 6, November/December 1992.

Treatment: Experimental

Abstract: A detailed description is given of an electronic stochastic analyzer for use with direct "real-time" measurements of the conditional distributions needed for a complete stochastic characterization of pulsating phenomena that can be represented as random point processes. The measurement system described here is designed to reveal and quantify effects of pulse-to-pulse or pulse-to-phase memory propagation. The unraveling of memory effects is required so that the physical basis for observed statistical properties of pulsating phenomena can be understood. The individual unique circuit components that compromise the system and the combinations of there components for various measurements, are thoroughly documented. The system has been applied to the measurement of pulsating partial discharges generated by applying alternating or constant voltage to a discharge gap. Examples are shown of data obtained for conditional and unconditional amplitude, time interval, and phaseof-occurrence distributions of partial discharge pulses. The results unequivocally show the existence of significant memory effects as indicated, for example, by the observations that the most probable amplitudes and phase-of-occurrence of discharge pulses depend on the amplitudes andlor phases of the preceding pulses. Sources of error and fundamental limitations of the present measurement approach are analyzed. Possible extensions of the method are also discussed. (43 Refs)

[183]

Van Brunt, R.J.; Stricklett, K.L.; Steiner, J.P.; Kulkarni, S.V., "Recent Advances in Partial Discharge Measurement Capabilities at NIST," IEEE Transactions on Electrical Insulation, Vol. 27, No. 1, February 1992.

Treatment: Applications (A); Practical (P)

Abstract: Three techniques for measuring the properties of partial discharges (PDs) are described. The first is concerned with an advanced, real-time PD measurement system that allows a complete characterization of the stochastic properties of PD. With this system it is possible to measure a set of conditional PD pulse-amplitude and pulse-time separation distributions from which memory effects characteristic of the discharge phenomena can be quantified and interpreted. Results for pulsating negative corona discharges in gases are shown. The second technique allows PD location in cables using time-domain reflectometry with appropriate statistical analysis. With the third technique, simultaneous measurements are made of the optical and electrical characteristics of PD in liquid dielectrics using fast photography combined with broadband, low-noise pulse current measurements. (39 Refs)

[184]

Van Brunt, R.J.; von Glahn, P.; Las, T., "Partial Discharge-induced Aging of Cast Epoxies and Related Nonstationary Behavior of the Discharge Statistics," Proceedings of the 1993 IEEE Conference on Electrical Insulation and Dielectric Phenomena, 1993.

Treatment: T; (Theoretical); X; (Experimental)

Abstract: Additional evidence for partial discharge (PD)-induced changes in epoxy surface resistivity and the relationship of these changes to observed non-stationary behavior in the statistical characteristics of the PD are presented with the aid of a previously described Monte Carlo simulator. The model was modified to allow a decay of PD-deposited negative charge on the dielectric surface. The model also allows the probability of extracting an initiatory electron from the negatively charged surface to increase with increasing negative charge density. With these features, it is possible to simulate conditions under which positive PD pulses will disappear with increasing surface conductivity. ( 8 Refs) 


\section{[185]}

Van Brunt, R.J.; von Glahn, P.; Las, T., "Nonstationary Behavior of Partial Discharge During Discharge Induced Ageing of Dielectrics," IEE Proceedings Science, Measurement and Technology, Vol. 142, No. 1, 1995. Treatment: Experimental (X)

Abstract: Changes in the stochastic behavior of pulsating partial discharge with time have been observed when an alternating voltage is applied to point-dielectric gaps in which the dielectric is a cast epoxy resin either with, or without, $\mathrm{Al}_{2} \mathrm{O}_{3}$ filler. The changes in discharge behavior are shown, with the help of a Monte-Carlo simulation, to be consistent with discharge induced increases in the surface conductivity of the epoxy. This 'ageing' effect is shown to be accelerated as the frequency of applied voltage is increased from 50 to $800 \mathrm{~Hz}$. The implications of the results on accelerated ageing tests and definition of partial discharge 'signatures' for possible pattern recognition are discussed. The relationship between average partial discharge current and partial discharge pulse height distributions is also discussed. (31 Refs)

\section{[186]}

van Roggen, A.; Zhou, H., Data Analysis in Dielectric Time-Domain Spectroscopy," Proceedings of the 1992 IEEE Conference on Electrical Insulation and Dielectric Phenomena, 1992.

Treatment: Theoretical (T)

Abstract: None

Reviewer's comments: The authors describe an approach, which they claim to overcome some of the limitations of Mopsik's Time-Domain Spectroscopy, in particular those associated with the use of a reference capacitor. The discussion appears to be entirely theoretical, no experimental data are reported.

$* * * * * * * * * * * * * * * * * * * * * * * * * * * * * * * * * * * * * * * * * * * * * * * * * * * * * * * * * * * * * * * * * * * * * * * * * * * * * * * * * * * * * * * * * * * * * * * * * * * * * * * * * * *$

[187]

Vettese, G.; Libotte, M.; Pompili, M.; Mazzetti, C., "Ultrahigh Frequency Study of PD Pulses," Conference Record of the 1994 International Symposium on Electrical Insulation, 1994.

Treatment: Experimental (X)

Abstract: Conventional partial discharge (PD) measurements are carried out with instruments of relatively limited bandwidth. There arises the question as to the temporal characteristics of the actual pulses and the significance of the results so obtained. To gain a detailed knowledge of the risetime, duration, and amplitude of these pulses, a study has been undertaken using as detector a $500 \mathrm{MHZ}$ digitizing oscilloscope in combination with a pointplane electrode geometry. In this paper the pulse characteristics of a PD in air were studied as a function of polarity under dc and ac conditions. (7 Refs)

[188]

von Glahn, P.; Van Brunt, R.J., "Performance Evaluation of a New Digital Partial Discharge Recording and Analysis System," Conference Record of the 1994 International Symposium on Electrical Insulation, 1994. Treatment: Experimental (X)

Abstract: We describe the design and performance evaluation of a new digital partial discharge (PD) recording system capable of real-time recording of PD pulse trains for later off-line computerized stochastic analysis. The new recording system consists of a new 16-bit parallel digital interface installed in a personal computer. The digitizer is under software control with the resulting data being stored in binary files on the computer's hard disc. Since post-test analysis software run on the computer provides the needed stochastic analysis of the data files, the new system offers a unique capability to perform stochastic analysis on nonstationary PD data such as found in aging studies. Sample stochastic analysis results are presented, demonstrating the additional insights possible with the new system. (16 Refs) 
[189]

Wichman, A.; Grünewald, P.; Weidner, J., "On-Line Monitoring for Incipient Fault Detection in HV Equipment," Proceedings, Sixth International Symposium on High Voltage Engineering, 1989.

Treatment: Experimental (X)

Abstract: Partial discharges and arcing due to broken strands or similar defects in high voltage windings produce radio frequency(RF) signals that can be measured and located by high frequency testing systems. This report describes a monitoring system for HV equipment in power plants. It consists of three coupling units connected to the surge wave protection capacitors on the generator main leads. Another coupling location for RF signal monitoring is the exciter bearing of the generator. Thanks to this method of multiple coupling not only defects in the generator transformer, auxiliary power transformer, and other HV equipment in the main leads can be detected. During field trials on 1600 MVA generators, at least one fault detected at an early stage could have caused a stator winding breakdown within some hundred hours of future service. In another power station, sporadic discharges of high energy were detected in an 850 MVA main transformer by the on-line RF monitor. (11 Refs)

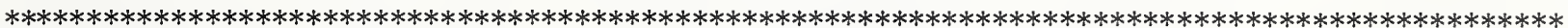
[190]

Xiansheng, W; Demin, T., "Verification of the Trap Model of Electric Breakdown in Polymer by Photo Ageing," Proceedings of the Symposium on Electrical Insulating Materials, Inst. of Electrical Engineers of Japan, Tokyo, 1993. Treatment: T; (Theoretical); X; (Experimental)

Abstract: Though the life formula of polymer under electrical ageing has been found, the change of chemical structure in the process of ageing. In recent years, the trap model of electrical ageing and breakdown of polymer was put forward by authors through a lot of research and experiments. When the electron is injected into the dielectric by electrical stress is trapped, the energy released makes another electron become a hot electron of high energy. The photo ageing of PP film is taken in this paper. The dielectric strength, the change of microscopic chemical and physical structure, and the trap density are measured. (9 Refs)

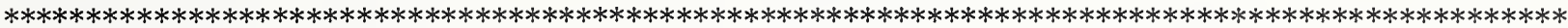

[191]

Yamashita, H., "Partial Discharge Measurements in Dielectric Liquids under Impulse Voltage," IEEE Transactions on Electrical Insulation, Vol. 28, No. 6, 1993.

Treatment: Practical (P); Experimental (X)

Abstract: Current pulses caused by partial discharges (PDs) are measured using light-emitting diodes (LEDs) and fiber optics under impulse voltage conditions. This system has the advantage of having good isolation from the HV power supply and no effect from electromagnetic noise as compared with ordinary systems. It can detect a PD pulse having a half width of $3 \mathrm{~ns}$, and has the capability of measuring PD pulse charges in the range of 1 to $2000 \mathrm{pC}$, when the optimum DC bias is applied. PD pulses and light emission or streamer formation in dielectric liquids are measured simultaneously by using an image converter camera. (15 Refs)

$* * * * * * * * * * * * * * * * * * * * * * * * * * * * * * * * * * * * * * * * * * * * * * * * * * * * * * * * * * * * * * * * * * * * * * * * * * * * * * * * * * * * * * * * * * * * * * * * * * * * * * *$

[193]

Zingales, G., "Present State and Prospects of Standardization on PD Measurements," IEEE Transactions on Electrical Insulation, Vol. 28, No. 6, December 1993.

Treatment: General, Review (G)

Abstract: The contents of the past and present IEC Standards on partial discharge (PD) measurements are examined, in view of the preparation of a new edition. New standards should take into account the more sophisticated measuring systems produced in the last decades and their lower sensitivity to external disturbance. Little knowledge has however been added on the PD aging effects on HV apparatus. (2 Refs) 
NISTIR 5760

$-86-$ 


\section{8 - INDEX OF AUTHORS AND CO-AUTHORS}

(Numbers refer to [items], not pages)

\begin{tabular}{|c|c|c|c|}
\hline Agoris, D.P. & 1,139 & Cernyar, E.W. & $175,176,178,181,182$ \\
\hline Aihara, M. & 49 & Chan, J.C. & 37 \\
\hline Aksenov, Y.P. & 10 & Changchang, W. & 38 \\
\hline Aksyonov, Y.P. & 2,3 & Chen, Y.P. & 149 \\
\hline Ali, A.S. & 4 & Cheng, X. & 159 \\
\hline Allan, D. & 5 & Cicciari, M. & 24 \\
\hline Alsheikhly, A. & $6,7,8$ & Clavreul, $\mathrm{R}$. & 68 \\
\hline Andreev, A.M. & 4 & Coletti, G. & $23,39,40$ \\
\hline Antonov, B.D. & 2 & Contin, A. & $24,26,34,41$ \\
\hline Arakelyan, V.G. & 9 & Cooke, C.M. & 169 \\
\hline Arsentiev, V. & 10 & Danikas, M.G. & $27,28,42$ \\
\hline Arsentyev, V.M. & 2,3 & Daryan, L.A. & 9 \\
\hline Austin, M.E. & 11 & Davies, A.E. & 137 \\
\hline Banford, H.M. & 12,13 & Dehend, Z. & 38 \\
\hline Bansal, R. & 116 & Dejean, P.P.F. & 43,44 \\
\hline Barsch, R. & 14 & Dejean, $\mathrm{H}$. & 43,44 \\
\hline Bartnikas, $\mathrm{R}$. & $15,119,120$ & Demin, $\mathrm{T}$. & 190 \\
\hline Bengtsson, $\mathrm{T}$. & 110 & Dissado, L.A. & 45,46 \\
\hline Berdala, J. & 68 & Dobreva, E.D. & 81 \\
\hline Bernstein, S. & 16,17 & Domitz, S. & 87 \\
\hline Bespalova, E.B. & 157 & Domun, M.K. & 47 \\
\hline Besprozvannykh, A.V. & 132 & Doyle, T.E. & 117,118 \\
\hline Blackburn, T. R. & 147 & $\mathrm{Du}, \mathrm{Z}$. & 48 \\
\hline Blundell, M. & 5 & Duchateau, F. & 68 \\
\hline Boggs, S.A. & 18,19 & Duffy, P. & 37 \\
\hline Bohme, $\mathrm{H}$. & 52 & Ebinuma, Y. & 49,142 \\
\hline Borsi, H. & $20,21,22,155$ & Egiziano, L. & 50 \\
\hline Bortnik, I. M. & 88 & Ehara, Y. & 51 \\
\hline Boyd, K. & 5 & Ellis, E. & 158 \\
\hline Bozzo, R. & 23,24 & Elshabini-Riad, A. & 158 \\
\hline Brancato, E.L. & 17 & Endoh, T. & 89 \\
\hline Braun, J.M. & 25 & Fantana, N.L. & 52 \\
\hline Bressani, M. & 26 & Femia, N. & 50 \\
\hline Bristol, R. & 96 & Feser, $\mathrm{K}$. & 97,98 \\
\hline Bromley, J.C. & 10 & Florkowska, B. & 53 \\
\hline Bruning, A.M. & $27,28,29$ & Florkowski, M. & 54 \\
\hline Burnay, S.G. & $30,31,32,33,109$ & Fothergill, J.C. & 45 \\
\hline Cacciari, $\mathrm{M}$. & 34 & Foulon, N. & 44 \\
\hline Campbell, F.J. & 29 & Foulon-Belkacemi & $43, \mathrm{~N}$. \\
\hline Capponi, G. & 35,36 & Fournier, D. & 105 \\
\hline
\end{tabular}


From, U. $\quad 100$

Fruth, B.

Fuhr, J.

$54,55,56$

Fukunaga, K. $\quad 57,58,143$

Gao, B. $\quad 174$

Garamella, G. $\quad 50$

Giddings, J. $\quad 59$

Given, M.J. $\quad 12,13$

Gjaerde, A.C. $\quad 60,61$

Gladchenko, V.Y. 132

Glodjo, A. $\quad 10$

Gluchowski, S. $\quad 62$

Gockenbach, E. $\quad 155$

Goldman, M. 43, 44,162

Goldman, A. $\quad 43,162$

Golovkov, M.Y. 2, 3, 10

Gosse, J.P. $\quad 135$

Gosse, B. $\quad 135$

Gross, D. $\quad 54$

Grünewald, P. $\quad 63,189$

Gryazin, V.A. $\quad 64$

Guastavino, F. $\quad 24,39,40,63$

Gubanski, S. $\quad 66,128,129$

Guerra, G. $\quad 65$

Gulski, E. $\quad 67,99,101$

Gururaj, B.I. $\quad 154$

Gutfleisch, F. $\quad 56$

Guzman, H. 6

Hadid, A. $\quad 68$

Haga, K. $\quad 49$

Hagi, A. 23

Hanson, B.A. $\quad 69$

Hantouche, C. $\quad 70$

Hasegawa, T. 71, 72

Hassig, M. $\quad 56$

Hatziargyriou, N.D. 1

$\mathrm{He}, \mathrm{Q}$. $\quad 73$

Heng, G. $\quad 38$

Henriksen, M. $\quad 74,76$

Higashimura, Y. $\quad 84,85$

Hiivala, L.J. $\quad 37$

Hikita, $M$.

Hilder, D.

Hill, D.J.T.

Hinde, D.
$75,93,94,95,140$

59

11

5
Hitchon, J.W.

30,31

Hofmann, J. $\quad 14$

Holboll, J.T. $\quad 74,76$

Homma, $\mathrm{H}$. $\quad 77$

Hoof, M. $\quad 78,79$

Ichiyanagi, N. $\quad 141,170$

lizumi, M. $\quad 133$

Ikeda, C. $\quad 89$

Ishida, T. $\quad 80$

Ishii, $M$. $\quad 92$

Ito, $\mathrm{T}$. $\quad 51$

Ivanov, S.I. $\quad 81$

Iwata, Z. $\quad 170$

Izumi, K. $\quad 77$

James, R. E. $\quad 147$

Jianaing, L. $\quad 82$

Jinping, Y. $\quad 82$

Juchniewicz, J. $\quad 62$

Kahle, M. $\quad 83$

Kako, Y. $\quad 84,85$

Kandibolotskaya, T.B.

Kang, D.S. $\quad 86$

Karady, G.G. $\quad 87$

Karapetyan, M. $\quad 88$

Kärner, H.C. $\quad 90$

Kasuya, M. $\quad 133$

Katsuta, G. $\quad 89,142$

Kemp, I.J. 73, $\quad$ $\quad 38$

Kexiong, T. $\quad 38$

Khachatryan, A. S. 88

Kikuchi, T. $\quad 173$

Kim, Y.J. $\quad 86$

Kimura, K. 71, 72

Kishida, $\mathrm{H}$. $\quad 51$

Koizumi, N. $\quad 51$

Komatsubara, M. 92

Komori, F. $\quad 75,93,94,95,140$

Kong, A. $\quad 96$

König, G. $\quad 97,98$

Konigstein, D. $\quad 56$

Kopf, U. $\quad 98$

Kosaki, M. $\quad 80$

Kozubov, E.D. $\quad 2$

Kranz, H.-G. $\quad 6,7,8$

Kreuger, F.H. $\quad 67,99,100,125$
157 
Krivda, A.

Kuffel, J.

99,101

Kulkarni, S.V. $\quad 180,183$

Kurrat, M. $\quad 102$

La Bozetta, R. $\quad 106$

Laghari, J.R. 103

Lakdawala, V.K. $\quad 180$

Lamarre, L. $\quad 105$

Landinger, C. $\quad 96$

Las, $\mathrm{T}$.

Lasky, J.S.

Laurent, C.

Lawson, J.

Lee, W.Y.

Lefkowitz, S.

Leijon, $M$.

Lemke, E.

Li, Y. 174

Libotte, $\mathrm{M}$.

Loggini, M.

Lokhanin, A.K. 9

Lundgaard, L.E. $\quad 112$

Lupo, G. $\quad 50$

Lyons, C. S. $\quad 167$

MacKinlay, R. 47, 73, 113

Mammeri, M. $\quad 68,114$

Marks, J. 16

Marteau, C. $\quad 135$

Martzloff, F.D. $\quad 115$

Maruyama, Y. 141

Mashikian, M.S. $\quad 48,116$

Mason, L.R. $\quad 117,118$

Matsunobu, K. $\quad 84,85$

Mayoux, C 107, 108

Mazroua, A.A. $\quad 119,120$

Mazzanti, G. $\quad 121$

Mazzetti, C. $\quad 187$

McDermid, W. 10

Meketa, R. $\quad 87$

Miller, R. 47

Ming, L. $\quad 110$

Miri, S.M. $\quad 122,123$

Misakian, M. $\quad 180$

Miyamoto, T. $\quad 171$

Mizumo, $Y$.
Mizutani, T. $\quad 75,93,94,95,140$

Montanari, G.C. $\quad 24,34,66,121,128$,

Moorty, S. $\quad 159$

Mopsik, F.I. $\quad 124$

Morin, R. 105

Morshuis, P.H.F. $\quad 125,126,127$

Motori, A. 66, $\quad 628,129,130$

Muraoka, K. $\quad 89$

Murata, K. 131

Naboka, B.G. $\quad 132$

Nagao, M. $\quad 80$

Nagaoka, A. $\quad 142$

Nakanishi, K. $\quad 171$

Nakanishi, Y. 133

Nakatani, Y. $\quad 133$

Nattrass, D.A. $\quad 134$

Nema, R.S. $\quad 160$

Nemamcha, M. 135

Nemeth, E. $\quad 136$

Nensi, T. $\quad 137$

Niemeyer, L. $\quad 55,56,138$

Nikolopoulos, P.N. 139

Nishiguchi, N. $\quad 73,93,94,95$

Noriaki, N. $\quad 140$

Northrop, R.B. $\quad 116$

Novak, J.P. $\quad 15$

O'Donnell, J.H. $\quad 11$

Oda, T. 141

Ogishima, M. 49

Ohno, $\mathrm{H}$. $\quad 142,143$

Okamoto, T. $\quad 144,171$

Oliva, J.R. $\quad 87$

Osvath, P. $\quad 145$

Palmieri, F. $\quad 116$

Patsch, R. $\quad 78,79$

Pechenyakova, V.P. 81

Peier, D. $\quad 102,156$

Petrov, Ch.V. $\quad 81$

Pfeiffer, W. 146

Phung, B. T. $\quad 147$

Pietsch, R. $\quad 148$

Pintal, Y.S. 2, 3,10

Pomery, P.J. $\quad 11$

Pompili, M. 187 


\begin{tabular}{|c|c|c|c|}
\hline Privette, A. & 122,123 & Stone, G.C. & 165,166 \\
\hline Pronin, B.D. & 2,3 & Stricklett, K.L. & 183 \\
\hline Qi, Z.N. & 149 & Strobel; J. M. & 167 \\
\hline Rabach, G. & $26,34,41$ & $\mathrm{Su}, \mathrm{W}$ & 158 \\
\hline Ramsey, N.W. & 150 & $\mathrm{Su}, \mathrm{Q}$ & 168 \\
\hline Rao, V. & 159 & Suh, K.S. & 169 \\
\hline Razza, F. & 26 & Svirachev, D.M. & 81 \\
\hline Reynolds, A.B. & $69,117,118$ & Swingler, S.G. & 137 \\
\hline Reynolds, P.R. & 151 & Takahashi, T. & 58,77 \\
\hline Riad, S.M. & 158 & Takehana, H. & 58,143 \\
\hline Robinson, G. & 152 & Tan, $\mathrm{M}$ & 58,143 \\
\hline Rozhkov, V.M. & 64 & Tanaka, $\mathrm{H}$. & $141,170,171,172$ \\
\hline Ryder, D.M. & 153 & Tanaka, T. & 144 \\
\hline Rygal, R. & 74 & Taniguchi, T. & 77 \\
\hline Sakaguchi, R. & 142 & Tedford, D.J. & 12,13 \\
\hline Sakkas, G.H. & 139 & Toya, A. & 89 \\
\hline Salama, M.M.A. & 119,120 & Tsutsumi, Y. & 173 \\
\hline Salon, J. & 114 & Tucci, V. & 50 \\
\hline Sandrolini, F. & 130 & Unsworth, J. & 174 \\
\hline Sarjeant, W.J. & 103,104 & Van Brunt, R.J. & $\begin{array}{c}115,175,176,177,178,179,180 \\
181,182,183,184,185,188\end{array}$ \\
\hline Sasaki, N. & 142 & & \\
\hline Satish, L. & 154 & van Roggen, A. & 186 \\
\hline Sazhin, B.I. & 4 & Vaughan, A.S. & 137 \\
\hline Schichler, U. & 155 & Vettese, G. & 187 \\
\hline Schifani, R. & 35,36 & von Glahn, P. & $177,181,184,185,188$ \\
\hline Schmiegel, P. & 111 & Wan, Z.H. & 149 \\
\hline Schmuck, F. & 14 & Wang, S.-N. & 141 \\
\hline Schnettler, A. & 156 & Ward, B.H. & 164 \\
\hline Secco, M. & 26 & Wasik, J. & 37 \\
\hline Sedding, H.G. & 25 & Watanabe, S. & 84,85 \\
\hline Sekii, Y. & 89 & Weidner, J.R. & 63.189 \\
\hline Shalimov, V.V. & 157 & Wichman, A. & 189 \\
\hline Shawn Addington, J. & 158 & Wlodek, R. & 53 \\
\hline Shibuya, Y. & 71,71 & Xiansheng, W & 190 \\
\hline Shihab, S. & 159 & Yamashita, $\mathrm{H}$. & 191 \\
\hline Shobha, R. & 160 & Yasuda, S. & 131 \\
\hline Sigmond, $\mathrm{T}$. & 162 & Yonekura, T. & 173 \\
\hline Sigmond, R.S. & 161,162 & Yoshida, S. & 58,143 \\
\hline Simmon, E. & 115 & Zahn, H. & 145 \\
\hline Simmons, $\mathrm{M}$. & 59 & Zavarzina, V.V. & 64 \\
\hline Simoni, L. & 121 & Zhou, H. & 186 \\
\hline Sletbak, J. & 61 & Zhuravleva, N.M. & 4 \\
\hline Stein, J. & 25 & Zingales, G. & 192 \\
\hline Steiner, J. P. & $115,163,164,183$ & Zorin, G.A. & 157 \\
\hline
\end{tabular}



